\title{
Zur Rekonstruktion von Damascius' Leben des Isidorus.
}

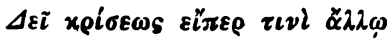

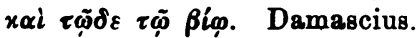

Die Wiederherstellung der von Damascius verfabten Biographie des Isidorus wurde bereits von Valesius in Aussicht genommen; wenigstens versprach dieser Gelehrte in einer Anmerkung zu Socrates Hist. eccl. 1. VII c. 15 p. 86 , eine um das Doppelte des bei Photius erhaltenen Bestandes vermehrte Ausgabe unseres Werkes zu liefern. Er führte jedoch seinen Vorsatz nicht aus. Auch Tillemont trat diesem Gedanken näher: In seiner Kaisergeschichte, für welche er die von dem Biographen gebotenen Historica ausgiebig verwertete, bemerkte er t. VI (Bruxelles 1740) p. 215b bezüglich jener Bruchstücke: „On en pourrait tirer beaucoup de choses touchant les philosophes payens de ce siècle (sc. de Zénon) en y joignant Suidas qui a beaucoup de choses de Damasce: mais je ne sais si cela en vaudrait la peine". Trotzdem beschäftigte sich weiterhin Küster in seiner Suidasausgabe im Sinne von Valesius und Tillemont eingehend mit unserer Frage, indem er sich ernstlich bemühte, die Übereinstimmungen der Damasciusglossen bei Suidas unter sich selbst und ihre Beziehungen zu entsprechenden Eklogen bei Photius aufzuzeigen. Einen nützlichen Beitrag zur Rekonstruktionsarbeit lieferte dann Fabricius durch seinen ausführlichen "Index philosophorum ac sophistarum clarorumque virorum, quorum in excerptis e Damascio mentio" (Bibliotheca Graeca X p. 761 ed. Harles; vgl. III p. 485), in welchem er allerdings Suidas nicht berücksichtigte. Mehr im Geiste Tillemonts und Küsters gehalten ist die von Wernsdorf versuchte Lebensskizze Isidors, die sich in seiner gründlichen „Dissertatio de Hypatia" I (Vitembergae 1747) p. 35sq. findet; freilich verzichtet sie fast gänzlich auf die formale Wiederherstellung der Quellenschrift. Eine brauchbare Handhabe für die Weiterarbeit schuf Brucker durch eine Berichtigung der Isidorischen Chronologie in seiner "Historia critica philosophiae“ III $2^{2}$ p. 339sq. (vgl. Append. VI p. 378sq.). Wie wünschenswert die Rekonstruktion wäre, betonte Iriarte in seinem "Catalogus codd. reg. Matrit." p. $329 \mathrm{~b}$ und $\mathrm{C}($ lavie) in der "Biographie universelle" u. „Damascius", der letztere unter gleichzeitiger Hervorhebung der Leichtigkeit der zu 
lösenden Aufgabe. Gleichwohl ist das Problem bis auf den heutigen Tag nicht wesentlich weiter gefördert worden. Wertvolle Anregungen gibt Zumpt in seiner Abhandlung „Über den Bestand der philosophischen Schulen in Athen und die Succession der Scholarchen" (Abh. der Ak. der Wissensch. z. Berl. aus d. J. 1842. Berl. 1844. Philos. u. hist. Abth. S. 27-119). Das bis zur Mitte des 19. Jahrhunderts Geleistete verzeichnet gewissenhaft Bernhardy in seiner Suidasausgabe, wobei er sich hauptsächlich auf Toups Emendationen zu Suidas beruft. Charakteristisch für den geringen Fortschritt ist es aber, dab er nur eine einzige Glosse (s. v. $\left.M \eta^{\prime} \imath \iota\right)$ selbständig in den Zusammenhang einzureihen wagt. Ruelles Ausführungen über den Philosophen Damascius (Revue archéologique 1861 I p. 151 sq.) kommen nicht über Fabricius hinaus. Das Bedeutendste, was nach ihm über unsere Frage geschrieben worden ist, verdankt man Zeller, der jedoch in seiner "Philosophie der Griechen" III $2^{4}$ S. $805 \mathrm{ff}$. die einzelnen Damasciusstellen auch blob in ihrer Vereinzelung und nicht im Zusammenhang des ganzen Werkes zu erläutern versucht. Auf eine Zusammenstellung der auf Isidorus bezüglichen Fragmente beschränkt sich Bucherer in seinen vorwiegend textkritischen „Beiträgen zu Damascius' Leben des Isidorus" (Programmbeilage von Wertheim 1892). Erst Kroll regt in seinem Artikel "Damaskios" in Pauly-Wissowas Realencyklopädie die Wiederherstellung der ganzen Biographie wieder an.

Als Grundlage für unsere Arbeit kommt heutzutage der Westermannische Photiustext ${ }^{1}$ ) hinter Cobets Diogenes Laertius und Bernhardys Suidasausgabe in betracht, wobei man jedoch auch die Bekkersche Rezension der Bibliothek ergänzend be ${ }^{i}$ ziehen muB. Diese ist überhaupt für die übrigen Damasciuspartien bei Photius unser einziges Hilfsmittel. Wir verweisen daher im folgenden mit bloBen arabischen Ziffern auf die Paragraphen bei Westermann und mit dem jeweiligen stichwort auf die Glossen bei Bernhardy. Den Zusammenhang zweier oder mehrerer Bruchstücke deuten wir nach dem Schema a (:b; c; d etc.) an.

Unter dem für die Rekonstruktion vorliegenden Material stehen die Auszüge bei Photius, Bibl. Cod. 242 an erster Stelle. Sie geben

1) Er enthält folgende Fehler: 9 : $\mu \iota \tau \alpha \mu \circ \rho \varphi o-$ (st. ov) $\mu \varepsilon v_{v} r_{i s} ; 23$ : unmotivierte

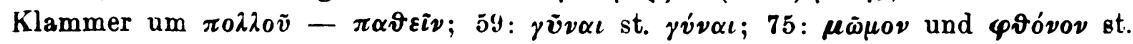

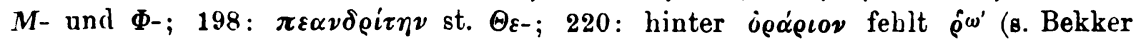

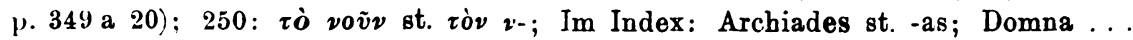
Dam. 300 st. 301 ; Emesa ... 263 st. 203; Eusebius . . 200 st. 203; Leontins imperaior ... $10 S$ st. 109; Pampreptus st. -pius; Proclus p. 178 a 9 v. u.: 250 st. 248; Proclus Isidori filius ... 300 st. 301; Sodga st. Sogda. 


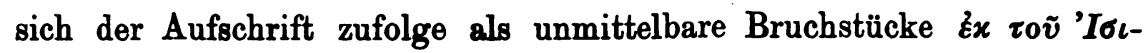

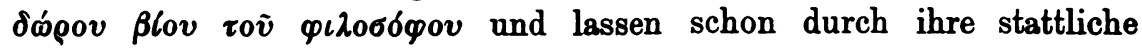
Menge - es sind nicht weniger als 312 Paragraphen - den Versuch, dieses Werk daraus wiederherzustellen, als einen nicht aussichtslosen erscheinen. Es handelt sich jedoch bei diesen Eklogen nicht um eine einzige fortlaufende Reihe, sondern um eine Zusammenstellung von verschiedenen Einzelserien. Hinter 230 findet sich die Bemerkung: ö $\sigma \alpha$

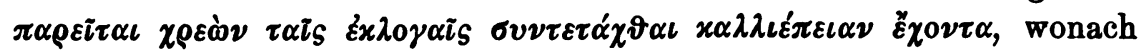
man in den folgenden Nummern einen aus stilistischen Gründen gefertigten Nachtrag zu den vorausgehenden zu erblicken hätte. Dem ist aber nicht so. Vielmehr ist auch weiterhin für den Exzerptor nicht ausschlieblich das formale Interesse, sondern auch der Inhalt maBgebend gewesen, und zudem enthält die angebliche Ergänzung eine ganze Anzahl von Fragmenten, welche bereits in der Anfangspartie vorkommen. Es sind dies: $233=9 ; 238=22 ; 246=40.39 ; 249=80 ; 251=89$; $270=139 ; 289=171 ; 292=179 ; 302=212 ;$ zwei derselben, 249 und 270, gehen sogar nicht einmal über den Umfang der ihnen entsprechenden Stücke hinaus. Es liegt somit hier eine zweite, selbständige Exzerptsammlung vor. $\left.{ }^{1}\right)$ Dies läßt sich auch durch das merkwürdige Verhältnis beweisen, in welchem einige andere Glieder dieser

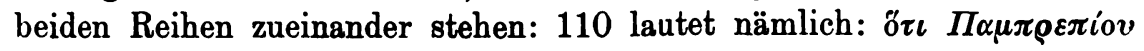

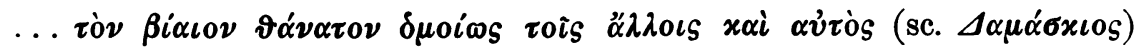

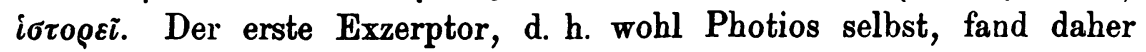
über diesen Punkt bei Damascius nichts Besonderes vor. Er erledigte ihn deshalb schon hier und verzichtete auf spätere Mitteilungen an der Stelle, wo der Biograph im weiteren Verfolg hiervon gehandelt hatte. Damit steht aber 291, d. h. die Ekloge, welche dort einzureihen ist in Widerspruch, indem sie, offenbar mit Beziehung auf das Haupt

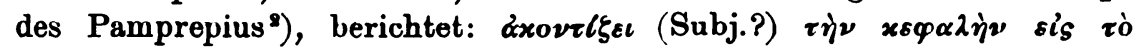

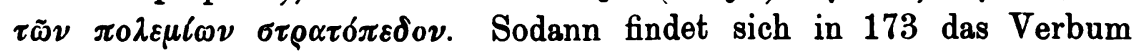
$\pi \varepsilon \rho \iota \rho \tilde{\alpha} \sigma \vartheta \alpha \iota$ ohne jede weitere Erklärung im Sinne von „ein Auge auf etwas werfen ${ }^{\text {(3) }}$; der Patriarch sah demnach nichts Auffälliges in diesem Gebrauch; wohl aber der zweite Exzerptor: denn dieser hielt es in 254 , einem wahrscheinlich von derselben Sache handelnden Stücke, für notwendig, ihn ausdrücklich als ungewöhnlich zu bezeichnen und besonders zu interpretieren. Die zweite Sammlung geht somit, wie schon die bisherigen Beispiele zeigen, in der Weise neben der ersten her, daB sich ihre einzelnen Nummern Stück für Stück in

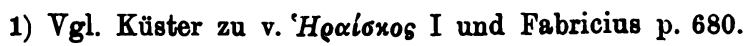

2) S. Tillemont VI p. 212 b:

3) Nicht von "aspernari“, wie die Schottsche Übersetzung will. 
diese einreihen lassen. Denn obgleich dies noch von niemand bemerkt worden ist, folgt sowohl die erste als die zweite einem und demselben stofflichen Anordnungsprinzip ${ }^{1}$ ), in welchem wir unbedenklich die ursprüngliche Gedankenfolge unserer Biographie wiedererkennen dürfen. Aber auch mit der zweiten Serie hat es noch nicht sein Bewenden. Sie geht nämlich bloß bis 307 . Die hierauf folgende Ekloge greift auf einmal wieder zurück und leitet eine dritte Kollektion ein. Diese schliebt wiederum mit 310, so daB noch ein Rest von zwei Fragmenten bleibt. Allein auch dieser ist nicht einheitlich. Denn 311 deckt sich teilweise mit 59, und 312 berührt sich mit 15. Man kann daher die fünf letzten Nummern als drei verschiedene Nachträge zur zweiten Sammlung ansehen. Die Gruppierung der Eklogen bei Photius ist somit folgende: $\mathrm{I}=1-230 ; \mathrm{II}=231-307 ; \mathrm{II}=308-310 ; \mathrm{IIb}=311$; IIc $=312$. Vielleicht erklärt sich die Vereinigung dieser Parallelserien am einfachsten so, daB man dem Patriarchen bloB I, die übrigen Elemente aber irgendeinem oder auch mehreren Mitarbeitern an seinem offenbar schnell und im einzelnen nicht überall sorgfältig redigierten Riesenwerke zuweist.

Der Bestand bei Photius erfährt eine schätzenswerte Bereicherung durch die von ihm Bibl. Cod. 181 gegebene Kritik unserer Schrift, die

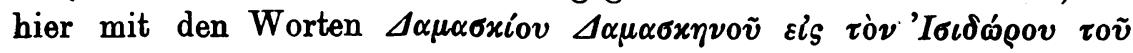

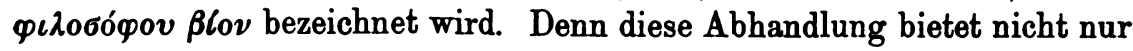

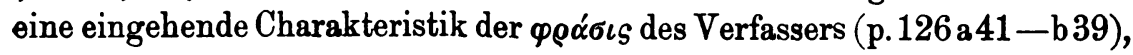
sondern sie berichtet uns auch, daB die Biographie 60 Kapitel umfaBt habe (p. 125 b 31.32) und einer gemeinsamen Schülerin ihres Helden und seines Lobredners, einer gebildeten Hellenistin namens Theodora, gewidmet war (p. 125 b $32-116$ a 8). Wir erfahren genau den Inhalt (p. 126 a 8-16) des Werkes, lernen seine antichristliche Tendenz (p. 126 a 8-16) kennen und werden mit der kritischen Methode (p.126 a 18-31), der philosophischen Bedeutung (p.126 a 31-40) und dem Bildungsgang (p. 126 b $40-127$ a 14) des Autors bekannt gemacht. Die Art, wie dies geschieht, verrät, ganz abgesehen von den gelegentlich eingestreuten

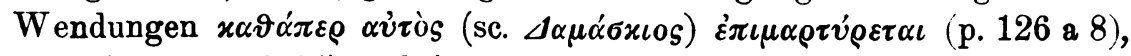

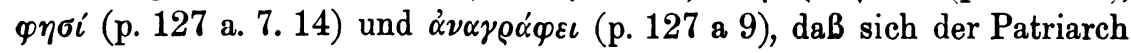
dabei eng an seine Vorlage anschlieBt. Leider versagt er sich aber jede Andeutung, aus der wir etwas über die Stoffverteilung entnehmen könnten. Immerhin kann man jedoch seine Mitteilungen, deren Richtigkeit durch die Fragmente vollauf bestätigt wird, nicht bloß zur allgemeinen Orien-

1) Das oft nachgesprochene Verdikt Bruckers, die Exzerpte bei Photius folgten ${ }_{n}{ }^{n}$ illo ordine ${ }^{\mu}$ sufeinander $\left(I^{2}\right.$ p. 340), entiveiuri somit der tatsächlicinen Begründung. 
tierung, sondern auch zur Rekonstruktion gewisser Abschnitte unserer Lebensbeschreibung verwerten. Die Stellen, wo dies möglich ist, müssen sich aus den Damasciusfragmenten selbst bzw. aus ihrem Verhältnis zu Cod. 181 ergeben. ${ }^{\text {) }}$

Es verlohnt sich der Mühe, hier einiges über diese Wechselbeziehung vorwegzunehmen, was auf gewisse Eigenheiten der Isidorusvita ein bezeichnendes Licht wirft: $\mathrm{Zu}$ der Tatsache, daB diese einer allseitig gebildeten Frau gewidmet ist, paBt die geflissentliche Hervorhebung weiblicher Persönlichkeiten, die mit den dargestellten Begebenheiten in irgendeinem näheren oder entfernteren Zusammenhang stehen. Es sind:

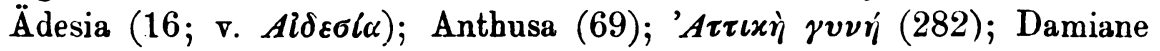

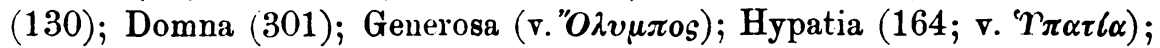

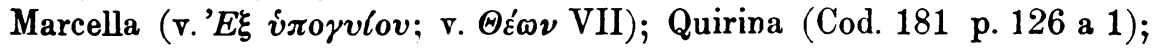

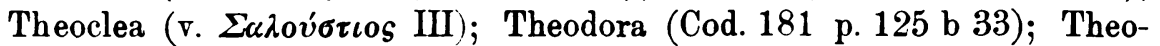

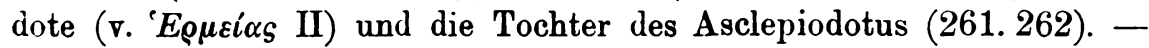
Von den zahlreichen $\delta \iota \eta \gamma \eta \dot{\eta} \mu \tau \alpha$, welche nach p. 126 a 11 die Schrift so

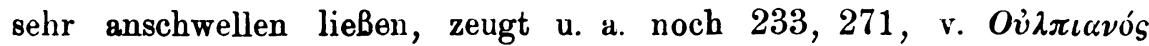

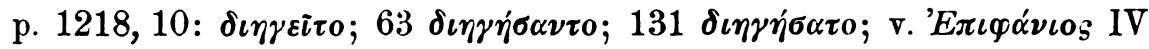

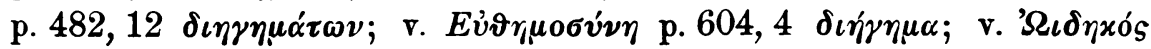
p. 1250,15 $\delta \iota \eta \gamma \eta \dot{\eta} \mu \alpha \iota$. - Der p. 126 a 13 getadelte MiBbrauch der

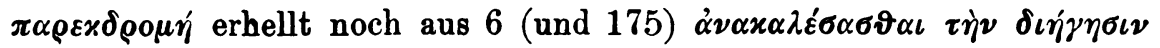

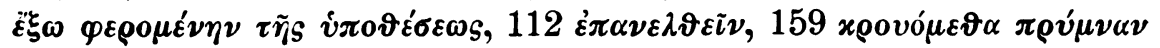

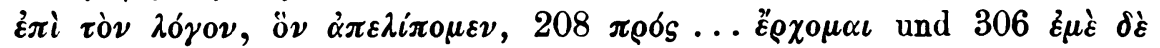

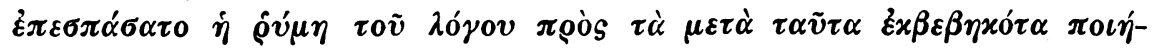

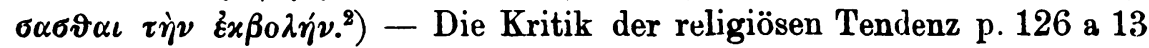

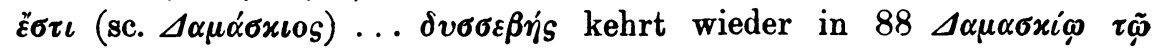

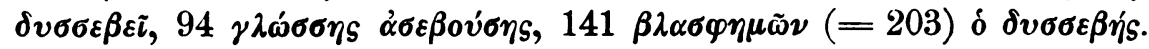
Diese antichristliche Richtung war wohl schon der Familie des Damascius eigen; hieB doch sein Bruder nach $180 ; 185$; v. $\Sigma \varepsilon \beta \eta \rho \iota \alpha \sigma^{\prime}$

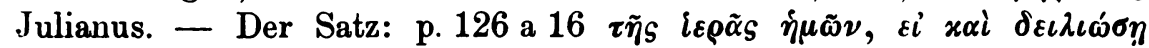

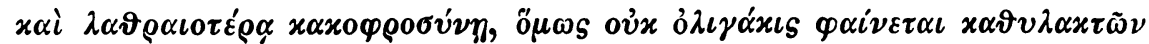

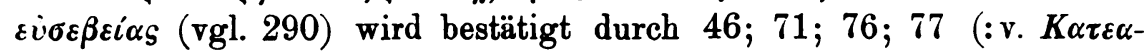

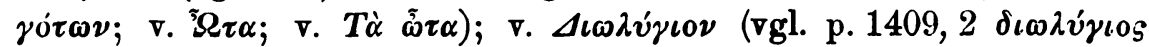

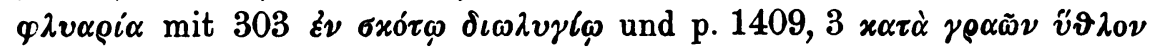

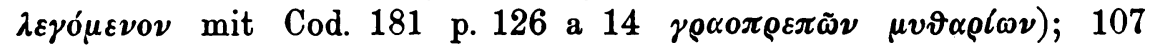

1) Vgl. Krumbacher, Geschichte der byzant. Litteratur 2. A. S. 519.

2) Da 6 und 306 gar keine stofflichen Elemente enthalten, sondern sich auf die Wiedergabe einer von Damascius gebrauchten Übergangsform beschränken, so sind diese "Bemerkungen des Autors" wohl nicht mit Leo (Die griechisch-römische Biographie. Leipzig 1901 S. 260, 8) als ${ }_{n}$ im Exzerpt ... stehen geblieben ${ }^{4}$, sondern als absichtlich ausgezogene Musterwendungen zu bezeichnen. 


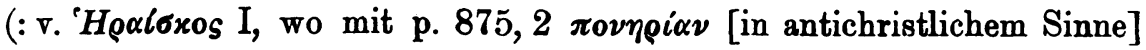

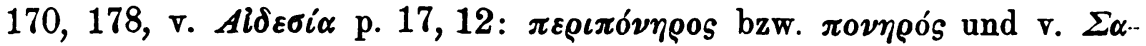

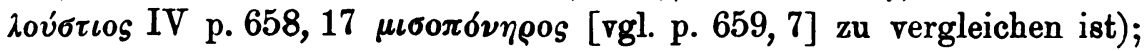

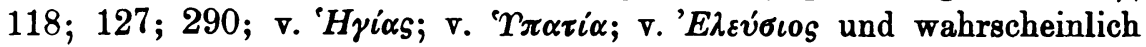
auch prinzipiell durch 22 (: 238; v. $\Psi v x \eta^{\prime} ;$ v. 'T $\Upsilon_{\eta v \varepsilon i \alpha}$ I. II p. 1301, 5sq.;

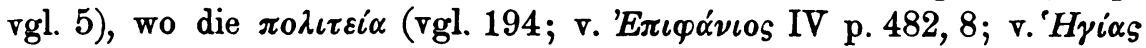

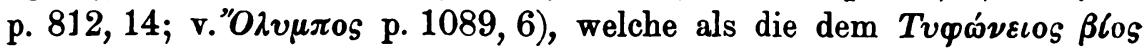
entsprechende und als í $\eta v \varepsilon i \alpha$ charakterisiert wird, auf das Christentum zu zielen scheint. ${ }^{1}$ ) - Die p. 126 a 23 dem Autor in den Mund gelegte

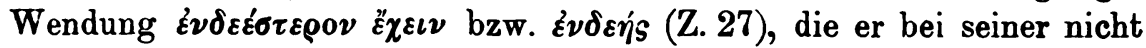
einmal vor Isidorus Halt machenden Verkleinerungssucht (Z. 30; vgl.

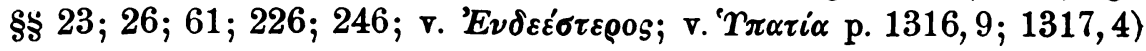
auf die von ihm hervorgehobenen Persönlichkeiten angewandt habe,

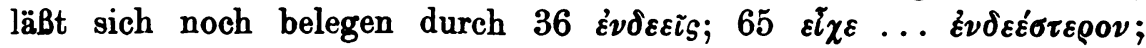

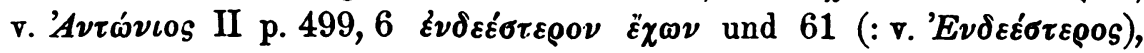

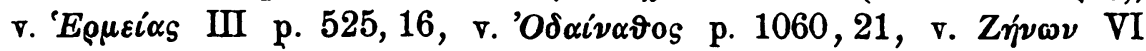

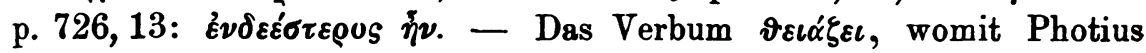
p. 126 a 20 die panegyrische Neigung des Biographen kennzeichnet, gebraucht er auch in 36. - Bei dem MaBstab, den Damascius nach p. 126 a 24 sq. bei der Würdigung seiner Helden anlegte, spielt die $\dot{\alpha} \gamma \chi i \nu \circ \iota \alpha, \dot{\varepsilon} \pi \iota \sigma \tau \eta \dot{\eta} u \eta$ und $\dot{\alpha} \varrho \varepsilon \tau \dot{\eta}$ die Hauptrolle. Dementsprechend ist von diesen unterscheidenden Merkmalen an folgenden Stellen die Rede: von

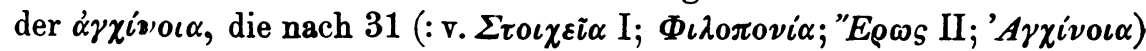
und 32 ein unterscheidendes Merkmal der wahren Forschernatur bildet,

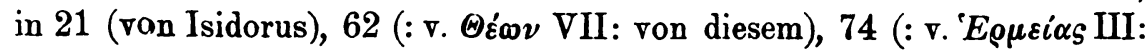
von diesem) und 126 (von Asklepiodotus), von der $\varepsilon \pi \iota \sigma \tau \eta \dot{\mu} \eta$ in v. $\Sigma \alpha$ -

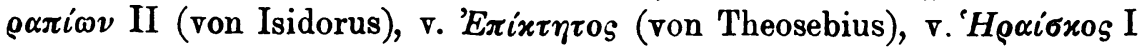

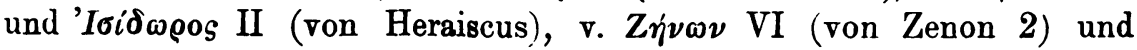

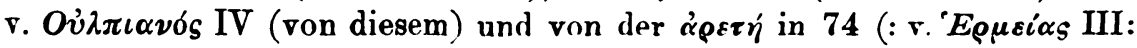

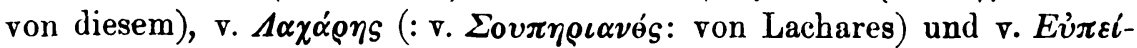
v gabe p. 126 a 31, Damascius habe in seiner Schrift sowohl fremde als

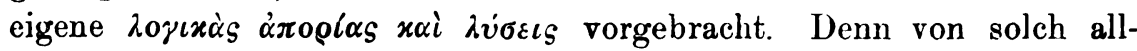

1) Vgl. Marinus Vita Procli c. $15 \pi \nu \varepsilon v \mu \alpha \dot{\alpha} \omega \nu$ Tv vóuœ $\zeta \infty \tilde{\eta}$, was Zumpt S. 84,4 auf Verfolgungen von christlicher Seite deutet;

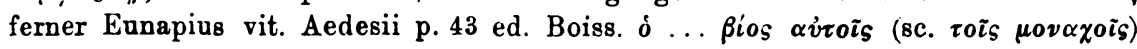

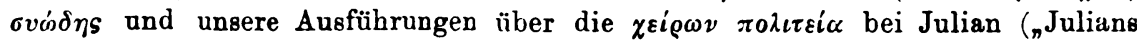
Galiläerschrift usw." Programmbeilage. Freiburg i. B. 1904 S. $15 \mathrm{ff}$.). Der Apostat vergleicht Or. II p. 71,20 ed. Hertlein charakteristischerweise den christlichen

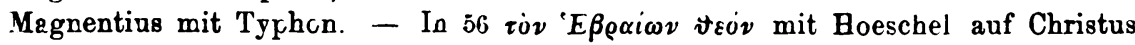
$z u$ beziehen, liegt kein Grund vor. 
gemein philosophischem Füllmaterial ist fast nichts mehr vorhanden.

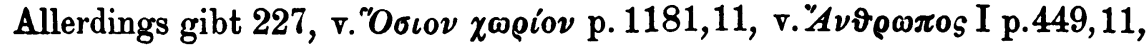

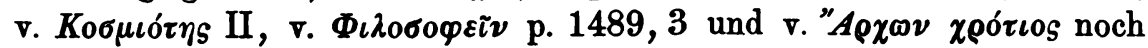
eine ungefähre Vorstellung von derartigen theoretischen Erörterungen. Vielleicht ist in der letztgenannten Glosse in den Eingangsworten $\tau \dot{\nu} \nu$

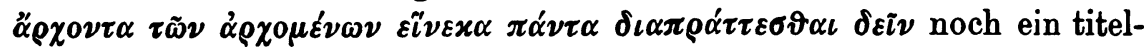
artiger Betreff einer $\alpha \dot{\pi} \log ^{\prime} \alpha$ erhalten. An solche Diskussionen wird

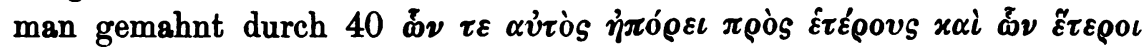

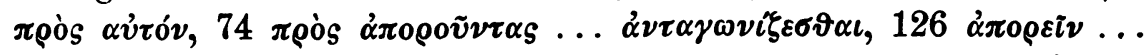

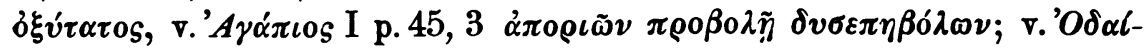

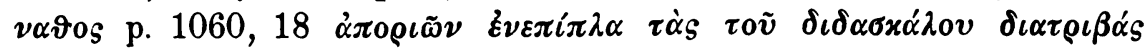

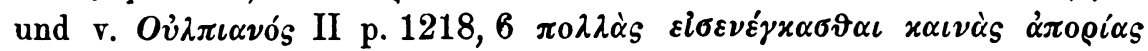

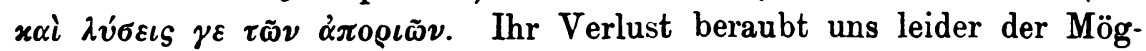
lichkeit, das abfällige Urteil des Patriarchen nachzuprüfen. Sie würden

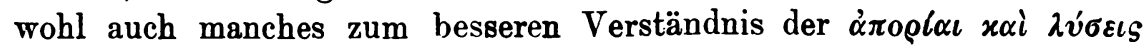
$\pi \varepsilon \varrho i \tau \tilde{\omega} \nu \pi \varrho \omega ́ \tau \omega \nu ~ \alpha \varrho \chi \tilde{\omega} \nu$ des Biographen beitragen, dio wir ihrerseits

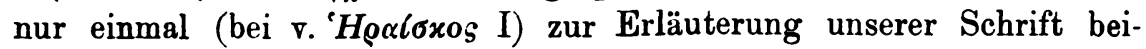
ziehen können. Wenn Photius nicht mehr Philosophica aus der Biographie exzerpierte, so war für diese Unterlassung wohl der Umstand maBgebend, daB ihm das meiste davon anderweitig bekannt geworden war. Teilt er doch u. a. in Cod. 214 und 252 reichhaltige Auszüge

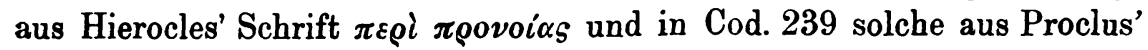
grammatischer Chrestomathie mit, wodurch sein Interesse an den späteren Neuplatonikern hinreichend dokumentiert wird.

Wohl aber lassen sich noch mit einer andern Schrift des Damascius auffallende Übereinstimmungen in unserem Werke feststellen. Freilich ist dieselbe bloB noch aus einem Referat des Photius bekannt. Dieser

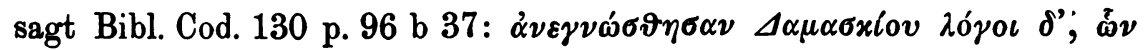

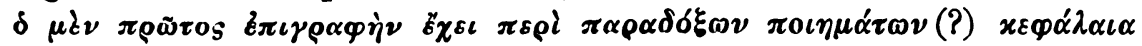

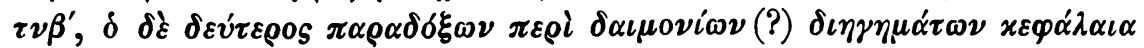

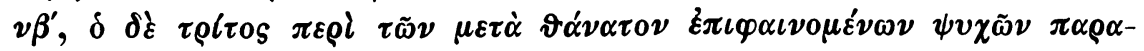

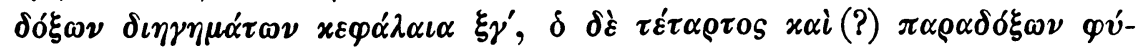

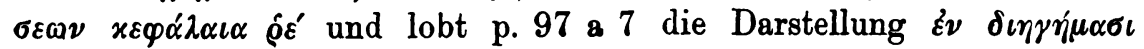

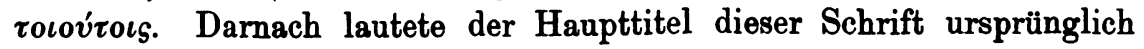

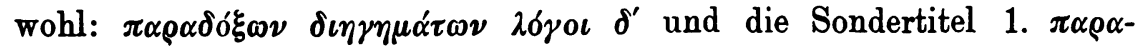

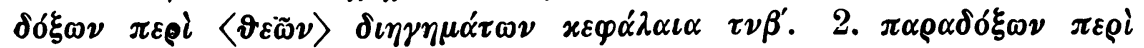

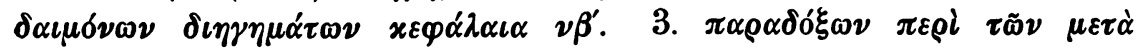

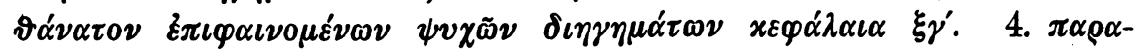

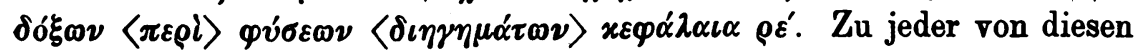
vier Unterabteilungen lassen sich in der Isidorusvita Belege nachweisen: Zu 1 vgl. 70, 76, 106 (: v. 'Hpalбxos I p. 872, 12), 198, 203 und 302; 


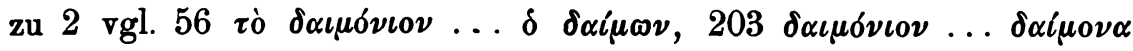

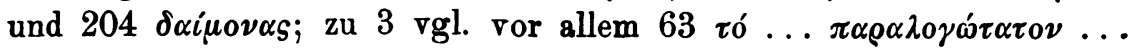

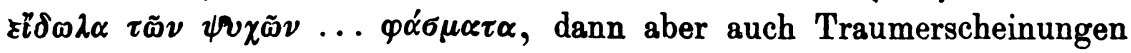

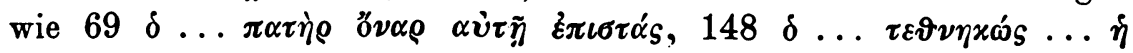

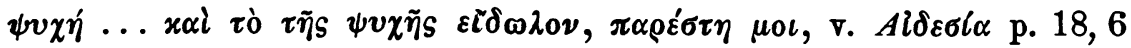

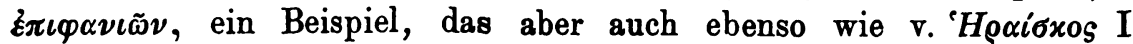
p. 874,7 (: 105; 253), v. Aouvivos p. 1432,$19 ; 1433,11$ und 138 auf

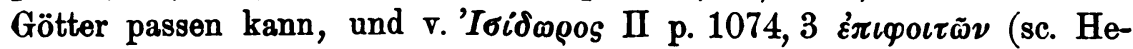

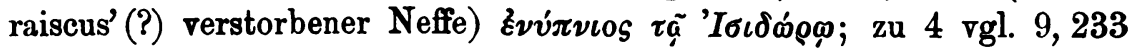

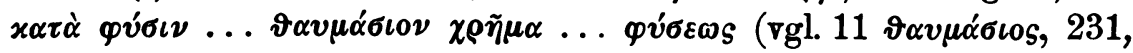

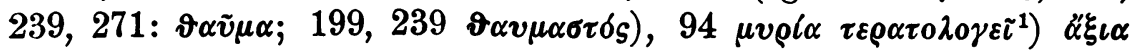

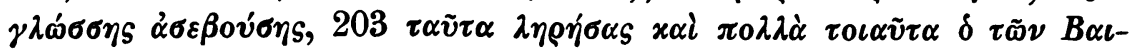

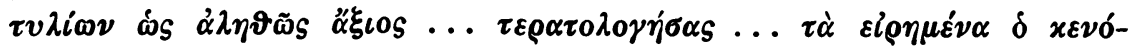

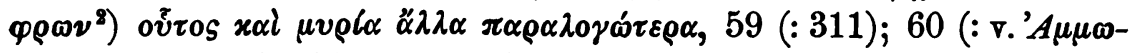

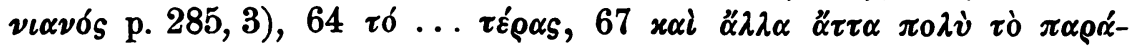

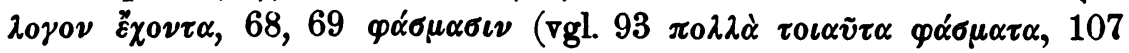

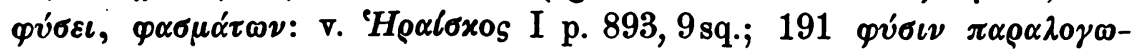

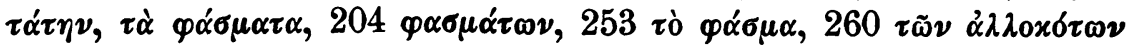

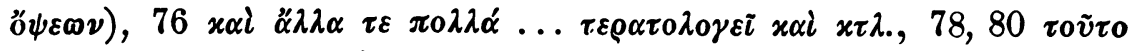

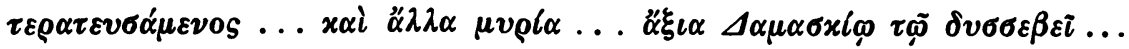

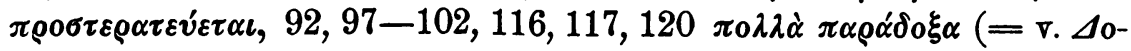

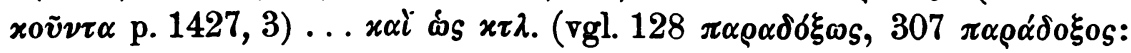

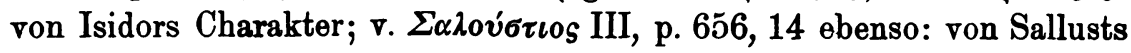

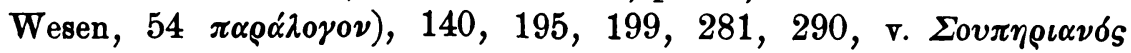
p. 834,11 und v. $M \eta \tau$ i

Demnach enthielt unsere Schrift einen stark paradoxographischen Einschlag, den man angesichts der den einzelnen Beispielen beigeschriebenen Würdigungen getrost mit den von Photius Cod. 130 p. 96 b 43

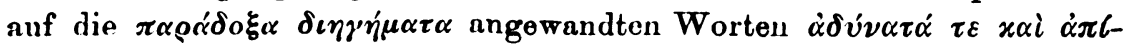

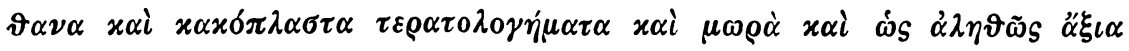

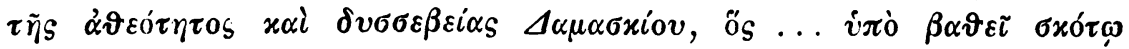

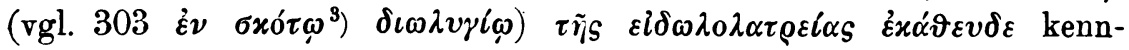
zeichnen könnte, zumal wenn man nach Cod. 181 p. 126 a 4 rĩ $\varepsilon i \delta \omega-$

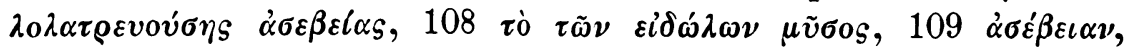
$121 \dot{\alpha} \sigma \varepsilon \beta \varepsilon \varepsilon \varepsilon, 204$ "E $E \lambda \lambda \eta \nu \ldots$. .

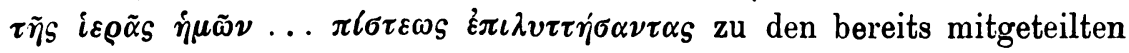

1) Tümpel in Pauly-Wissowas Realencyklopädie u. „Baitylia“ macht fälschlich den Asclepiades statt des Damascius zum Subjekt dieses Verbums.

2) Dementsprechend ist Cod. 181 p. 126 a 14 wohl statt $x \alpha \iota \nu \tilde{\omega} \nu$ mit Bekker $\varkappa \varepsilon \nu \dot{\omega} \nu \ldots \mu v \boldsymbol{\alpha} \alpha \hat{i}^{\prime} \omega \nu . . . \pi \varepsilon \pi \lambda \eta \rho \omega \mu \dot{\nu} \nu$ os zu schreiben.

3) Vgl. Julian Or. IV p. 169.9 und unser Programm S. 39. 
Bezeichnungen für den Hellenismus des Damascius hinzunimmt. Vielleicht hatten die beiden Werke die angeführten Paradoxa miteinander gemein. Einige derselben haben einen ausgesprochen physiognomonischen Charakter, der überhaupt in der ganzen Biographie insofern stark hervortritt, als nicht nur der Verfasser, sondern auch manche der von ihm gewürdigten Persönlichkeiten ein lebhaftes Interesse für die Physiognomonik verraten. Vor allem kommt hier $92^{1}$ ) in Betracht, wo Sallustius, Uranius und Nomus als Augenphysiognomoniker genannt werden; dann aber auch 98 und 99, wo es sich um Tierphysiognomonik

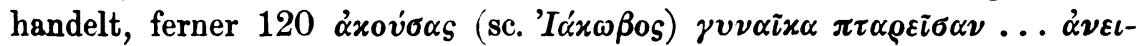

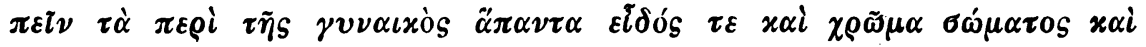

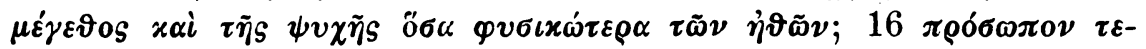

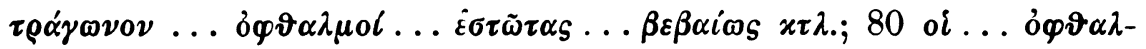

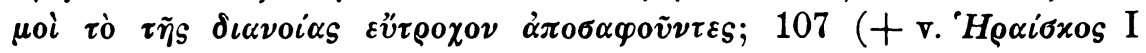

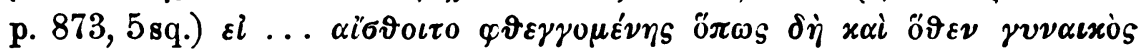

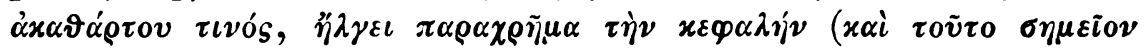

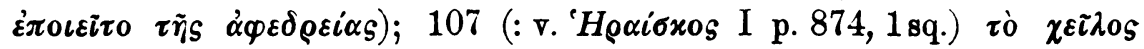

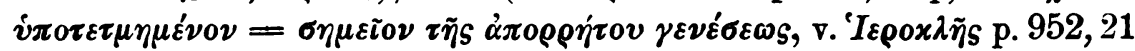

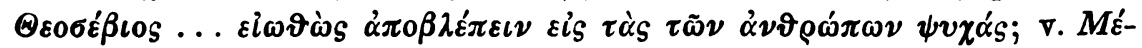

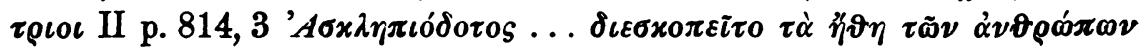

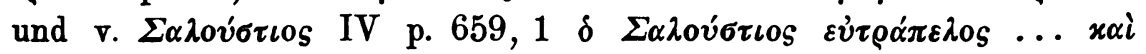

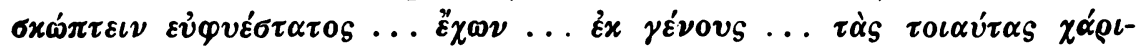
$\tau \alpha \varsigma^{2}{ }^{2}$ Wahrscheinlich hatten auch die (Götter-) Bilderbeschreibungen

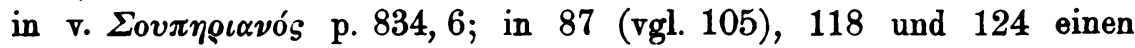
physiognomonischen Charakter.

SchlieBlich verdient noch hervorgehoben zu werden, daB die biographische und die paradoxographische Schrift auch die Einteilung in Kapitel und den stilistischen Vorzug der $\sigma \alpha \varphi \eta v \varepsilon \iota \alpha$ (vgl. p. 97 a 6 mit 126 a 40) miteinander gemein hatten.

Zwei Damasciuseklogen bei Photius erwecken einige Hoffnung auf ErschlieBung sekundärer Hilfsquellen für die Rekonstruktion unserer Biographie. Die eine ist der bereits oben beigezogene $\S 110$. Die hier erwähnten „andern" Gewährsmänner ${ }^{8}$ ) für die Wundersucht, Treulosig-

1) Bereits von Forster, Scriptores physiognomonici graeci et latini I p. XIII und LXXIV not. hervorgehoben. Reinesius Variae lectiones (Altenb. 1640) p. 294 vergleicht hiermit eines der ${ }_{n}$ signa interitus" des Kaisers Pertinax bei Capitolinus c. 14 (p. 111, 22 ed. Jordan-Eyssenhardt) ${ }_{n} \mathrm{Ea}$ die, qua occisus est, negahant in oculis eius pupulas cum imaginibus, quas reddunt spectantibus, visas".

2) Vgl. Julian, Misopog. p. 435, 16. 443, 11 u. 8., unser Programm S. 17 und unsern Aufsatz „Vergessene Physiognomonika (Philologus 64) 4 S. 428.

3) Tillemont VI p. 212 b. beinerkt ohne Gewähr, hiermit seien "payens" gemeint. 
keit und gewaltsame Todesart des Pamprepius dürften wohl am ehesten Malchus und Candidus sein, da diese nach Cod. 78 und 79 dem Patriarchen genau bekannt waren und auch tatsächlich in manchen Einzelheiten mit unserem Biographen übereinstimmen (vgl. Malchus

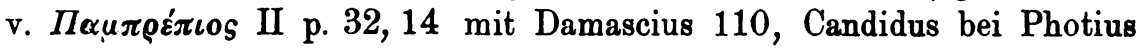

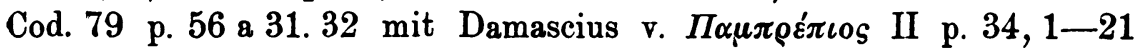
und denselben Candidus bei Cramer, Anecdot. Paris. II p. 83, 16-18 mit Damascius 290 p. 143, 21-23). Leider sind wir aber für diese vergleichende Kritik wiederum nur auf einige Bruchstücke angewiesen, so daB der erhoffte Gewinn auf einige tatsächliche Bestätigungen zusammenschrumpft. Noch weniger ist mit der ähnlich lautenden Stelle von den

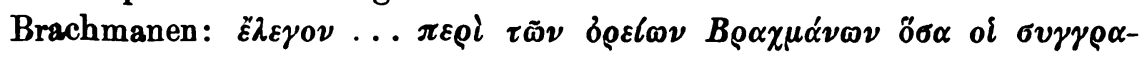

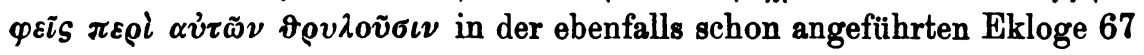
anzufangen, da wir nicht wissen, was für Autoren Photius hier vor Augen hat.

Nach dem Gesagten verdanken wir unter dem bei Photius gebotenen Material für die Wiederherstellung der Isidorusvita das schätzbarste Hilfsmittel der ersten Exzerptsammlung in Cod. 242; da diese offenbar dem ursprünglichen Gang der Darstellung folgt, liefert sie den zuverlässigsten Rahmen zur Einordnung aller übrigen Elemente. Weitaus den gröBten Bestand unter diesen bilden die zahlreichen und zum Teil auch sehr umfangreichen Auszüge, die Suidas aus unserem Werke gemacht hat. Seine Damasciusglossen ${ }^{1}$ ) verraten ihre Herkunft auf sehr verschiedene Art: Am deutlichsten sind sie als solche zu erkennen, wenn ihnen ein ausdrückliches Lemma oder eine einem solchen gleichwertige Bemerkung beigefügt ist. Die genauesten Angaben der Art

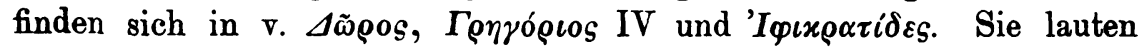

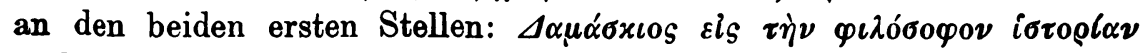

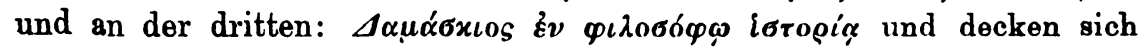
mit v. $\Delta \alpha \mu \alpha \dot{\sigma} x i o s$, worin dem Biographen ebenfalls eine

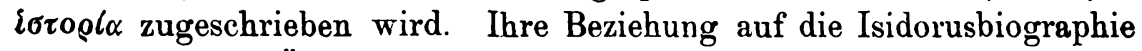
wird durch die Übereinstimmung der Gregoriusglosse mit 75 und die des Iphikratidesartikels mit 89 ohne weiteres erwiesen. Zudem dürfte man sich auch schon angesichts der Erklärung des, Photius Cod. 181

1) In Bernhardys sehr unvollständigem Index p. 1955 u. $\Delta \alpha \mu \alpha ́ \sigma x \iota s$ ist zu

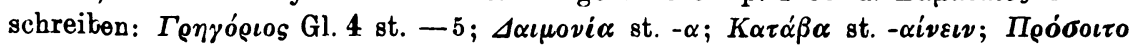

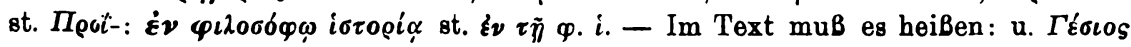

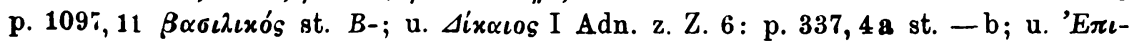

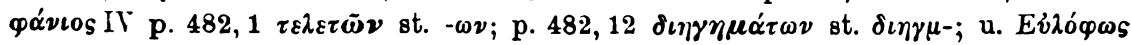

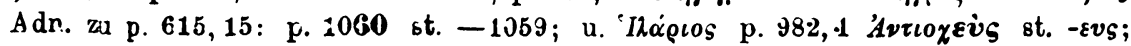

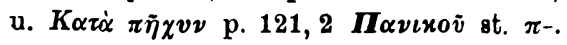




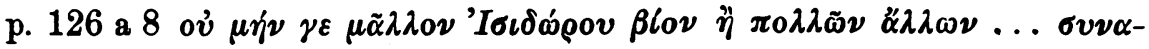
$\nu \alpha \gamma \rho \alpha ́ \varphi \varepsilon \iota$ (sc. $\Delta \alpha \mu \alpha \dot{\sigma} \sigma \iota 0 s$ ) an der Allgemeinheit der Titelfassung bei Suidas nicht stoßen. ${ }^{1}$ ) Liefert doch Damascius selbst durch Bemer-

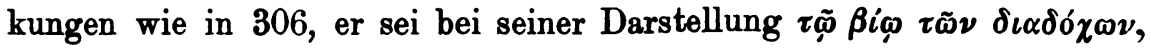

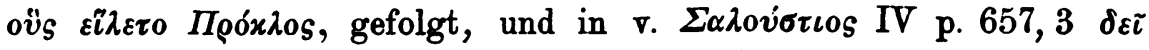

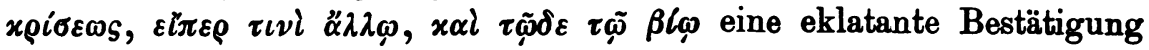
dieser Angabe. Unverkennbare Hinweise auf unsere Lebensbeschreibung

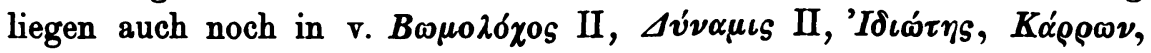

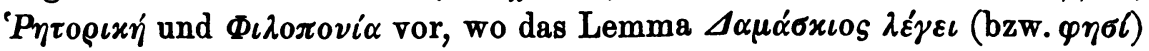

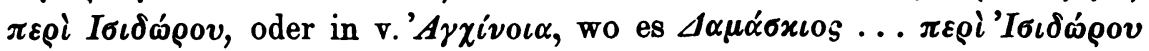
$\delta$ dógos lautet. An dritter Stelle sind die Artikel zu erwähnen, die

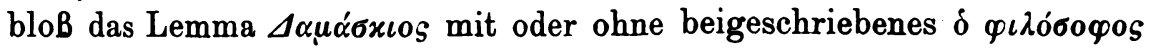

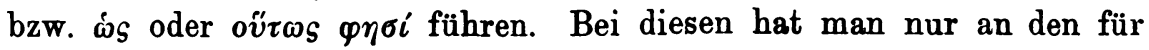
unser Werk charakteristischen Eigennamen, Gedanken und Ausdrucksformen eine Gewähr für ihre Provenienz. Diese Charakteristika sind es endlich auch, auf welche man bei den sehr zahlreichen Glossen, die gar keine Ursprungsbezeichnung tragen, allgemein angewiesen wäre, wenn nicht einige von diesen geradeso wie manche von den signierten mit der einen oder andern Photiusekloge in irgendeiner Beziehung stehen oder sich durch ihre Zugehörigkeit zu einer ausdrücklich dem Damascius zugewiesenen Glosse als dessen Eigentum erweisen würden. Da nun einerseits weitaus die Mehrzahl aller den Stempel des Damascius tragenden Suidasartikel deutlich auf das von ihm zitierte biographische Werk hinweist und sich andrerseits bei dem Lexikographen kein einziges Bruchstück aus einem anderen findet, so ist man wohl berechtigt, auch bei denjenigen Glossen, denen man nicht mit aller Bestimmtheit den ihnen zukommenden Platz in der Isidorusvita anweisen kann, gleichwohl an diese Quelle zu denken. Man wird schlieBlich auch durch manche seltenen Stichwörter, die gerade für unsere Schrift bezeichnend sind, an sie erinnert, selbst wenn es sich dabei um bloße Worterklärungen ohne einen literarischen Beleg handelt. Dies ist u. a.

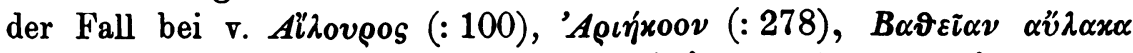

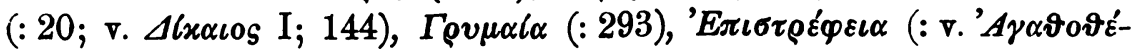

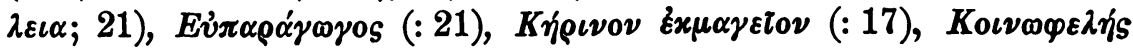

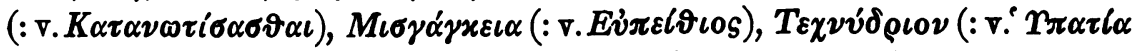

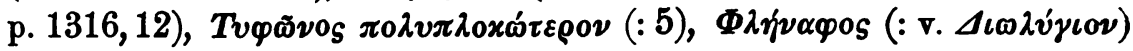

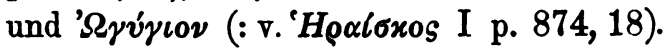

Die Damasciusfragmente bei Photius und Suidas zerfallen in zwei Klassen: in solche, bei denen ein bloB partikuläres formales oder stoff-

1) Ruelle p. 152 Anm. hălt im AnschluB an viele Vorgänger verkehrterweise die Biographie des Isidorus bloB für einen Teil der „Philosophischen Geschichte“. 
liches Interesse maßgebend war, und in solche, die ihre Erhaltung einer weitergehenden Wibbegierde verdanken. Jene fallen dem Leser sofort durch ihre beziehungslosen Partikeln, Konjunktionen, Partizipien, Apellativa, Pronomina, Zahl-, MaB-, Zeit- und Ortsbestimmungen, Objekte und Subjekte unvorteilhaft auf; sie machen zwar hinsichtlich ihrer Authentizität einen sehr vertrauenswerten Eindruck, dafür stellen sie aber in ihrer Vereinzelung der richtigen Erklärung die allergröBten Schwierigkeiten entgegen. Wie wenig diese ohne Kenntnis des $\mathrm{Zu}$ sammenhangs gelingen kann, geht am besten aus den vielen Fehlern der bisher versuchten Übersetzungen hervor, auf deren Hilfe man daher bei der Rekonstruktion des Gesamtwerkes füglich verzichten kann. ${ }^{1}$ ) Die gröBte Unklarheit herrscht bei den zahlreichen Stücken, worin nicht einmal das Subjekt deutlich namhaft gemacht ist. So lautet beispielsweise

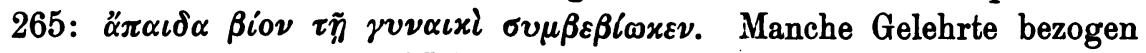
diesen Satz vorschnell auf Isidorus; sie gerieten aber hierdurch in Widerspruch mit 301, wonach unserem Philosophen von seiner Frau ein Sohn geboren wurde. Nach Ausweis von v. 'Ihá der Held dieser Glosse der kinderlose Ehemann, wodurch der ganze Streit über die Kinderlosigkeit des Vaters Isidorus gegenstandslos wird. ${ }^{2}$ ) Ähnlich liegt die Sache bei den im Index zu Westermanns Photiustext mit Unrecht auf diesen bezogenen Eklogen 26;36;49;240;247 und 296.

Die weniger abgerissenen und inhaltsreicheren Stücke scheiden sich wieder in zwei Gruppen: in solche mit und solche ohne deutliche Merkmale der Umformung von seiten des Exzerptors. Zu Referaten umgestaltet sind ohne Zweifel die mit ö $\tau \iota . . . \varphi \eta \sigma \ell$, oder bloßem $\varphi \eta \sigma \ell$, oder ö $\iota \iota$ mit einem andern Verbum dicendi oder bloßem ö $\iota \iota$ eingeleiteten Fragmente bei Photius und Suidas, die mit oṽzos, $\delta \delta \varepsilon$, Pronomen relativum, ỡ $\tau$ os $\eta^{\tilde{\eta}} \nu$ + Pronomen relativum (dies einmal auch bei Photius

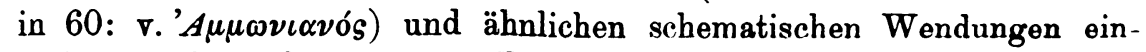
geleiteten bzw. fortgesetzten Bruchstücke bei Suidas und solche mit selbständigen Zusätzen des Photius, wie sie sich, abgesehen von den der ersten Gruppe zuzuweisenden rein lexikographischen Auszügen $(4 ; 52 ; 220 ; 254 ; 257 ; 295$; vgl. $12 ; 76 ; 88 ; 115 ; 233)$, namentlich in den bereits angeführten paradoxographischen und antichristlichen.Nummern finden, die zudem meist irgendeine abkürzend-zusammenfassende Wendung enthalten (vgl. aber auch $36 \ddot{\alpha} \lambda \lambda_{0} v_{S} \delta \grave{\varepsilon}$

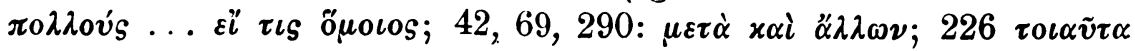

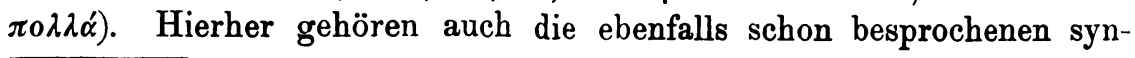

1) Vgl. Bruckers Verdikt über die Schottsche Photiusübersetzung $\amalg^{2}$ p. 340.

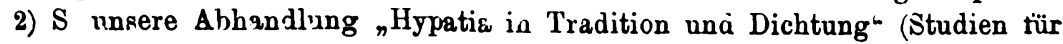
vergleichende Literaturgeschichte VII) S. $22 \mathrm{ff}$. 
kritischen Notizen in 67 und 110. Abgeändert sind ferner die Fragmente, in welchen Damascius entweder mit Namen genannt $(88 ; 290$;

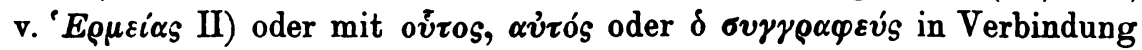
mit einem Verbum des Sagens bezeichnet wird. 200 enthält sogar

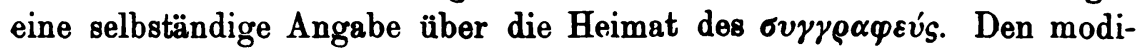
fizierten Stücken ist endlich noch beizuzählen 295 wegen eines sachlichen Scholions and der bereits genannte $\$ 88$ nebst 36 wegen einer byzantinischen Wendung. ${ }^{\text {) }} \mathrm{DaB}$ man jedoch auch da, wo derartige Modifikationsmerkmale fehlen, nicht ohne weiteres auf die Integrität des ursprünglichen Textes rechnen darf, zeigen die formalen Diskrepanzen mancher inhaltlich übereinstimmenden Photiuseklogen unter sich oder im Vergleich mit entsprechenden Suidasglossen. Dies ist z. B. bei 39 und 40 (:246; v. Moגvíxoos) der Fall, wo nur Photius I die richtige Reihenfolge erhalten hat, wenngleich nur aus Photius II der Zusammenhang klar hervorgeht. Überhaupt darf nicht verschwiegen werden, daB sich sowohl bei Photius II und den Nachträgen hierzu als auch bei Suidas in entsprechenden Partien manche bei Photius I nicht vorhandenen Einzelheiten vorfinden und namentlich manches Stichwort des Lexikographen in der Parallelversion bei dem Patriarchen vermiBt wird.

Die größte Gewähr für die Integrität des Originals bieten die ausdrücklichen Zitate, dann die abgerissenen Bruchstücke, von denen Suidas

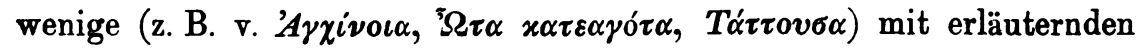

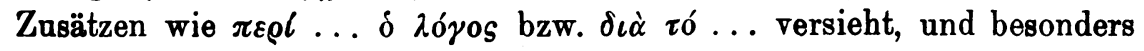
solche Fragmente, in welchen die Form der direkten Rede gebraucht wird. Bei ÄuBerungen in der ersten Person hat man es wohl in der Regel mit Damascius zu tun; bei den übrigen kann nur der Zusammenhang über die Persönlichkeit des Sprechenden entscheiden. Liegen dagegen bei Photius indirekt mitgeteilte Auslassungen vor, so bietet das regierende Verbum dicendi insofern einen Anhaltspunkt zur Feststellung des Subjekts, als man das Präsens jeweils auf den Biographen, und ein historisches Tempus auf einen von seinen Helden, meistens aber auf Isidorus selbst, deuten darf. Denn nach 8 sind ja dessen Mitteilungen die Hauptquelle des Damascius.

Eine ganz besondere Beachtung beanspruchen die zahlreichen Sonderviten, die Suidas aus dem Leben des Isidorus geschöpft hat. Es

1) DaB man die Konstruktion von $\varepsilon i_{S}$ mit dem Akkusativ st. $z v$ mit dem Dativ dem Damascius nicht zutrauen darf, stellt Bucherer S. 6 ff. richtig fest. Da es sich jedoch beidemale um eine mit ô $\tau \iota$ ( $\varphi \eta \sigma \iota v)$ eingeleitete Ekloge handelt, so hat man diese Konstruktion, wofür vielleicht ein im Urtext bereits vorhandenes $\varepsilon l_{S}$ den AnlaB geben konnte, wohl anf Rechnung des eilig epitomierenden Photins

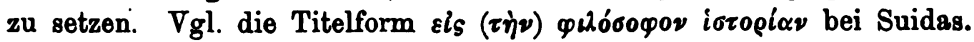




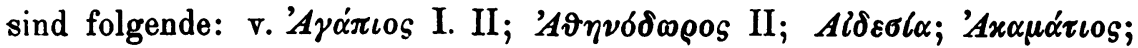

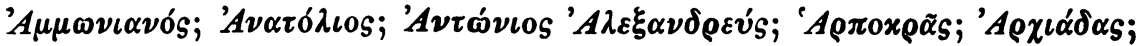

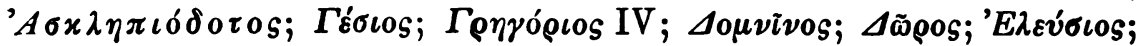

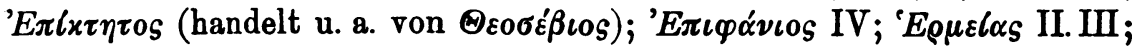

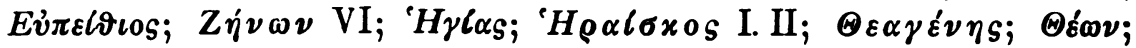

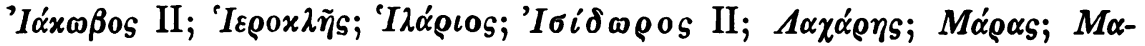

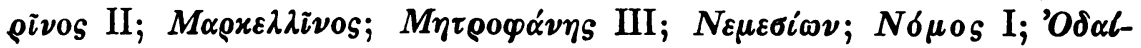

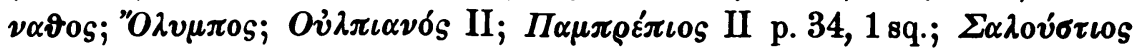
III. IV; $\Sigma \alpha \rho \alpha \pi l \omega \nu$ II; $\Sigma \varepsilon \beta \eta \rho \iota \alpha \delta_{s} ; \Sigma \varepsilon \beta \tilde{\eta} \rho \circ \mathrm{II} ; \Sigma \iota \lambda \beta \alpha \nu \delta_{s} ; \Sigma o v \pi \eta-$

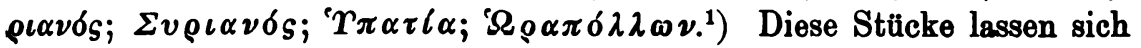
nur dann für die Rekonstruktion unseres Werkes richtig verwerten, wenn man sich auf Grund einer kritischen Untersuchung über ihre Zusammensetzung klar geworden ist. Denn man hat in ihnen gröBtenteils nicht etwa ursprünglich bei Damascius fertig vorliegende Lebensskizzen nach Art des Theodorabios in Cod. 181, sondern flüchtige und unkünstlerische Kompositionen $\mathrm{zu}$ erblicken, deren Elemente vielfach geradeso wie diejenigen des Damasciusbios a. a. O. an ganz verschiedenen Stellen des Originaltextes verstreut standen. ${ }^{2}$ ) Allerdings bot dieser gelegentlich bereits bei der erstmaligen Nennung einer Persönlichkeit einen ansehnlichen Grundstock zum weiteren Ausbau. Es finden sich auch da und dort bei ihm schon abschlieBende und abgrenzende Wen-

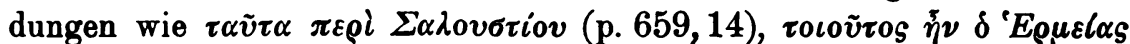

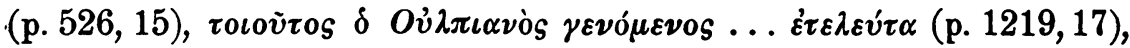

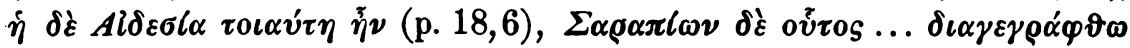

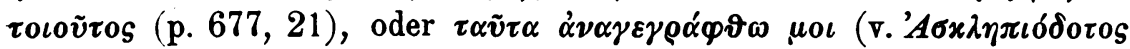
p. 793, 15; vgl. v.'Aví́vıos 'A $A \varepsilon \xi \alpha \nu \delta \rho \varepsilon v ́ s$ p. 500, 3) beim Übergang von einem biographischen Exkurs zur fortlaufenden Darstellung. Ferner macht sich, wie schon unsere obigen Belege für den von Damascius angelegten Maßstab zeigen, ein einheitliches Schema bemerkbar, so verschiedenartig auch die einzelnen noch erhaltenen Stücke in ihrem $\mathrm{Zu}$ schnitt sind. Sicherlich spielte der in 31 und 32 dargelegte Kanon

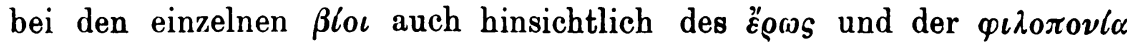
eine wichtige Rolle, da diese beiden Kardinaltugenden neben der $\dot{\alpha} \gamma \chi \chi^{i}$ $\nu o \iota \alpha$ des öfteren in betracht gezogen werden. Mustergültig ist hierfür

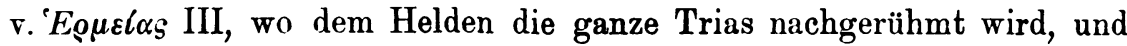

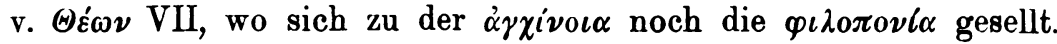

1) Die Zusammenstellung bei Flach, Untersuchungen über Hesychius Milesius (Rhein. Museum 35) S. 226, 11 ist unvollständig. v. 'A $\alpha_{\alpha}^{\prime} \tau \iota$ 's hat nichts mit Damascius zu tun.

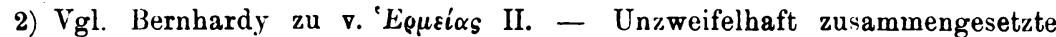
Glossen sind in unserem obigen Verzeichnis gesperrt gedruckt. 
Bei seiner Kompilationsarbeit vergewaltigte Suidas selbstverständlich den ursprünglichen Wortlaut, die ursprüngliche Anordnung und vor allem das ursprüngliche Volumen des von seiner Vorlage jeweils gebotenen biographischen Materials, das sich, nach den Resten zu schließen, meist auf das Nationale, die Genealogie, die unmittelbare Verwandtschaft, die Zeit," das Äußere, die Bildungs- und sonstige Entwicklungsgeschichte, den Stand, den Charakter, die Lebensbetätigung, irgendeine Würdigung und gelegentlich auch auf irgendwelche Anekdoten aus dem gerade in Betracht kommenden Lebenslauf erstreckt zu haben scheint. Bei der Zusammenstellung der biographischen Einzelheiten verfuhr aber der Redaktor so unachtsam, daB er die im Original durch ihre weite Distanz mehr entschuldbaren Wiederholungen einer und derselben Sache auf dem engen Raum seiner Elaborate ungescheut nebeneinander gruppierte und diese hierdurch verunzierte. Dies ist z. B. in sehr aufdringlicher Weise der Fall in v. $\Sigma \alpha \rho \alpha \pi i \omega \nu$ II, wo fast unmittelbar hintereinander die folgenden Fassungen ein und derselben Notiz wiederkehren:

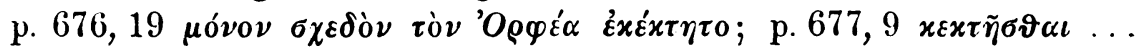

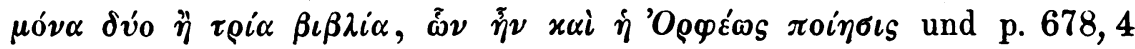

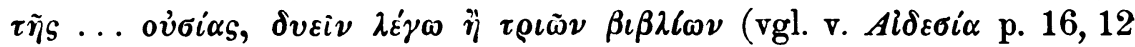
$=18,21 ; 17,11=18,8 ; 17,20=18,18)$. Von derselben Sorglosigkeit zeugen die vielen ganz schematischen und jeder Glätte entbehrenden Wendungen, mit welchen Suidas die zwischen den einzelnen Baugliedern klaffenden Risse zu verkleistern sucht, ganz abgesehen von den stereotypen Eingängen mit oṽ்os, ő $\delta \varepsilon$ oder ős, die er gelegentlich auch zur Weiterführung verwendet. Manchmal gibt er sich nicht einmal die Mühe, seine kompilierende Hand zu verbergen: So schiebt er z. B.

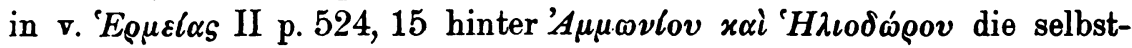
verfertigte Apposition $\tau \tilde{\omega} \nu$ $\delta \iota \delta \alpha \sigma \varkappa \alpha ́ \lambda \omega \nu \Delta \alpha \mu \alpha \sigma x i o v$ ein, verbindet in

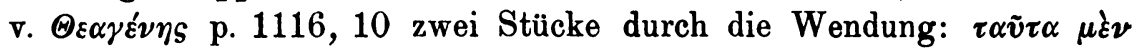

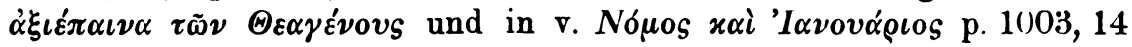

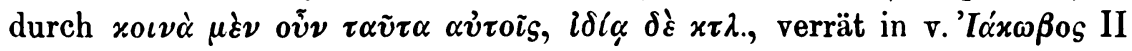

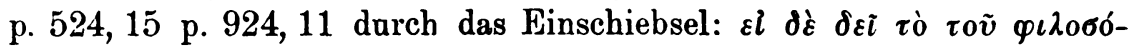
qov (sc. $\Delta \alpha \mu \alpha \sigma x i o v$ ) $\varepsilon i \pi \varepsilon i \nu, ~ d a B$ er bloß referiert, und gesteht in

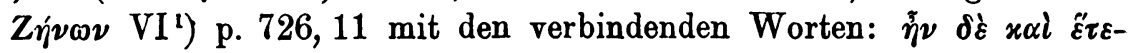

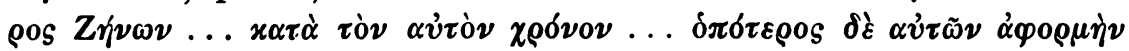

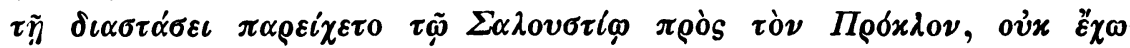
$\varphi \varrho \alpha ́ \xi \varepsilon l \nu, d a B$ er in der Geschwindigkeit den Zusammenhang der beiden

1) Flach S. 194 weist diese Glosse fälschlich dem Hesychius zu; Daub, Studien zu den Biographika des Suidas S. 133 will mit Küster bloß den zweiten Teil dem. Damascius geben. - Der Held von Julian. Epist. 45 hat als Zeitgenosse des Apostaten nichts mit unserem Fragment zu tun. 
wahrscheinlich ziemlich weit voneinander getrennten Stellen seiner Vorlage nicht klar erfaBte. Die Eile war wohl auch daran schuld, daB er hin und wieder ein und dieselbe Persönlichkeit unter Verkennung oder MiBachtung ihrer Identität bloB deshalb zum Gegenstand von zwei getrennten Glossen machte, weil er sie an verschiedenen Orten zitiert fand.

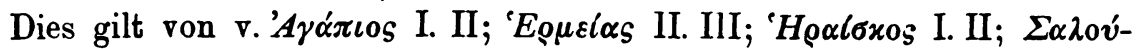

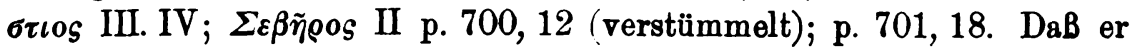
sich die Arbeit leicht machte, zeigen die zahlreichen aus ursprünglichen Einzelviten entnommenen Elemente, die er in seine Lebensskizzen nicht

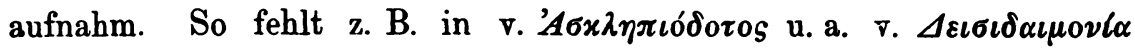
p. 1235,3 sq. Wie vielfach und wie zahlreich die Schwierigkeiten sind, mit denen man bei der Verwertung dieser Einzel-Bioc zu rechnen hat, erhellt vielleicht am besten aus folgenden teils durch Suidas, teils durch die Schuld seiner Abschreiber verwirrten Beispielen:

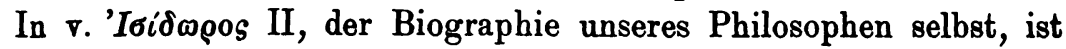
schon auf den ersten Blick die Dürftigkeit des Mitgeteilten auffällig. Denn diese Vita beschränkt sich auf eine ganz knappe Würdigung der Bildung Isidors, ohne daß wir auch nur die Namen seiner eingangs gestreiften Lehrer erführen, und auf die Erzählung eines ihm gewordenen Traumgesichts: ein Bestand, der selbst für Suidas ungenügend erscheinen muB. Tatsächlich ergibt sich auch gleich in der dritten Zeile p. 1073, 11 eine Lücke ${ }^{1}$ ), in welcher wohl das VermiBte zum Teil gestanden haben dürfte. Denn was nun folgt, pabt eher auf Heraiscus, den einen von seinen beiden Lehrmeistern, als auf ihn selbst, da einer-

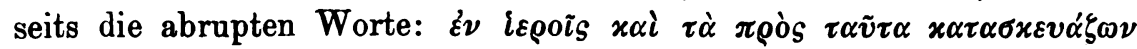

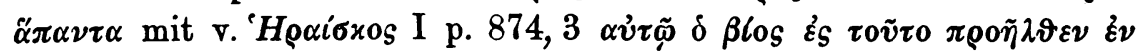

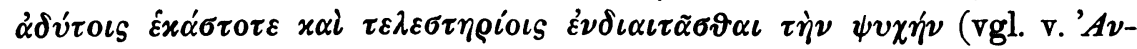

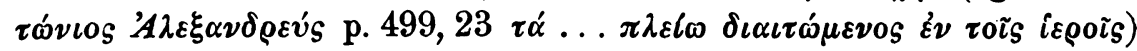

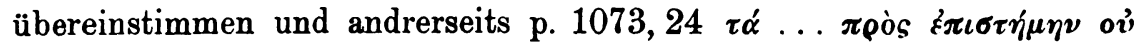

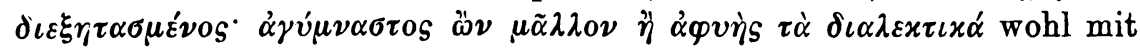

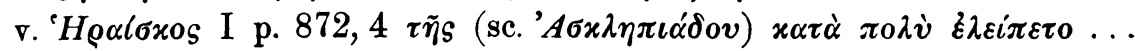

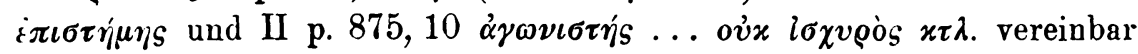

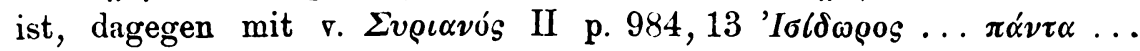

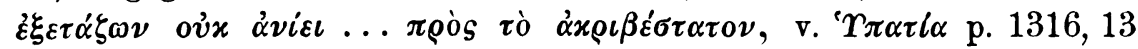

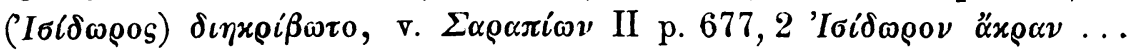

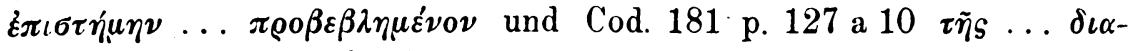

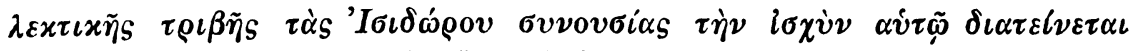

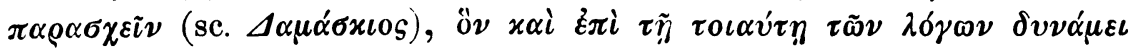

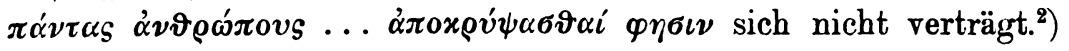

1) Zuerst von Bernhardy wahrgenemmen.

2) S. Zeller S. 899, 3. 
Eine ähnliche Vermengung nicht zusammengehöriger Elemente

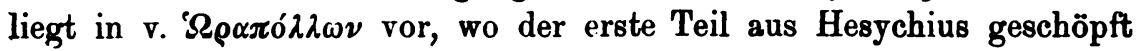
ist $^{1}$ ) und bloB der zweite, mit $\lambda \alpha \mu \pi \rho o_{s} x \tau \lambda$. p. 1267, 2 beginnende, dem

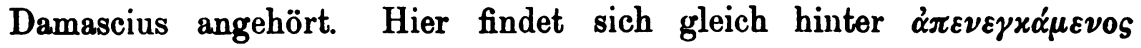
p. 1267, 4 eine Lücke, in welcher wahrscheinlich ein von Harpokras handelnder Abschnitt stand, da das Folgende nach Ausweis von

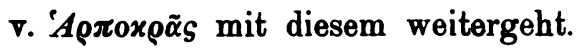

Ein noch komplizierteres Beispiel bietet v. ' $\Gamma \pi \alpha \tau \ell \alpha$. Diese Einzelvita besteht gleichfalls aus zwei Teilen, von denen nur der zweite aus Damascius geschöpft ist; der erste, p. 1312, $31-1313,12$, geht wohl auf Hesychius ${ }^{2}$ ) zurück, neben dem aber wahrscheinlich noch eine Ergänzung aus Philostorgius und p. 1312, 23 sicher eine Interpolation aus Damascius festzustellen ist. Der Interpolator hat nämlich hier die

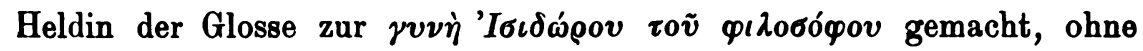
zu beachten, daB es gleich darauf im zweiten Abschnitt p. 1314, 2 von

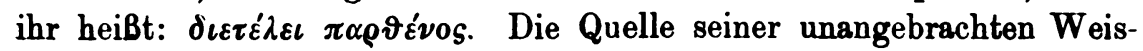

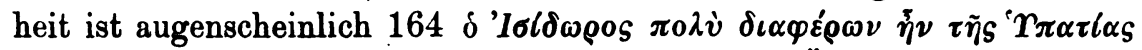
... oía pvvaıxòs àvŕ́, eine Stelle, die er mit Übergehung von 301

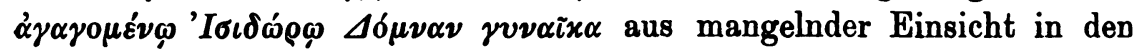
Zusammenhang irrtümlich interpretierte und damit in die Biographie der Hypatia und des Isidorus eine Menge Schwierigkeiten hineinbrachte. ${ }^{3}$ ) Aber auch das Damasciusfragment scheint nicht ganz einheitlich zu sein, wenn wir auch hier nicht an eine Entstellung denken müssen. Denn

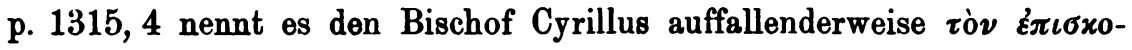

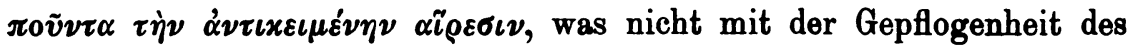
Damascius übereinstimmt. Dieser hätte wohl schlechtweg von einem

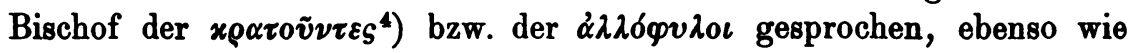

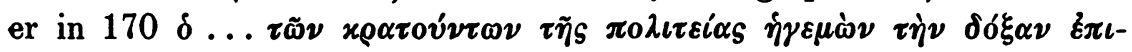

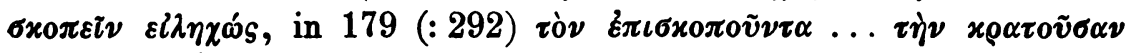

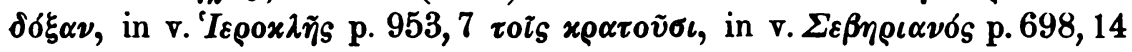

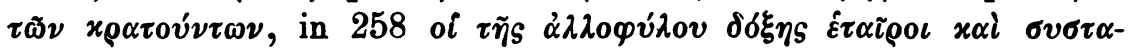

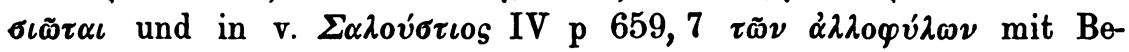
ziehung auf die Christen sagt. Jene Bezeichnung paBt dagegen sehr

1) Vgl. Flach, S. 225, 137, gegen dessen allerdings zu spitzfindige Erklärung Daub S. 429 verkehrterweise den ganzen Artikel dem Damascius zuweist. Hier-

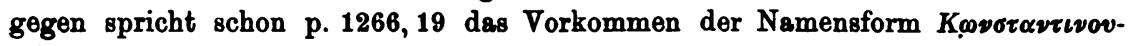

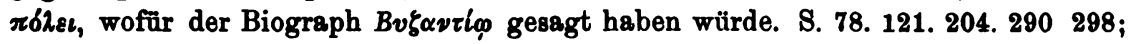

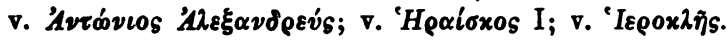

2) S. Wernsdorf p. 2 und Flach S. 223, 127.

3) S. unsere Abhandlung über Hypatia S. $14 \mathrm{ff}$.

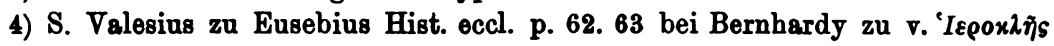
p. $963,7$. 
gut auf eine arianische Quelle, die vielleicht dieselbe war, mit der sich unser Biograph p. 1314, 6 (oi ... $\alpha \dot{\pi} \alpha(\delta \varepsilon v \tau o \iota ~ \lambda o ́ \gamma o \iota)^{1}$ ) auseinandersetzt. Da nun Philostorgius Hist. eccl. VIII c. 9 sagt: $\delta \iota \alpha \sigma \pi \alpha \sigma \vartheta \tilde{\eta} \nu \alpha \iota$ rò $\gamma v ́ v \alpha \iota \nu \nu$

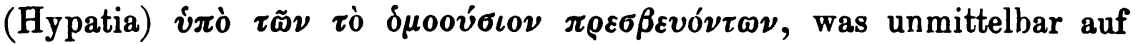
Cyrillus abzielt, dürfte dieser arianische Kirchenhistoriker sein Gewährsmann sein. Nun heißt es aber im ersten Teil unserer Glosse p. 1313,4

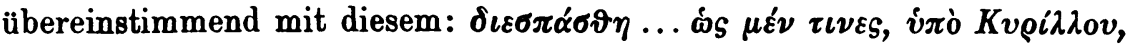

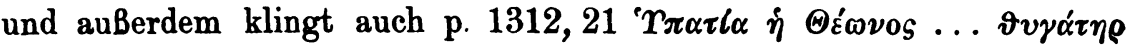

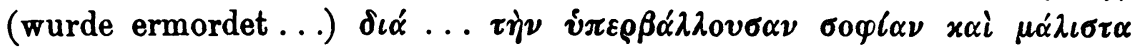

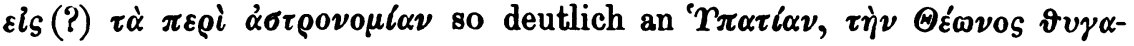

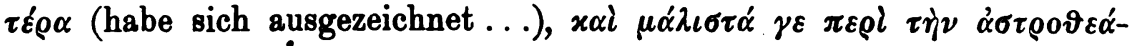

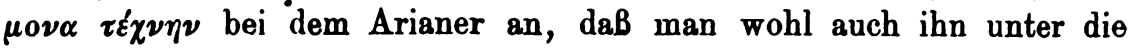
$\tau \iota \nu \varepsilon s$ zu rechnen hat. SchlieBlich verdient noch eine Besonderheit hervorgehoben zu werden, welche dieser Lebensabrib mit vielen andern gemein hat: dies ist die jeder Abrundung spottende Anfügung einer lang ausgesponnenen SchluBpartie (p. 1316, 1 sq.), die mit der Heldin fast gar nichts mehr zu tun hat. Suidas hat eben auch hier, wo es sich doch im Sinue des Bamascius um das Prototyp der hellenistischen Philosophin und Märtyrerin handelte, lediglich Steine gebrochen, ohne sie für seinen flüchtigen Bau noch sorgfältig zuzurichten. DaB Photius in seinem Auszug aus der Isidorusvita von dem Schicksal der Hypatia keine Notiz genommen hat, erklärt sich hinreichend daraus, daB wir ja gerade ihm unsere Philostorgiusepitome verdanken und Damascius ihm infolgedessen nichts wesentlich Neues bieten konnte.

Die Einzelbiographien, von denen auch bei Photius noch beträchtliche Reste erhalten sind, nehmen unter den von dem Patriarchen Cod. 181 p. 126 a 12 gerügten zahlreichen $\pi \alpha \varrho \varepsilon x \delta \varrho o \mu \alpha i$ den ersten Platz ein. Die Einordnung ihrer einzelnen Bestandteile in das zu rekonstruierende Ganze begegnet aber um so größeren Schwierigkeiten, als auch sie selbst von Digressionen unterbrochen wurden, die den Leser von ihrem jeweiligen Helden auf Nebenpersonen und -dinge ablenkten. Neben historisch-genetischen Herleitungen von irgendwelchen Kulturerscheinungen, biographischen Parallelen, Reisebeobachtungen oder den bereits erörterten $\delta \iota \eta \gamma \eta \tilde{\mu} \alpha \tau \alpha$ der besprochenen Persönlichkeiten spielt bei diesen Abschweifungen besonders dusjenige eine große Rolle, was der Verfasser selbst von sich und seiner Stellungnahme zu dem jeweiligen Gegenstand seiner Darstellung bemerken zu müssen glaubt. Er drängt sich nämlich bei jeder Gelegenheit aus allen möglichen Veranlassungen, worunter die pietätvollen Nachrufe auf Ädesia, Asclepiodotus und Antonius

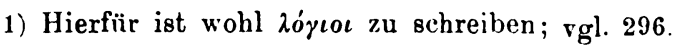


Alexandreus sich am vorteilhaftesten ausnehmen, in den Vordergrund, ein Mangel an Bescheidenheit (vgl. besonders $\left.\nabla .{ }^{~} P v \vartheta \mu l \xi \varepsilon \iota\right)$, den ihm Photius Cod. 181 p. 126 a 18; 28; 30 nachdrücklich zum Vorwurf macht. Obschon er sich nach 8 im Rahmen einer Biographie halten will, verschont er uns doch nirgends und nie mit allgemein philosophischen, persönlich kritischen und namentlich mit autobiographischen Auslassungen. Diese letzteren beschränken sich keineswegs auf den Lebenslauf des Haupthelden, sondern sie greifen demselben meistens vor. Zwei derselben, in 64 und 69, haben wenigstens den Vorzug, daB sie uns die ungefähre Abfassungszeit der Biographie, d. h. als terminus ad quem den im Jahr 526 erfolgten Tod Theoderichs d. Gr. und als allerdings unbestimmten terminus a quo die letzten Lebensjahre der bereits vor 470 verheirateten Seherin Anthusa ${ }^{1}$ ) verraten. Die beigezogenen Nebenpersonen lebten teils vor, teils gleichzeitig mit Isidorus, teils nach ihm (Cod. 181 p. 126 a 10), wodurch in der Darstellung ein Durcheinander von zeitlich weit auseinander liegenden Stoffkreisen entsteht. Da die gelegentlich vorkommenden Zeitbestimmungen fast stets nur relative

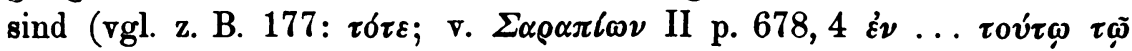
$\chi \varrho o ́ \nu \omega)$, so sind sie wenig geeignet, bei der Ermittlung des ursprünglich chronologischen Aufbaus des Hauptbios als Hilfsmittel zu dienen. Zudem enthielt dieser selbst wohl auch in seinem Urbestand nicht allzuviel tatsächliches Material; war doch Isidorus nach 17 eine im wesentlichen aus einer $\psi v \chi \eta^{\prime}$ bestehende Persönlichkeit. Wir haben daher aller

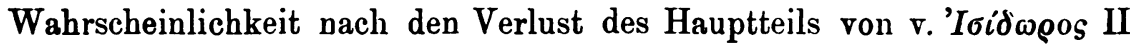
nicht allzutief zu beklagen, zumal die übrigen von Suidas aus Damascius zusammengestellten Einzelviten auch für den Isidorusbios keine großen Erwartungen wecken. Selbstzitate, von welchen aus man bei der Rekonstruktionsarbeit den Weg nach vor- oder rückwärts suchen und finden könnte, kommen in den erhaltenen Stiicken nur ganz wenige vor und lassen sich ebenso wie die gelegentlich unterlaufenden Dispositionselemente stets nur stationär verwerten.

Daher setzt sich die Wiederherstellungsarbeit aus einer Menge von Einzelbeobachtungen und -untersuchungen zusammen, bei welchen jeweils die Erwägung, daB das Erhaltene auf jeden Fall im Verhältnis zu dem Verlorenen quantitativ sehr geringfügig ist, zur größten Vorsicht mahnen muB. Man wird somit auch billigerweise an den ersten Rekonstruktionsversuch, den wir im folgenden wagen, angesichts der aufgezeigten Mißlichkeiten, keine allzu hohen und feinen Anforderungen stellen dürfen. Er hat seinen Zweck erreicht, wenn sich der Aufbau

1) S. Tillemont VI p. 241 b. 
der Isidorusbiographie daraus im Rohen soweit ergibt, daB sich die Wiederherstellung der einzelnen Bausteine mit gröBerer Aussicht auf Erfolg in Angriff nehmen läBt, als dies bei ihrer bisherigen Vereinzelung möglich war. Soviel glauben wir nämlich jetzt schon behaupten zu können, daß das Endziel der gesamten Rekonstruktionstätigkeit sich auf eine saubere Recensio ${ }^{1}$ ) und $\cdot$ richtige Anordnung der aus Damascius geschöpften Stücke bei Photius und Suidas zu beschränken haben wird. Denn bei dem Vorwiegen der epitomierenden Referate äber die unmittelbaren Zitate wird sich der Urtext des Damascius trotz des häufigen Vorkommens von Parallelversionen in den meisten Fällen nicht mehr herstellen, sondern höchstens andeuten lassen.

\section{Titel und Einteilung des Werkes.}

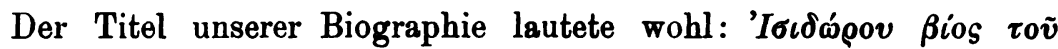

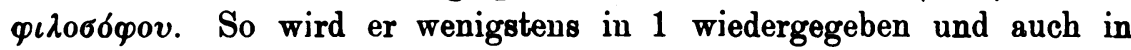
Cod. 181 p. 125 b 30 durch die Fassung $\Delta \alpha \mu \alpha \sigma x i o v \Delta \alpha \mu \alpha \sigma x \eta v o \tilde{v} \varepsilon l_{S}$

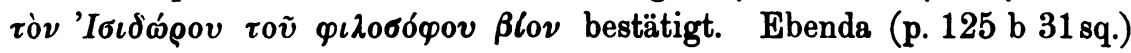

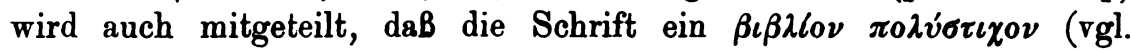
p. $126 \mathrm{~b} 35 \mathrm{sq}$.) $)^{2}$ ) war und in 60 Kapitel zerfiel, eine Einteilung, an welche in den erhaltenen Fragmenten nichts mehr erinnert. Wohl aber läBt das Referat bei Photius einerseits und die Eigenart einiger Bruchstücke andrerseits den SchluB zu, daB unser Werk eine deutlich unterschiedene Einleitung, Durchführung und Schlußpartie hatte.

\section{Die Finleitung des Werkes}

bestand aller Wahrscheinlichkeit nach aus zwei Teilen: Eine Art von Proömium hatte wohl die in Cod. 181 p. 125 b 3sq. skizzierte Widmung an Theodora zum Gegenstand. Diese Zueignung war im Rahmen einer jener von Photius hervorgehobenen Einzelviten gehalten und handelte nach Cod. 181 p. 125 b 33 zunächst von Theodora an sich, indem sie ihren Glauben und ihre Bildung besprach. Dann wurden darin ihre Beziehungen zu dem Verfasser und Isidorus, ihr Stammbaum und ihr Anteil an der Veranlassung zur Entstehung des Werkes erörtert. Damascius ließ sich nämlich durch sie und einige andere Persönlichkeiten zur Abfassung desselben bestimmen. Von der Einleitung im engeren Sinne, welche $\mathrm{zu}$ der Biographie selbst hinüberleitete, ist nichts mehr vorhanden.

1) Hiermit ist zurzeit Dr. J. Hardy, Professor am Collège Communal de Bouillon in Belgien, beschäftigt.

2) Bucherers Bezeichnung "Werkchen (S. 3)" ist somit nicht angebracht. 


\section{Die Durchführung des Werkes.}

A. Die Herkunft des Isidorus.

Eingangs der Durchführung machte der Biograph den Leser wohl mit der Herkunft ${ }^{1}$ ) und dem Stammbaum seines Helden bekannt; dies kann man wenigstens nach dem Theodorabios und dem in den sonstigen Einzelviten befolgten Schema vermuten. Vielleicht gehörte zu diesem

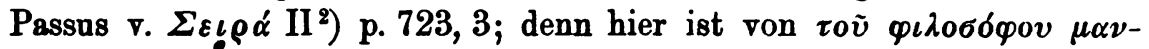
$\tau \varepsilon \dot{v} \mu \alpha \sigma \iota$ die Rede, denen ein Ungenannter folgen will. Da nach 40

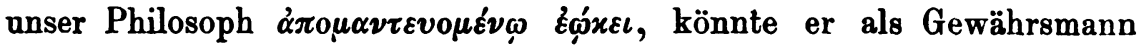
des Damascius hier gemeint sein, zumal dieser nach 8 (vgl. 25) sich vor allem auf die Mitteilungen seines Lehrers stützen will. Auf Isidorus' Vater könnte sich v. 'A p. 82,18 und 83,3 beziehen.

\section{B. Charakteristik des Isidorus.}

An den genealogischen Eingang knüpft der Verfasser wohl eine allgemeine Charakteristik unseres Philosophen an, die von dessen Nationale ausging. Denn 1 enthält im wesentlichen die Behauptung, die Ägypter seien die ältesten Menschen. Die Anknüpfung mit rolvvv läBt vermuten, daB dies im vorhergehenden ausgeführt worden war, und das beigefügte $\mu \varepsilon ́ v$ stellt noch einen zweiten Gesichtspunkt in Aussicht, unter welchem dem genannten Volke das höchste Alter zuzuerkennen ist. Diesen erfahren wir aus 231. Hier ist das Partizipium $\delta \iota \alpha \mu \eta \chi \alpha \nu \omega-$ $\mu \varepsilon ́ v o v s$ wohl mit einem priesterlichen Beziehungswort zusammenzubringen; denn von derartigen Leuten konnte es am ehesten heißen, sie seien im Interesse ihrer eigenen Jenseitshoffnung und für die Wohlfahrt der übrigen Ägypter mit geheimen Dingen beschäftigt. Auf diese

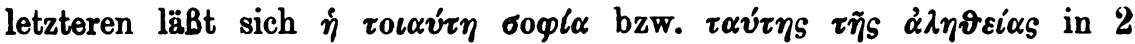
beziehen. Die hiermit bezeichnote mythologisierendo Geheimweisheit

1) D\&B or ein Ägypter war, legt bereits $1 \mathrm{ff}$. nahe; für Alexandria als Ge-

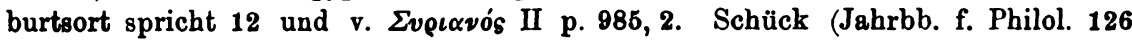
S. 439) behauptet unrichtig, Damascius nenne ihn einen Alexandriner, widerlegt aber mit guten Gründen die von Wernsdorf p. 35, Brucker p. 341, Gibbon, History of the Decline etc IV p. 118, Saint-Martin zu Le Beau, Histoire du Bas Empire

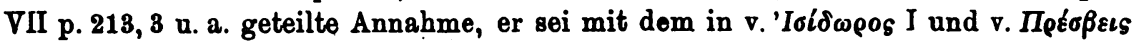
gemeinten Gazäer identisch gewesen, die bereits von Zumpt S. 63, 4 bekämpft worden war. Dieser sagt S. 86, 3 irrtümlich, Suidas nenne den Ulpianus Gazseus einen Bruder des Philosophen Isidorus, während er dieses tatsăchlich nur von Ulpianus schlechtweg tut. Schück wirft diesen viel jüngeren Philosophen mit jenem Mitschüler des Proclus zusammen.

2) Die Aufeinanderfolge der gesperrt bzw. fett gedruckten Stichworter und Zahlen bezeichnet die von uns für richtig gehaltene Reihenfolge der Fragmente. 
(vgl. 38; De princ. p. 13, $5 \mathrm{~K}$.) und die durch das Adverbium ovitws angedeutete Art ihrer Enthüllung dürfte unmittelbar vorher dargestellt worden sein. Hierauf folgte eine genauere Schilderung der ägyptischen Theosophie. Denn nach 3 verehrte man namentlich Osiris und Isis als göttliche Prinzipien. ${ }^{1}$ ) 4 umfaBt bloB die rein sprachliche Bemerkung,

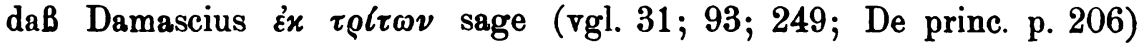

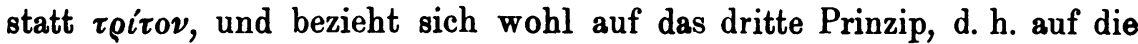
ursprünglich göttlichen, aber zur Materie (dem Typhon; s. 5; v. $\Sigma \alpha \rho \alpha-$ $\pi l \omega \nu$ II p. 678, 9 sq.) herabgestiegenen Seelen (vgl. v. 'E ${ }^{\prime} \mu \varepsilon i \alpha s$ III p. 525, 11 sq.). Die von diesen handelnde Lehre war eine hieratische und keine rein philosophische. Diesen Unterschied stellt v. ${ }^{C} I \varepsilon \alpha \tau\left(x \eta^{9}\right)$ grundsätzlich klar und leitet die von dem dritten Prinzip ausgehende Beschäftigung mit der Seele von der ägyptischen Hieratik her. Die

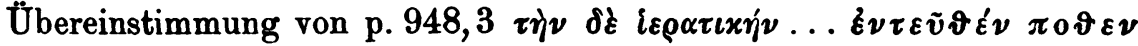

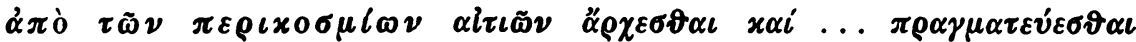

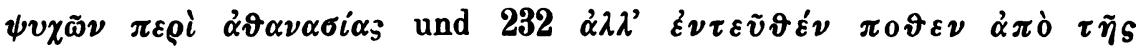

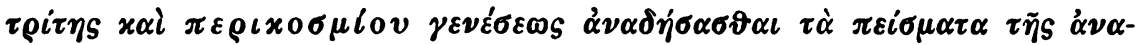

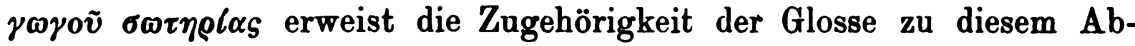
schnitt. Die Quintessenz der ägyptisch-griechischen Seelentheorie ist

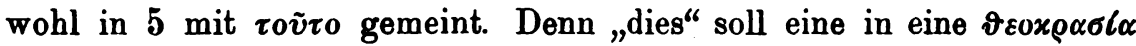
(vgl. 106) auslaufende Wiedervereinigung unserer ins Reich des Typhon herabgezogenen Seelen mit dem Göttlichen sein.

$1-5$ ist nach 6 eine Digression. Da $\alpha \tilde{v} \tau \eta$ in 7 offenbar auf die vom Himmel zur Erde herabgestiegene Seele ${ }^{3}$ ) geht und Damascius nach 8 die Abkunft seines Philosophen von einer ganz bestimmten $(\tau o \tilde{v} \delta \varepsilon)$ Seelengattung behauptet hatte, bezweckte diese Abschweifung eben diese Herleitung; der wieder aufzunehmende Gegenstand ist ohne Zweifel die Persönlichkeit des Isidorus selbst. Welcher Gestalt seine

1) Bucherer S. 7, 3 bestreitet die Zugehörigkeit von $\delta \eta \mu \iota v \rho \gamma \varepsilon \tau \nu$ zu $\tau \dot{\eta} \nu d \dot{v} x \tau \lambda$. und schlägt die Einschiebung von $\sigma \dot{c} \xi \varepsilon \iota \nu$ vor; vgl. dagegen Julian. Epist. 52 p. 558, 4

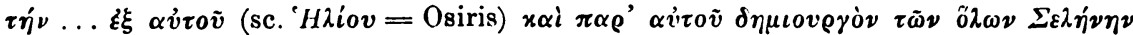
(= Isis) ở $\sigma \alpha \nu$ ov่ $\alpha i \sigma \vartheta \alpha \dot{\nu \varepsilon \sigma \vartheta \varepsilon . ~}$

2) Von Bernhardy mit Unrecht angezweifelt. Für die Authentizität der Glosse

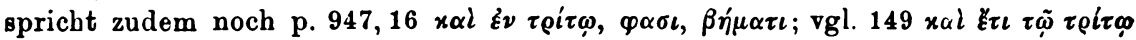
$\beta \eta^{\prime} \mu \alpha \tau$, wo $z_{\tau \iota}$ wohl das Richtige ist. Die Reihenfolge der Sätze ist wahrschein-

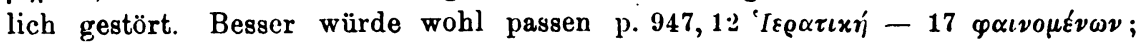

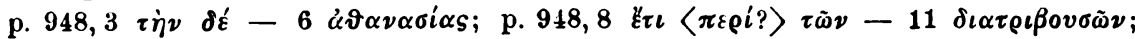

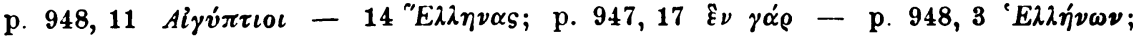

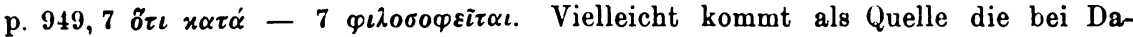

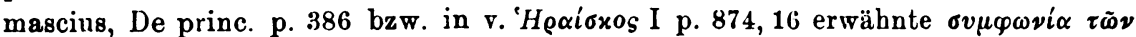
$\vartheta \varepsilon 0 \lambda_{0} \iota \tilde{\omega} \nu \dot{\alpha} \pi \alpha \sigma \tilde{\omega} \nu$ des Asclepiades in Betracht.

3) Auf die Seele üborhaupt, nicht, wie Bucherer S. 10 il 1,1 meint, auf

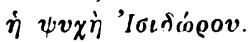


Seelenheimat war, erhellt, abgesehen von $\alpha \dot{\alpha} \delta \varepsilon v \mu \alpha x \alpha \rho i \alpha s$, aus v. $K \alpha \rho \rho \omega \nu$, wo ihn Damascius sich selbst seines Herabstiegs aus einer besseren Welt rühmen läBt. Den Übergang zum folgenden bildet 8 mit der Bemerkung, die Biographie solle die Richtigkeit der postulierten Abstammung durch eigene Mitteilungen Isidors erhärten.

$\mathrm{Zu}$ dem versprochenen Beweismaterial gehört auch 9 (:233; v. $\Sigma \varepsilon-$ $\beta \tilde{\eta} \varrho$ os II p. 700, 13). Die hiernach von Severus [470 römischer Konsul] erzählte Geschichte von den sogenannten Mond- bzw. Sonnensteinen enthielt nämlich wohl das $\zeta \eta \tau o v ́ \mu \varepsilon v o v$, worüber sich Isidorus nach 10

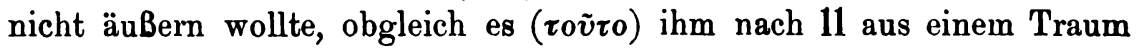
bekannt war. Vielleicht gehört dieser Passus einem autobiographischen Exkurs des Damascius über einen von ihm mit seinem Lehrer gepflogenen Meinungsaustausch an, dessen Gegenstand hier von ihm bloB vorweggenommen und erst in 94 bzw. 230 an der chronologisch richtigen Stelle gründlich erörtert wird. Die abgerissenen Eklogen 234

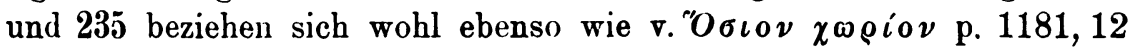
auf das Schicksal des wahrscheinlich gelegentlich einer syrischen Forschungsreise zeitweilig verschwundenen Asclepiades (vgl. 94; s. u).

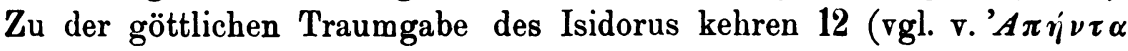
p. 572,10$)-14$ zurück. $\mathrm{Da}$ in 13 der hindernde EinfluB der $\alpha i \sigma \vartheta \eta \sigma \iota s$ auf sein Hellsehen hervorgehoben wird, so entstammen wohl auch 312 und 15 diesem Zusammenhang: denn dort heißt es, der Philosoph habe

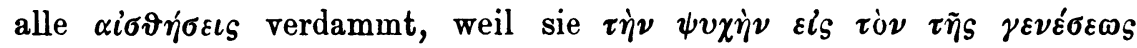

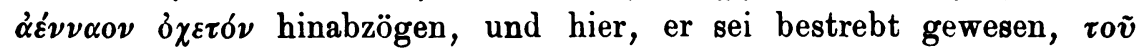

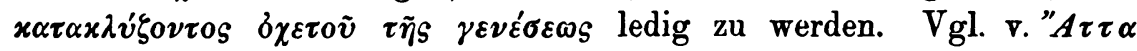
p. $822,28$.

Für die Stichhaltigkeit seiner These führte Damascius nach $1^{1}$ ) (vgl. 284; 307) auch das Äußere des Isidorus an, das nur ein Abbild soines Innern war. In diesem letzteren herrschte nach 17 das rein Seelische über die Sinne und die Phantasie vor. Selbst im Zorn behielt bei ihm nach 18 (: v.' $\Upsilon \pi 0 x \circ \rho(\zeta \varepsilon \tau \alpha \iota)$ die Vernunft noch die

1) Bucherer vermiBt S. 84, 3 in der Beschreibung der Augen ein entsprechendes

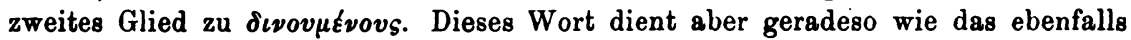
von ihm beanstandete $\pi \omega s$ $\varphi \alpha \dot{v} \alpha \iota$ zur Erläuterung des diesem vorausgehenden

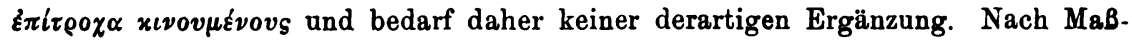

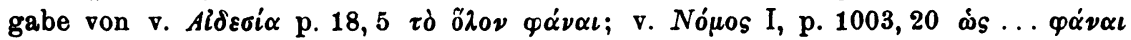

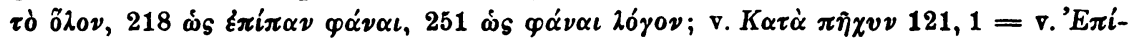

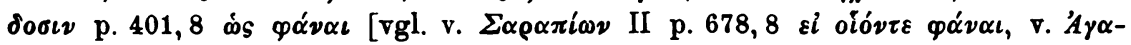

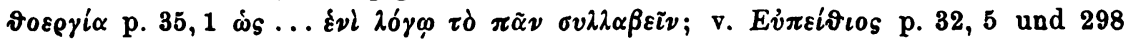

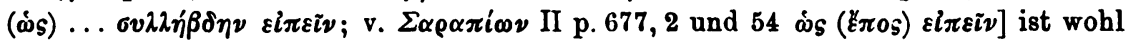

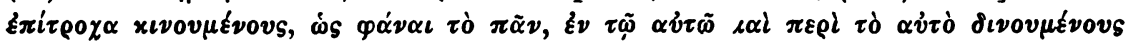
zu schreiben. 
Oberhand. Diese Leidenschaft ist wohl mit $\alpha \dot{v} \tau \eta \dot{\eta} \pi \alpha \dot{\vartheta} \eta$ (schwerlich echt!) in 236 gemeint, die als eine vom freien Willen unabhängige Regung auch mit reinen (Seelen) vereinbar sei. Das einleitende $\delta \dot{\varepsilon}$ in 18 scheint anzudeuten, daB im vorhergehenden unserem Philosophen eine solche zuerkannt worden war. Vgl. $\nabla$. ' $E \pi \varepsilon x \alpha \dot{\alpha} \varepsilon \varepsilon$ p. 366, 1 und

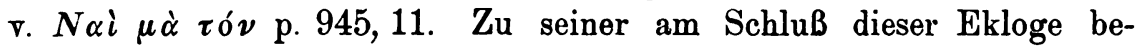
tonten Verachtung der Schmeichelei gegenüber dem Schlechten paßt seine in $\nabla . ' E \nu \alpha \gamma \varepsilon i_{S}$ (: v. " $A \mu \alpha \chi o \nu$ p. 267,5$)$ und $\Theta o i \nu \eta$ p. 1218,13 hervorgehobene Unbestechlichkeit und Standhaftigkeit gegenüber den

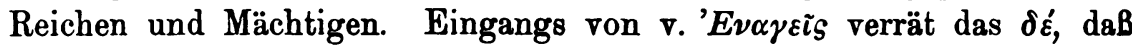
der Verfasser vorher von einer weniger verabscheuenswerten Menschenklasse gesprochen hatte. Als positive Ergänzung zu 19 (vgl. 30), wo Isidorus gegen den Verdacht der Streitsucht in Schutz genommen wird, dient 237 (: v. B $\lambda \alpha \varkappa \varepsilon v$ vं $\alpha \iota$ (vgl. 50; 171), wonach er die Lässigen be-

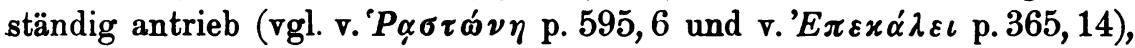

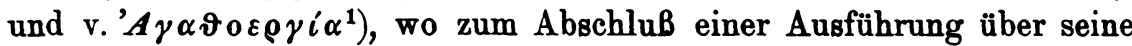

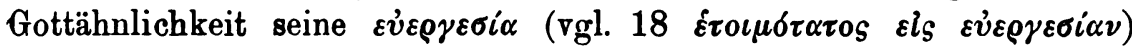
zusammenfassend gewürdigt wird. Der Anfang von 20: $\tau$ o $\alpha \tilde{v} \tau \alpha \delta \dot{\eta} \mu \varepsilon^{\prime}-$

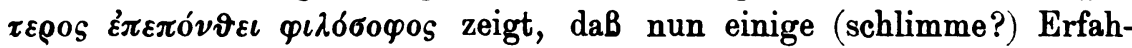
rungen folgten, die er seiner Besserungssucht verdankte. Ergänzend

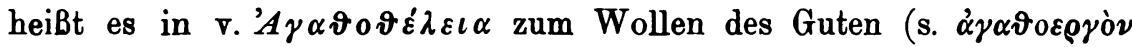

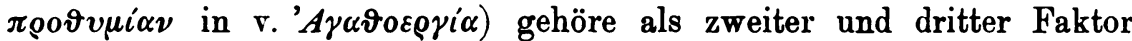

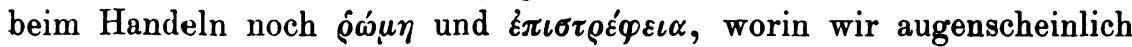
ein von Damascius herrührendes Dispositionselement zu erblicken haben.

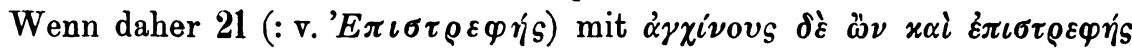
anfängt, so hatte er seinem Helden wohl vorher auch $\rho \omega ́ \mu \eta$ (s. v. 'Iбl-

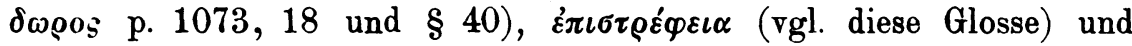
$\left.\alpha^{\gamma} \gamma \chi^{i} \nu \circ \iota \alpha^{2}\right)$ nachgerühmt. $\mathrm{Zu}$ diesen guten Eigenschaften gesellte sich

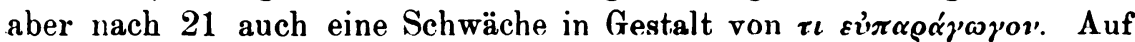

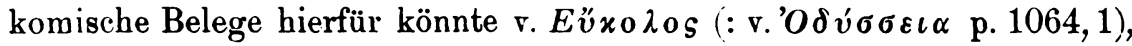

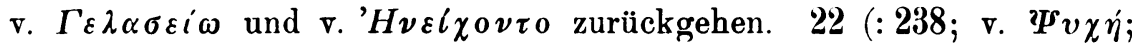
v. ' $\left(\eta \nu \varepsilon i^{3} \alpha^{3}\right)$ I. II p. 1301, 5sq.; vgl. 5) beginnt mit den disponierenden

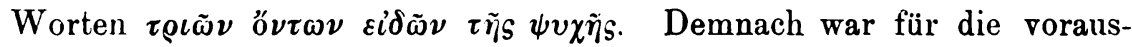
gehende Seelenschilderung diese Dreiteilung maBgebend gewesen, was

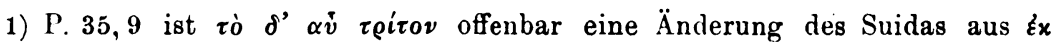
d' $\alpha \bar{v} \tau \rho i \tau \omega \nu ;$ s. o. zu 4 .

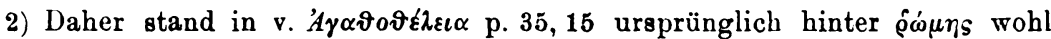
$x \alpha i \dot{\alpha} \gamma x \iota v o i \alpha s$.

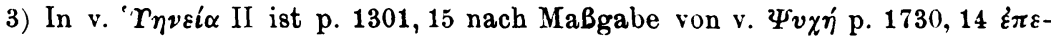

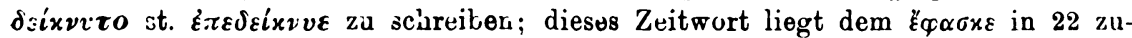

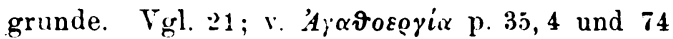


auch noch aus $18 \mathrm{zu}$ erschließen ist, da hier tatsächlich von $\lambda o \gamma \iota \sigma \mu o ́ s$ und $\vartheta v \mu o ́ s$ die Rede ist.

Nun werden die diesen beiden und der $\dot{\varepsilon} \pi \iota \vartheta v \mu l \alpha$ entsprechenden Lebensarten ( $\pi 0 \lambda \iota \tau \varepsilon \tau \tilde{\alpha} \iota)$ behandelt. Zur Darstellung der vornehmsten

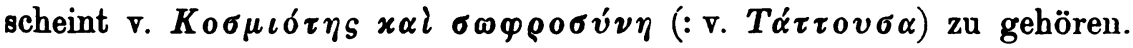
Wahrscheinlich wollte der Biograph zeigen, daß Isidorus dieser bzw.

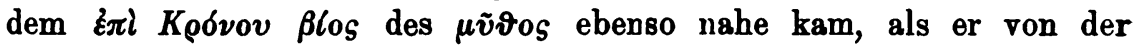
zweiten und dritten entfernt war. Als Illustration hierfür führte er wohl die Freundschaft seines Helden mit dem Theosophen Sarapion an, und zwar dürfte hier zunächst v. $\Sigma \alpha \rho \alpha \pi l \omega \nu$ II p. 677, 3-8 gefolgt sein, wonach dieser Alexandriner unserem Philosophen $\tau$ ìv $\mu v \vartheta \varepsilon v o ́ \mu \varepsilon v o v$ K@óvıv Blov verwirklicht zu haben schien. Tatsächlich entsprach

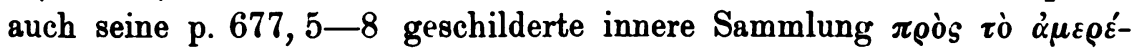

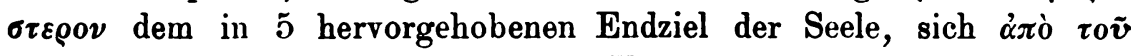
$\pi 0 \lambda \lambda_{0} \tilde{v} \mu \varepsilon \rho \iota \sigma \mu о \tilde{v}$ der Typhonischen Verderbtheit loszusagen und zu konzentrieren. An p. 677,8 schloB sich dann wohl v. $\Sigma \alpha \rho \alpha \pi i \omega \nu$ II p. $675,12-677,3\left(:\right.$ v. $\left.\left.\Lambda \alpha^{\prime} \vartheta \varepsilon \beta \iota \omega^{\prime} \sigma \alpha \varsigma\right){ }^{1}\right)$ an. Mit p. 676,7-9 vgl.

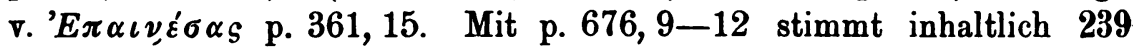

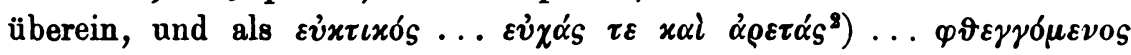
(p. 676,9) gibt Sarapion auch ein passendes Subjekt für $240 \mathrm{ab}$, worin

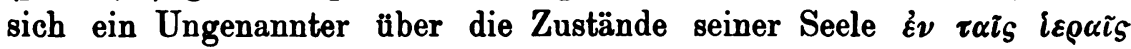
$\varepsilon \dot{v} \chi \alpha \tilde{i} s$ ausläBt. Da Isidors Freund nach p. 676, 20 ein Orphiker war,

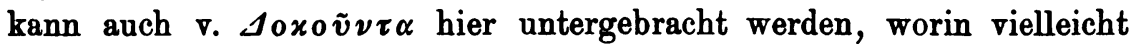
Orpheus selbst als Gewährsmann $\left.\left(\lambda \varepsilon^{\prime} \gamma \varepsilon \iota \text { ? }\right)^{3}\right)$ für seine Eschatologie an-

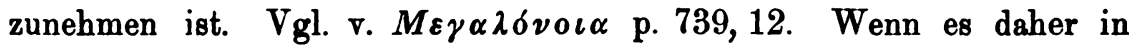

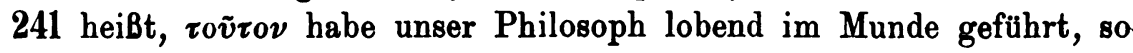
hat man hierbei wohl an Sarapion zu denken.

23 (: v. 'A hebt $\pi \rho \dot{s} \tau \eta \eta \hat{\alpha} \varphi \varepsilon \lambda \varepsilon l \alpha$ noch die ungeschminkte Offenheit Isidors hervor.

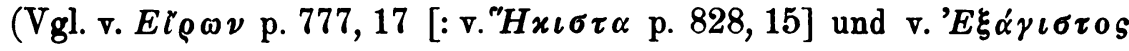
p. 288, 11). Danach hätte Damascius im vorhergehenden von jener

1) P. 676, 4 ist wohl $\pi v \vartheta \varepsilon \sigma \theta \alpha \iota$ statt $\pi \varepsilon i \sigma \varepsilon \sigma \theta \alpha \iota$ zu schreiben.

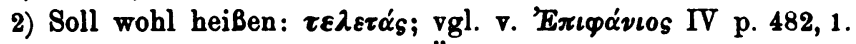

3) Bernhardy macht in seiner Utbersetzung den Isidorus selbst zum Subjekt von $\lambda \dot{\varepsilon} \gamma \varepsilon \iota$.

4) Für die von Bucherer S. 6 o. und S. 16, 29, 2 nach MaBgabe von 23

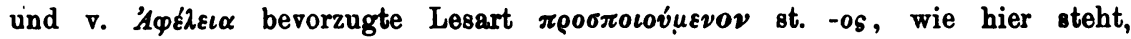

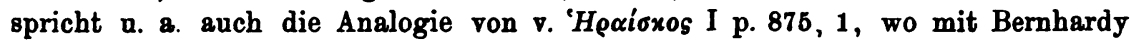

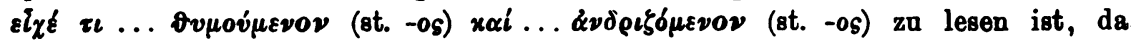
das folgende $\pi \alpha \rho \varepsilon x \beta \alpha i \nu \omega \nu$ zu $\eta^{\nu} \nu$ (Z. 1) gehört and der Emendation nicht im Wege steht. 
Tugend gesprochen. In $\left.24\left(: \mathbf{v} . \Delta \iota \alpha \vartheta \varepsilon^{\prime} \tau \eta s\right)^{1}\right)$ nennt er seinen Helden

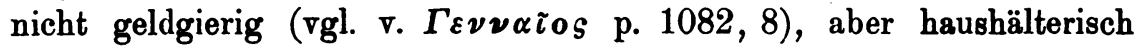

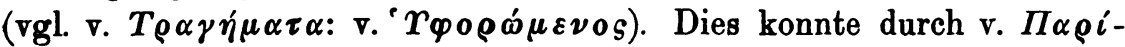

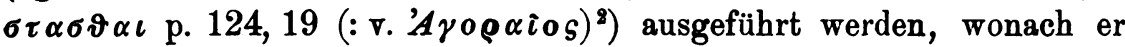
nicht gerne Geld preisgab, sondern ungetreue Schuldner bis vor Gericht verfolgte. Für ein derartiges Vorgehen berief er sich wohl gelegent-

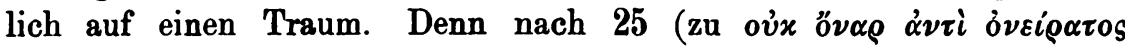

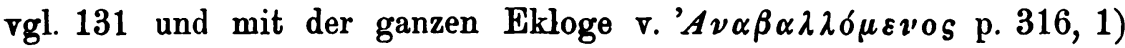
erzählte er manchmal morgens einen solchen, und Damascius beleuchtet nun eine derartige Probe mit der in $26^{3}$ ) (: v. $\Delta\left(x \alpha \iota \iota_{s} \mathrm{I}_{i}\right.$ vgl. v. $\Pi \iota$ $\sigma \tau$ ó $\eta$ s p. 284, 21) unvollständig mitgeteilten Geschichte von dem ge-

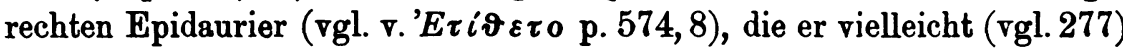
von Marinus gehört hatte. Diese Begebenheit dürfte identisch sein mit dem in 2424) gestreiften Vorfall, der überzeugender wirken soll, als

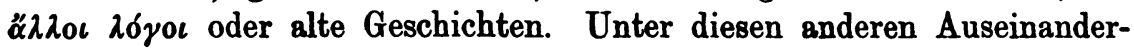
setzungen sind wahrscheinlich moralphilosophische Erörterungen über innere und äußere Gerechtigkeit (vgl. 74) zu verstehen. Möglicherweise wollte der Biograph mittels einer solchen die formale Konsequenz Isidors kritisieren und diese Kritik durch seine eigene Anekdote noch

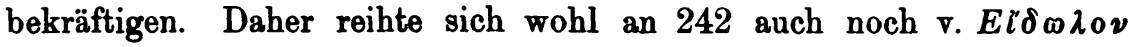
p. 755,5 (: v. $\Sigma x \iota \dot{\alpha} \delta v \varepsilon l \rho \omega v)$ an, wo die Mitteilung von Tatsachen dem Vorbringen bloßer Gleichnisse gegenübergestellt wird.

Da sich im folgenden wiederholt Züge fiuden, welche an Sarapion erinnern, so scheint $\tau$ ò $\tau o \iota$ ṽ $\tau$ v, für dessen Erweis in 27 auf die weitere Darstellung verwiesen wird, mit dieser Parallele zusammenzuhängen.

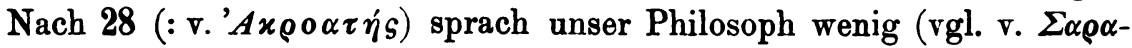
$\pi i \omega \nu$ II p. 676, 14-16) und hörte lieber älteren Leuten zu (vgl.16;51).

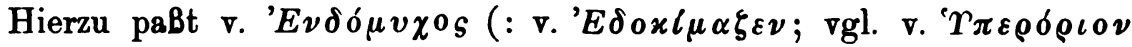

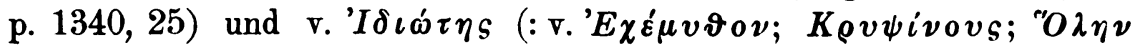

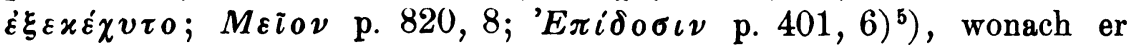

1) Mit einem bloBen ở $\delta^{\prime}$, wie Bucherer S. 6 will, läBt sich die Lücke zwischen 21 und dem vorhergehenden Fragment nicht überbrücken.

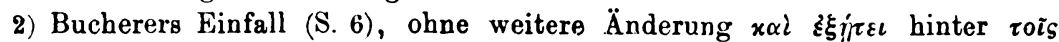

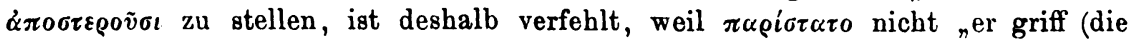
Schuldner) an", sondern nur, wie Bernhardys Übersetzung richtig wiedergibt, nsibi vindicabat (sc. rem debitam)" heißen kann.

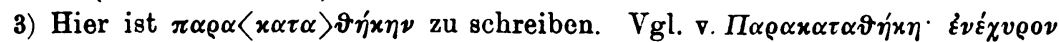

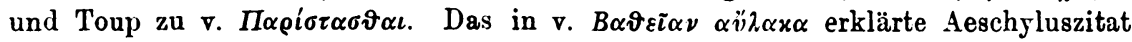
(Septem 598) kehrt in 144 wieder.

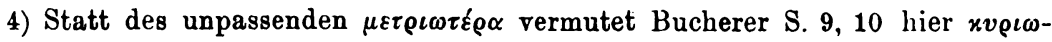

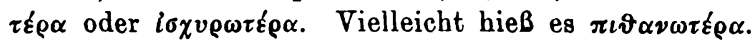

5) Hier verwendet Suidas eine Wendurg des Danascius zur Erklärung eines

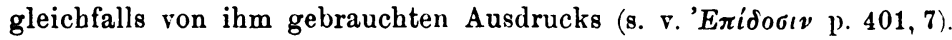


zurückhaltend (vgl. 10) und schweigsam (vgl. 29) war, wenn es aber galt, die Tugend zu fördern und dem Laster Abbruch zu tun, seine ganze Seele ausschüttete. Dem entspricht v. $\Delta \rho \alpha \sigma \tau \eta \eta \emptyset \iota v$ p. 1459, 6

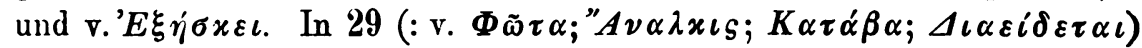
wird dann der Begriff des großen Mannes bestimmt. Hierauf folgte

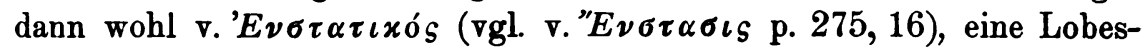
erhebung über Isidors unerschütterliches Festhalten an dem einmal eingenommenen Standpunkt, und 30 (vgl. v. $\Delta \eta \mu \iota 0 v \rho \gamma \delta ́ s$ p. 1248, 17

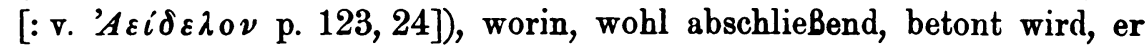
sei wohl ein Tadler, aber deshalb noch kein Zänker gewesen (vgl. 19).

Der nächste Abschnitt gilt dem Nachweis, daB Isidorus dem Ideal

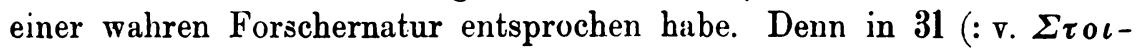

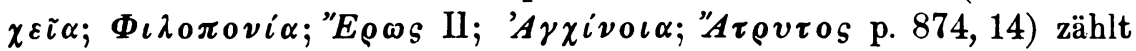
Damascius disponierend die drei Kardinaltugenden einer solchen auf.

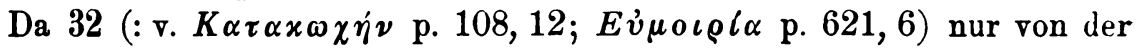
à $\gamma$ ivo $\alpha$ (vgl. 21) handelt, so ging dieser Isidorischen Begriffsbestimmung wohl diejenige des in 31 an erster Stelle genannten $\ddot{\varepsilon} \rho \omega s$ voraus, wogegen nach MaBgabe derselben Ekloge auf 32 die Definition ron

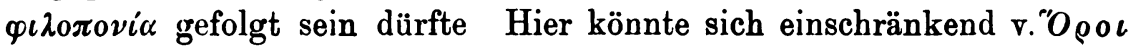

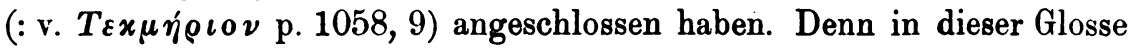
wird die genannte Begriffstrias hinsichtlich der Erkenntnis der menschlichen Dinge näher bestimmt, die unser Philosoph von der Erfassung der göttlichen scharf unterschied. Hier wurde wahrscheinlich sein weltverachtendes Emporstreben zu der Gottheit (vgl. 15; 312) noch einmal

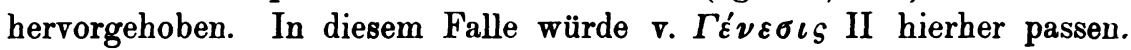
Seine geringe Veranlagung für diese Welt betont auch 33 (: $\nabla . \Sigma v \rho \iota \alpha-$ vós II p. $984,13-985,1$; v. ' $A \nu l \varepsilon \iota$ p. 438,5$\left.)^{1}\right)$, wo vielmehr seine Neigung zur Spekulation eines Plato und Iamblichus hervorgehoben wird. Den Chalkidier verteidigt Damascius in 34 gegen die Angriffe

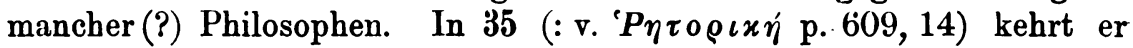
wieder zu seinem Helden selbst zurück, betont dessen spärliche Beschäftigung mit Rhetorik und Poetik (vgl. $61 ; 201)$ und erörtert seine Stellungnahme zu einigen Philosophen im besondern. Hierbei konsta-

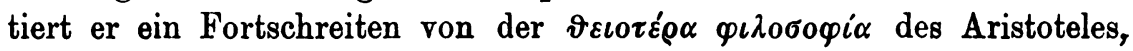

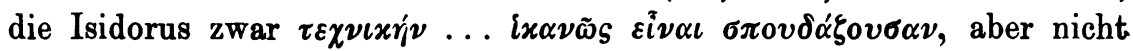

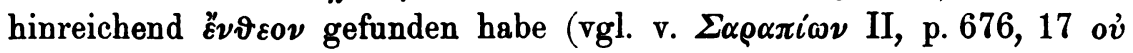

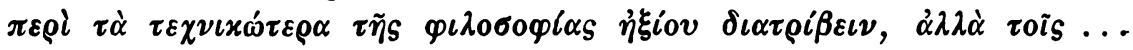

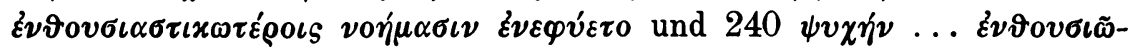

1) Der Zusammenhang dieser beiden Bruchstücke (vgl. Zeller S. 899, 1) erhellt

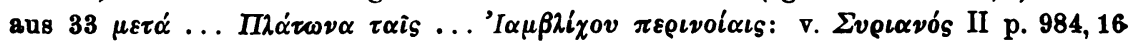

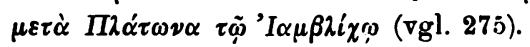


$\sigma \alpha \nu ; 43)$, zu der platonischen Lehre, der er fortan seine ganze $\sigma \pi 0 v \delta \dot{\eta}$ widmete (vgl. v. $\Delta \tilde{\omega} \varrho \circ$ ). Dem entspricht v. $\Sigma \pi \circ v \delta \dot{\eta}$ (: v. $\Pi \rho \circ \beta \varepsilon \beta \eta-$ $\varkappa \delta \sigma \iota)$, wonach or die $\sigma \pi 0 v \delta \dot{\eta}$ in der (menschlichen) Philosophie dem jugendlichen, das fromme ( neren Alter für angemessen erachtete. Vielleicht stand hier u. a. auch

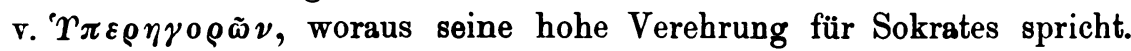
Vgl. v. ' $\Omega \iota \delta \eta x \delta ́ s$ (eine Auslassung des Sokrates?). Wie schon in 34

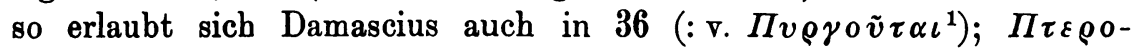

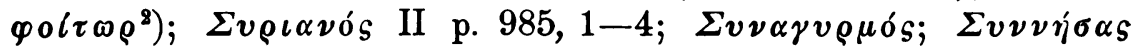
p. 971, 13) wieder, seine eigene Ansicht vorzutragen. Als Maßstab zur Beurteilung der besprochenen alten, mittleren und neueren Philosophen dient ihm deren Verhältnis zur göttlichen Philosophie (vgl. v. Aíœos). Von der großen Begabung Isidors für das philosophische Studium legt 243 Zeugnis ab, wonach seine Lehrer (oc $\delta \varepsilon$ ) ihn auch bei ihren ägyptischen $\xi_{\eta} \eta^{\prime} \sigma \varepsilon \iota_{S}$ (vgl. 2) mit Erfolg zu Rate zogen. Bei diesen Lehrern ist, abgesehen von der erst später genauer $z u$ besprechenden Trias, Asclepiades, Heraiscus und Asclepiodotus, auch an Sarapion zu denken,

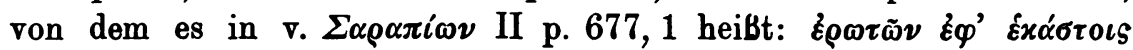

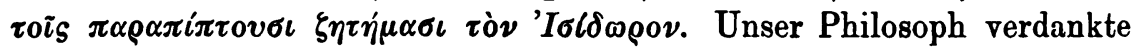
nach 243 das helle Licht, das er den Leitern seiner Studien gelegentlich aufsteckte, seiner eigenen Intuition und nicht fremder Bücher-

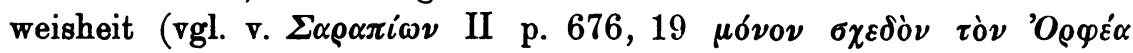

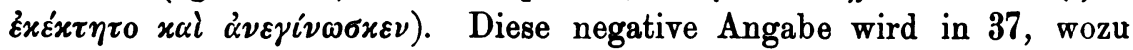

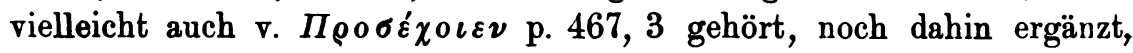
daB Isidorus sich lediglich an die Worte seines Lehrers hielt, unter welchem hier wohl sein Pädagoge Asclepiodotus zu verstehen ist. Hier würde sich passend eine Auseinandersetzung über das göttliche Licht der Intuition anschließen, wie sie nach 244 (vgl. v. X $\varrho \tilde{\eta} \mu \alpha$ p. 1665, 5) zu vermuten ist. Denn hier ist von einem Erlöschen die Rede, das die seinen Strahlen nicht gewachsenen Menschen (vgl. 2) zu gewärtigen

1) Die Übereinstimmung der folgenden Glossen mit 36 spricht gegen Bernhardy, der Aristoteles hereinziehen möchte. Bucherer S. 22, 58, 2 will angesichts von 57 hinter $\Sigma v \rho \iota \alpha \nu \tilde{\omega}:$ I $\operatorname{có}_{x} \boldsymbol{\omega} \omega$ anfügen.

2) Das von Gaisford mit Unrecht korrigierte und von Bernhardy falsch be-

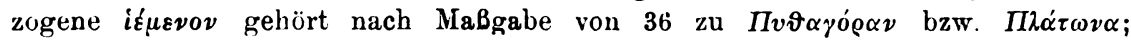

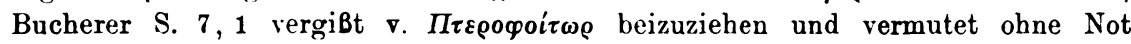
nach dem Vorbild von Plat. Legg. X 905 den Ausfall von $\alpha \dot{\nu} \alpha \pi \tau \tilde{\alpha} \sigma \alpha \iota$ hinter $\tau o ́ \pi o \nu$. Die Stelle lautete wohl ungefähr folgendermaBen: $\tau \tilde{\omega} \nu \mu \grave{\varepsilon} \nu \pi \alpha \lambda \alpha i \tau \alpha \tau \alpha$

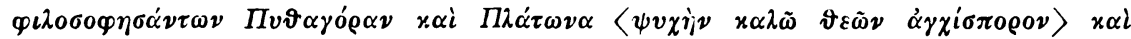

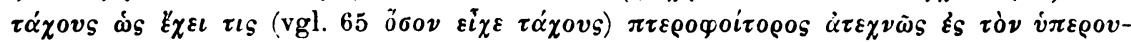

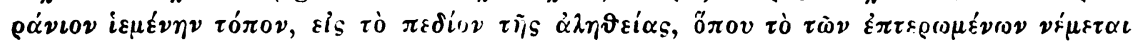

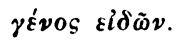


haben. Dem entsprechend stellt $38^{1}$ ) unseren Philosophen als einen agnostischen Gottsucher hin (vgl. De princ. p. 13,5 K). Vielleicht wurde dabei auf den syrischen Agnostiker Odainathos hingewiesen, den $\nabla . ' O \delta \alpha l \nu \alpha \vartheta$ os zum Gegenstand hat. Der genaueren Schilderung dieser Seite Isidors konnte auch v. ${ }^{\prime} T \pi \varepsilon \rho \beta \alpha^{\prime} \vartheta \mu \iota 0 \nu$ dienen, wonach sich unser Philosoph bei seinem gottsuchenden Streben innerhalb der seinem Alter gezogenen Schranken hielt (vgl. v. $\left.\Sigma \pi 0 v \delta \eta^{\prime}\right)$.

\section{Leben und Lebenssphäre des Isidorus.}

\section{In Alexandria (Anfange).}

Die eigentliche Lebensbeschreibung seines Helden begann Damascius wohl erst nach dem AbschluB seiner allgemeinen Charakteristik, in welcher allerdings auch schon manche biographischen Einzelheiten eingefügt waren. Das erste einigermaßen greifbare Datum liefert uns 245, wonach Isidorus notgedrungen Pädagog wurde. Vielleicht waren seine Zöglinge die Kinder des in $44 \mathrm{ff}$. erwähnten Schnellschreibers. Seine Lehrtalente werden in 39, $40\left(: 246^{2}\right)$; v. $\Pi$ o $\lambda v \dot{\eta} x$ oos p. 344, 10 sq.;

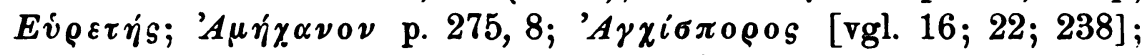

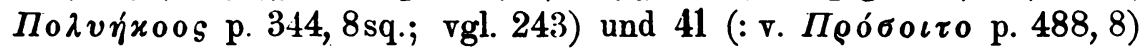
geschildert, woraus wir ihn als Exegeten, Wahrheitsfinder und -künder und Beurteiler des sprachlichen Ausdrucks kennen lernen. In 41 weist das $\delta \varepsilon ́$ am Anfang auf eine vorausgegangene Bemängelung hin (vgl.226).

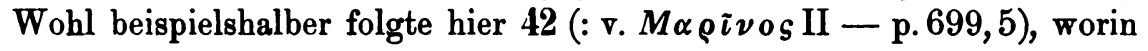
er als Begutachter philosophischer Werke auftritt. Seiner Lehrweise ist endlich auch 43 (vgl. 35) gewidmet.

Isidorus muB um diese Zeit mit Kreisen Fühlung gewonnen haben, die eine antichristliche religiös-politische Tätigkeit entfalteten. Denn der nun folgende Abschnitt berichtet von solchen Bestrebungen. In 44 ist von einem antlichen Tachygraphen ${ }^{*}$ ) die Rede, von dem dor Vorfasser bei gegebener Zeit des Genaueren zu sprechen verheibt. Diese Gelegenheit scheint aus 45 hervorzugehen. Denn hier deutet Damascius ebenso wie auch in 111 eine ihm unangenehme Angelegenheit an, von der er lieber schweigen wolle. Da nun 46 und wohl auch 47 von dem traurigen Schicksal eines erst hellenistischen, später aber zum Christen-

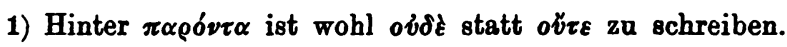

2) Bucherer S. 18, 37 a verkennt die Identität von 39, 40 und 246.

3) Fabricius p. 762 identifiziert diesen mit Damascius, was schon wegen des

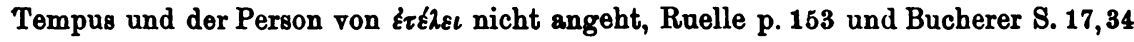
mit Isidorus. Letzterer bringt zudem v. Mŕvt p. 838, 13 mit 44 in einen unmittelbaren Zusammenhang (s. u. hinter 150). 
tum abgefallenen Mannes namens Leontius ${ }^{1}$ ) handelt, so könnte der sonst nicht näher bekannte Schnellschreiber, der, nach dem oix $\alpha \delta \varepsilon$ in $46 \mathrm{zu}$ schließen, ein Alexandriner war, mit dem geuannten Leontius identisch und in die Angelegenheit von 111 verwickelt gewesen sein. Vielleicht wurde unser Philosoph gerade von diesem Leontius und von dem in 108 gleichfalls in hellenistisch-antichristlichem Lichte geschilderten Severus (vgl. 9; 64 sq.) in diese Zirkel eingeführt. Daher dürfte hinter 47 u. a. auch dieser Römer genannt worden sein. Die hellenistische Repristinationsbewegung in Alexandria ging offenbar sehr weit zurück. Denn Damascius gedachte hier des kilikischen Philo-

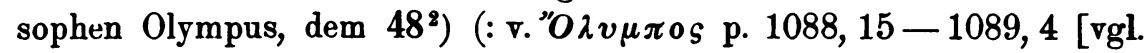

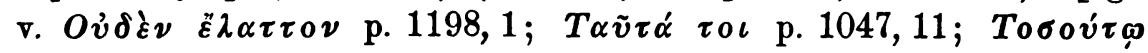

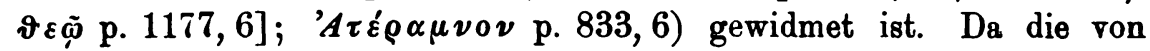
ihm handelnde Glosse ihn als den Bruder der Generosa einführt, so war wohl im vorhergehenden von dieser Frau die Rede. Vor $\tau \alpha \tilde{v} \tau \alpha$

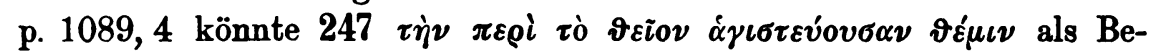

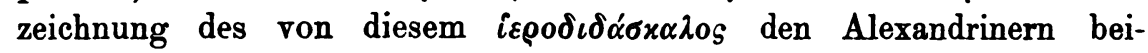
gebrachten Lehrgegenstandes gestanden haben. Seine Lebenszeit wird durch die ihm p. 1089, 11 nachgerühmte Vorhersagung der Zerstörung des Serapeums [391] näher bestimmt. Während 49 (: v. "O $O v \mu \pi 0$ S p. 1088, 10) noch der äußeren Erscheinung dieses Mannes gilt (vgl. 16;

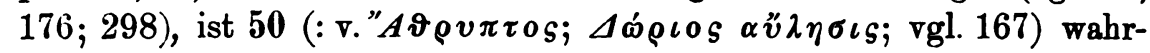
scheinlich wieder auf Isidorus, und zwar auf seine Lebenshaltung zu

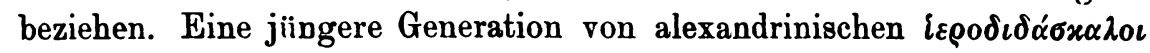
bildeten die älteren Leute, mit welchen unser Philosoph nach 51 ${ }^{3}$ )

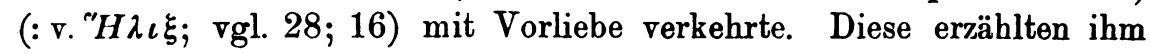

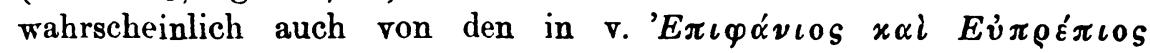

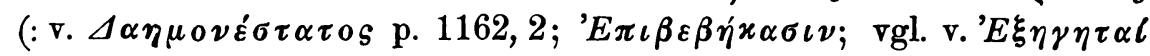
p. 315, 12) gekennzeichneten Theosophen. Ihre Charakteristik ist wegen des p. 482, 4 vorkommenden Hinweises auf die später zu gebende

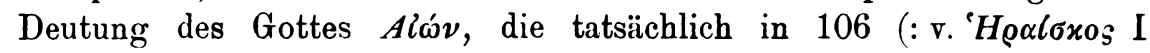

1) Fabricius p. 763 und Ruelle p. 154 werfen diesen Mann zusammen mit dem in 108 genannten Usurpator gleichen Namens.

2) Brucker p. 348 bezieht diese Ekloge mit Unrecht auf Isidorus. Reinesius möchte unseren Olympus mit Olympius, dem Adressaten von Synesius Epist. 45; $97-99 ; 133 ; 148 ; 149$ H, einem Schüler der Hypatia (s. Epist. 133), identifizieren. Tillemont V p. $136 \mathrm{~b}$ weist die von ihm handelnde Glosse fälschlich dem Eunapius zu. P. 1089, 6 fehlt darin vor $\pi 0 \lambda \iota \tau \varepsilon i \alpha_{S}$ wahrscheinlich ein das Christentum kenn-

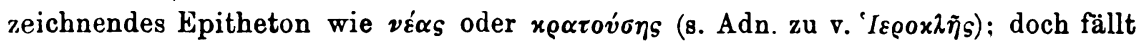

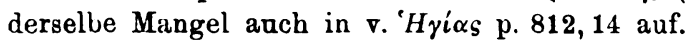

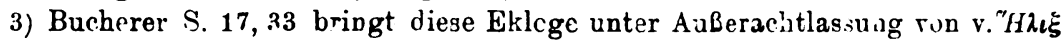
mit 28 in Zusammenhang.

Byzant. Zeitschrift XVIII 3 u. 4. 
p. 872, 13 sq.) erfolgt, sicherlich vor diese Ekloge zu setzen. Da die

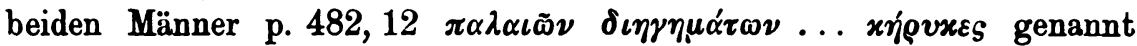
werden, so gehört vielleicht auch v. Ev่v $\eta \mu \sigma \sigma v \dot{\nu} \eta$ hierher, wo ein derartiges alexandrinisches $\delta\left(\eta \gamma \gamma \eta \mu \alpha^{1}\right)$ gestreift wird. Epiphanius war wahrscheinlich der Sohn des Mathematikers Theon und somit der Bruder der berühmten Hypatia $\left.[\dagger 415] .{ }^{2}\right)$ Daher knüpfte Damascius vielleicht an die Besprechung des Bruders die Geschichte der Schwester

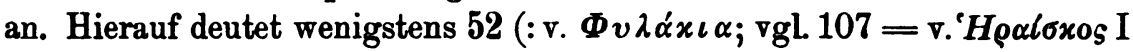
p. 873,2 sq. u. $\$ 12$ a. E.) hin, worin man ohne Zweifel ein Fragment aus der in v. ' $T \pi \alpha \tau l \alpha$ p. $1313,13-1316,1^{3}$ ) (zu p. 1315, 20 vgl. v. ' $\Gamma \pi 0 \sigma \pi \alpha \iota \rho \circ v \sigma \eta s$ p. 1374,5) berichteten seltsamen Liebesgeschichte ${ }^{4}$ ) zu erblicken hat. ${ }^{5}$ ) Mit den hier genannten $\varepsilon_{x \mu \alpha \gamma \varepsilon i \alpha} \tau \tilde{\omega} \nu$ $\gamma v \nu \alpha \iota x \varepsilon l \omega \nu$ $\mu 0 \lambda v \sigma \mu \tilde{\nu} \nu$ verband unser Biograph anscheinend eine Digression über den sakralen Gebrauch derselben bei der EheschlieBung. ${ }^{6}$ ) Denn von den bei diesen letzteren beobachteten Förmlichkeiten handelt 53.

AnschluB fand Isidorus u. a. wohl auch an den bereits in 36 gestreiften alexandrinischen Philosophen Hierokles und dessen Schüler

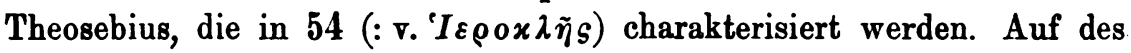
ersteren $\varepsilon \dot{v} \gamma \lambda \omega \tau \tau i \alpha$ könnte sich $\nabla . ' E \nu \tau \eta \xi^{\prime} \alpha_{S}$ beziehen, wouach ein ungenannter Lehrer diese Fertigkeit seinen Schülern beibrachte. Ferner

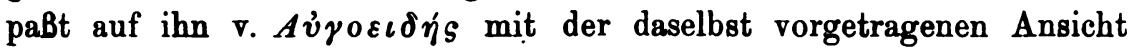
von einem licht- und sternartigen, ewigen Seelenvehikel. ${ }^{7}$ ) Dem Theo-

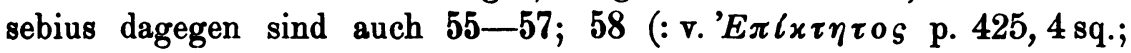

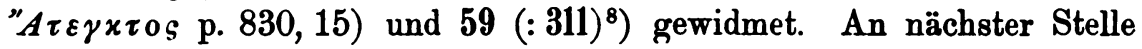
erscheint der in 60 (: v. 'A $A \mu \omega \nu \iota \alpha \nu$ ó $\left.^{9}\right)$ ) geschilderte Grammatiker und

1) Bernhardy schlägt ohne Grund $\delta \iota \alpha \dot{\tau} \alpha \gamma \mu \alpha$ vor.

2) Diese bereits von Wernsdorf I \& 3 geäuBerte Vermutung erhält durch den von uns zwanglos hergestellten Zusammenhang die von Hoche, Hypatia, die Tochter Theos (Philologus 1860) S. 140 vermiBte Grundlage.

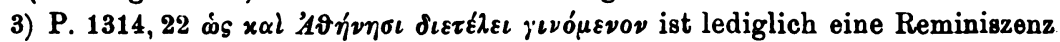
des Biographen und hat, wie Hoche S. 411, 33 mit Recht betont, nichts mit Hypatia zu tun. Vgl. u. v. $\Theta \varepsilon \alpha \gamma \varepsilon \dot{\varepsilon} \eta \eta$.

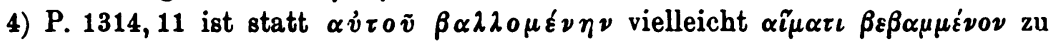

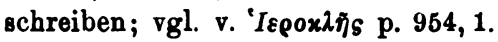

5) Dies sah bereits Wernsdorf p. $26 \mathrm{~m}$.

6) Vgl. A. Mommsen, 'Póxos auf attischen Inschriften (Philologus 1899), S. 344 ff., wo unsere Stelle fehlt. Die in Betracht kommende Göttin ist wohl Artemis, da ihr die Katamenien unterstellt gewesen zu sein scheinen.

7) S. Zeller S. 815, 3.

8) Fehlt bei Zeller S. 818, 2.

9) Fabricius p. 761 u. "Ammonius aut Ammonianus" unterscheidet diesen Mann mit Rocht von "Ammonius Hermiae filius" und von dem in 292 genannten Ammonius. Doch dürften die beiden letzteren trotz Zellers (S. 893,4) Bedenken wohl identisch sein. 
Dichterexeget Ammonianus. Von diesem kommt Damascius in 61

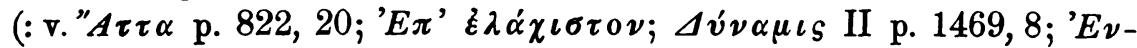
$\delta \varepsilon \dot{\varepsilon} \sigma \varepsilon \varepsilon \rho \circ \varsigma ;{ }^{\prime} P v \vartheta \mu i \zeta \varepsilon \iota ; T \varepsilon \lambda \varepsilon \sigma \iota 0 v \rho \gamma \delta \nu$; vgl. 35; 201), womit wahr-

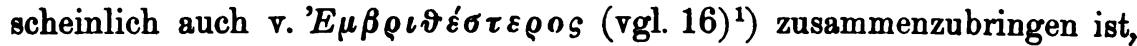
noch einmal, und zwar diesmal eingehender, auf Isidors Verhältnis zur

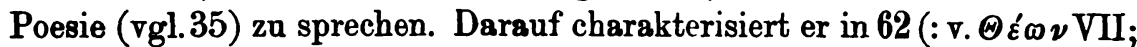

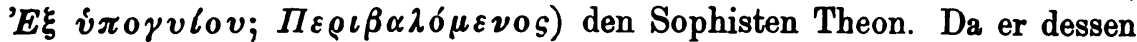
Ahne, die „heilige" ${ }^{\text {(s) }}$ Marcella, wie eine bekannte Persönlichkeit erwähnt, wird er wohl im vorhergehenden länger bei ihr verweilt haben. Als trefflicher Geschichtskenner dürfte Theon unserem Philosophen die in 63 vorgetragene Geschichte von einer römisch-gotischen Geisterschlacht [492] mitgeteilt haben. Hier folgte wohl Cod. 181 p. 126 b 41, worin der Biograph ouf sich selbst vorgreift. An Theon schloB sich in 64-66 (: v. $\Sigma \varepsilon \beta \tilde{\eta} \rho \circ \varsigma$ II p. 701, 18 sq.; $\left.\Delta v \sigma \chi \varepsilon \rho \alpha \sigma \mu \alpha^{\prime} \tau \omega \nu\right), 67^{3}$ ) und 68 der bereits in 9 (:233) flüchtig erwähnte Staatsmann Severus. Da in 65 von einem Pferd die Rede ist und in 64 eine an dem Pferd des Severus zutage getretene vorbedeutende Wundererscheinung erwähnt wird, so sind wohl die Besitzer beider Tiere identisch; auf des Römers Wundererzählungen bzw. auf entsprechende Ergänzungen von seiten des Damascius pabt aber auch der Charakter von 69-73, so daB die um Severus gruppierten Eklogen von 64 bis 73 reichen würden. Vielleicht ist auf seine Lebensbetätigung während seines Konsulates die zu v. $\Sigma \varepsilon$ -

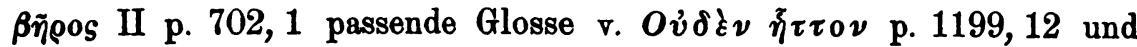
auf seinen Aufenthalt in Alexandria v. $K \alpha \tau \varepsilon \beta \delta$ ó und v. $K \rho \varepsilon i \sigma \sigma \omega \nu$ zu beziehen. Hieran schloB sich die Charakteristik des alexandrinischen Philosophen Hermias und seiner Angehörigen (vgl. 26) in 74-76 (: v. ${ }^{e} E \varrho \mu \varepsilon l \alpha \varsigma$ II; III ${ }^{4}$ ), wahrscheinlich getrennt durch eine längere

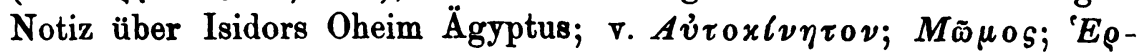

1) Die Lesart $\tilde{\eta} \pi \tau \varepsilon \tau o$ ist wohl die richtige.

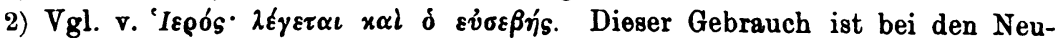

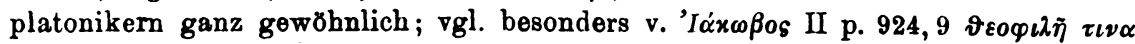

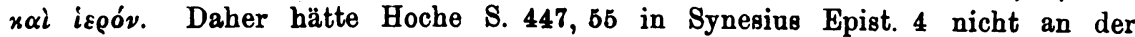

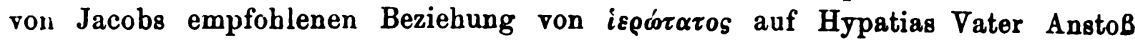
nehmen sollen.

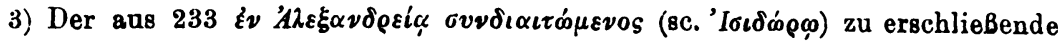
Verkehr des Severus mit unserem Philosophen ist anf jeden Fall vor sein Konsulat zu setzen. Hiernach ist Tomascheks Datierung „um das Jahr 500" (PaulyWissowas Realencyklopädie $\mathfrak{n}$. „Brachmanes" (ungenau nach Lassen, Ind. Altert. II S. 378) zu berichtigen. Für die Zeitbestimmung ist entscheidend 64 \& $\pi i^{\text {'Pó} \mu \eta \eta \nu, ~}$

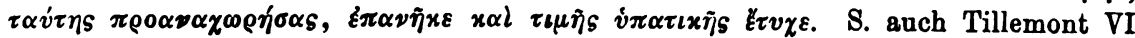
p. $145 \mathrm{~b}$ und Le Beau VII p. 30. Wernsdorf nimmt p. 36 sq. irrtümlicherveise die Zeit nach der Niederwerfung der Empörung des Illus an.

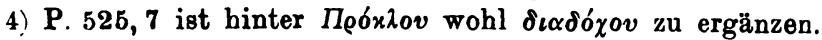




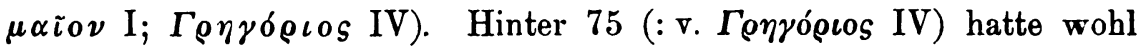
v. $\left.A i \delta \varepsilon \sigma i \alpha^{1}\right)$ seinen Platz, so daB nach dem Bruder des Hermias seine Gattin besprochen worden wäre. Die dieser gewidmete Glosse wurde wahrscheinlich p. 17, 20 durch v. 'A $A \varepsilon \chi \nu \tilde{\omega} s$ p. 834, 2, p. 18,1 durch

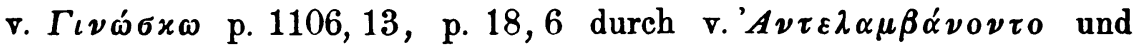

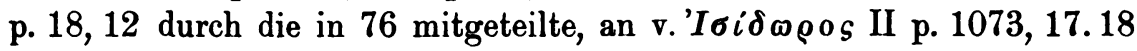
anklingende Wundergeschichte von dem ersten Kinde des Philosophen unterbrochen; auf diese dürfte sich 77 (: v. $K \alpha \tau \varepsilon \alpha \gamma \gamma$ ó $\boldsymbol{\omega} \nu ;{ }^{\zeta} \Omega \tau \alpha ; T \grave{\alpha}$ $\bar{\omega} \tau \alpha)$, ein Fragment über die Verspottung von theosophischen Mysterien, und v. $\mathcal{S} \iota \omega \lambda \dot{v} \gamma \iota 0 \nu$ p. 1409, 2 (vgl. 121; 303), eine entsprechende

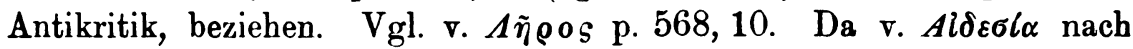
Besprechung der Söhne des Hermias mit der Erwähnung ihrer gemeinsam mit ihrer Mutter und Hierax, einem Bruder des Synesius, unternommenen Reise nach Athen schlieBt, so folgte wohl hier die Charakteristik dieses Mannes (vgl. 78; vgl. v. $\Phi \varrho \varepsilon v 0 \beta \lambda \alpha \beta \eta$ s). Vielleicht wurde er mit Ammonius verglichen; so würde es sich wenigstens erklären, daB 79 (: Cod. 181 p. 127 a 5-8) noch einmal auf diesen zurückgreift.

\section{Erster Anfenthalt des Isidorus in Athen.}

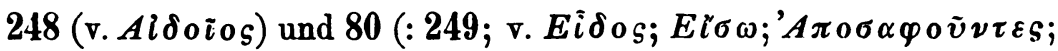

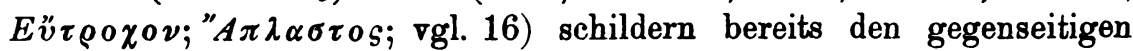
Eindruck, den Proclus und Isidorus bei ihrer ersten Begegnung aufeinander machten. Daher muB vor 248 die Reise unseres Philosophen von Alexandria nach Athen erzählt worden sein. Wahrscheinlich war er in Begleitung der Ädesia, ihrer Söhne, des Hierax und seines Pädar gogen Asclepiodotus, eines Schülers des Proclus (s. 139), dahin gelangt.

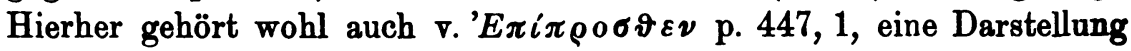
von Proclus' Verhältnis zur Theologie. In der Philosophenstadt lernte Isidorus den vielseitigen Sallustius kennen. Dieser war nach 250

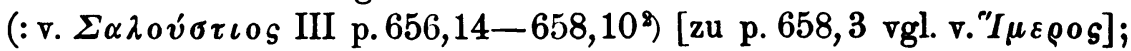
$\Pi(\nu \circ s)$ ein Schüler des Eunoius ${ }^{8}$ ), er fand aber später die rhetorischen Leistungen dieses Mannes unzureichend. Von dessen Inferiorität handelt auch 81 und wahrscheinlich auch 82. Dieses Eklogenpaar dürfte daher in die Sallustiusglosse hinter p. 657, 11 und vor dem Inhalt von 250 einzuschieben sein. Ein anderer Bekannter unseres damals anscheinend vorwiegend grammatisch-rhetorischen Studien obliegenden Philosophen

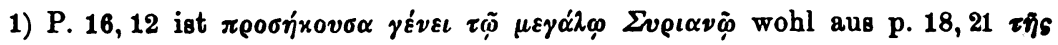

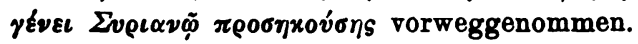

2) P. 656,13 and 14 ist wohl rom SchluB an den Anfang gerückt. Buelle p. 155 unterscheidet ohne Not einen Rhetor und einen Philosophen Sallustirs.

3) Bei Rnelle p. 153 heiBt er "Eunaeus“. 


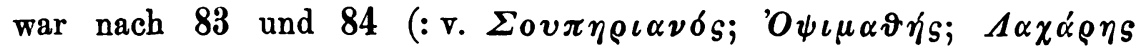

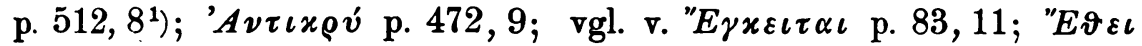
p. 118,18 ; "Exжолоs p. 145,16$)$ Superianus, ein Schüler des Lachares, der auch selbst zu ihm in nähere Beziehung trat. Da Lachares in

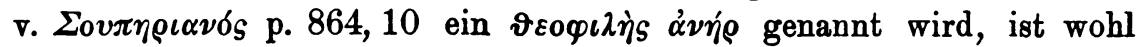

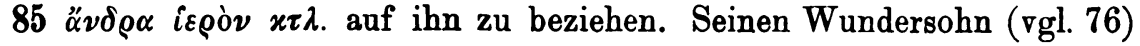

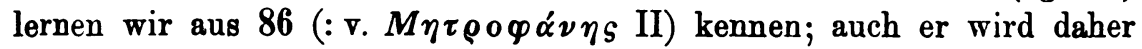
wohl mit Isidorus verkehrt haben. Einem vorgreifenden Exkurs ist aber wahrscheinlich die in 87 gegebene Beschreibung eines von Damascius bewunderten Aphroditebildes (vgl. 105; 138; 290) zuzuweisen. In die philosophischen Kreise seines Helden führt er uns in 88 zurück, wo Hierius ${ }^{2}$ ), der Sohn des Plutarchus, auftritt. Zwischen dieser und der folgenden Ekloge klafft eine Lücke, die sich vielleicht mit Hilfe

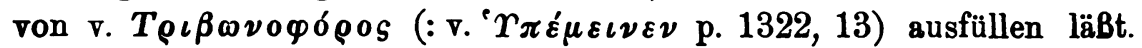
Nach dieser Glosse konnte sich nämlich Isidorus trotz der Aufforderung des Proclus nicht entschließen, die Philosophentracht (vgl. 295) anzulegen; kam ihm doch nach 153 erst viel später die wahre Liebe zur Phiosophie. An seinem Sträuben könnte sein Freund Sallustius mit schuld gewesen sein. Denn diesen hatte nach v. $Z \dot{\eta} \nu \omega \nu$ VI p. 762,12sq. ein gewisser Zenon dem Proclus abwendig gemacht, und nun machte er zuch seinerseits nach v. 'A $A \tilde{\eta} \gamma \varepsilon \nu^{3}$ ), wozu vielleicht auch die auf Dranascius vorgreifende Glosse v. 'A $\boldsymbol{x} \delta \boldsymbol{\delta} \varepsilon \iota \rho \alpha$ gehört, geflissentlich den Philosophen überhaupt die jungen Leute abspenstig. $\mathrm{Zu}$ diesen ist

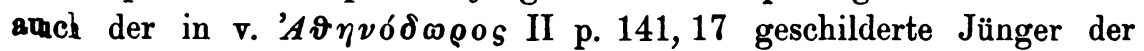
Phibsophie zu zählen. Nach v. $\Sigma \alpha \lambda \circ v ́ \sigma \tau \iota 0 s$ III bestritt Isidors Freund und Berater den Menschen schlechtweg die Fähigkeit zum Philosophieren

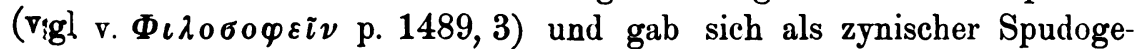
loiios. Die Aufzählung seiner Witzworte p. 659, 14 wurde vielleicht miit der in v. $X \alpha \rho \iota \varepsilon \nu \tau / \zeta \varepsilon \iota \varsigma$ enthaltenen sich selbst Einhalt gebietenden $W^{\prime}$ exdung abgeschlossen. Hierauf konnte dann eine Darstellung des in

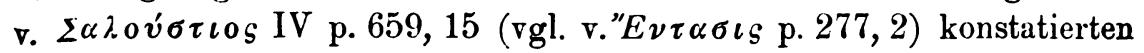
Zynismus des Sallustius folgen. Dieser Ausführung gehört v. Xvथ@ó-

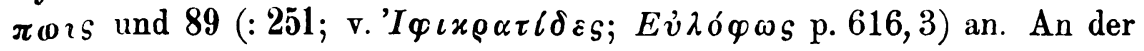

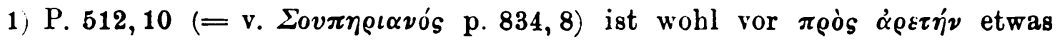

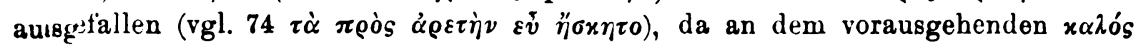

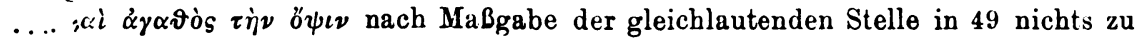
änıdırn ist.

2) Ruelle p. 154 verzeichnet unverständlich „Hieriens, les fils du Plutarque (ó igò̀s $\Pi \lambda$.) d'Athènes".

3) P. 568 ist wohl $\pi \rho \circ \sigma x \rho o v \sigma \alpha \zeta$ statt $-\omega \nu$ zu schreiben und hinter p. 568, 7

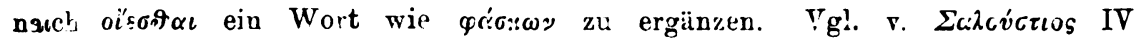
p. $65^{2}, 11 \not k \varphi \eta$. 
Hand von 251 und der Biographie des Zynikers gelangen wir zu dem

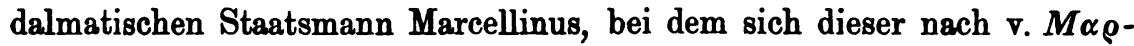
$x \varepsilon \lambda \lambda i v o s$ p. 702, 2 einmal [vor 467] aufhielt. Da ebenda p. 701, 15

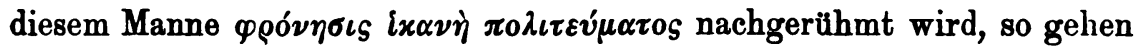
die in 90 gepriesenen $\pi 0 \lambda \iota \tau \varepsilon v ́ \mu \alpha \tau \alpha$ wohl auf ihn, umsomehr als 91 sein trauriges Schicksal [ $†$ 468] zum Gegenstand hat und sich am Schlusse mit der von ihm handelnden Glosse deckt (s. p. 701, 8; 11-13). Er

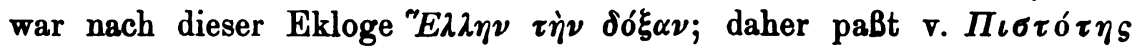
p. 284, 18 hierher, worin seine fromme Glaubenszuversicht hervorgehoben wird. Die Verbindung mit 92, wonach Sallustius die Gabe besaB, den Leuten ihr gewaltsames Ende an den Augen abzusehen, bildete wohl die Angabe, er habe auch seinem Gastfreund gegenüber hiervon Gebrauch gemacht. Da sich unter den hier von Damascius erwähnten Physiognomonikern auch Nomus befindet, dürfte wohl hier auch v. Nó $\mu$ o s p. $1003,5-17$ und $1004,1-5$ (vgl. v. " $A \lambda \lambda \omega s$ p. 246, 2) gestanden haben.

\section{Zweiter Aufenthalt des Isidorus in Alexandria.}

Mit Sallustius begab sich unser Philosoph nach v. $\Sigma \alpha \lambda o v \sigma \tau \iota 0 s$ III p. 656,$13 ; 14$ wieder zurück nach Alexandria. Hier begann offenbar

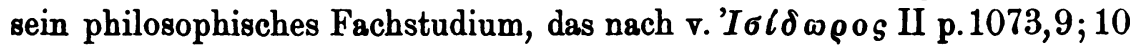
von zwei Brüdern geleitet wurde. Damit sind wohl Asclepiades und Heraiscus gemeint, von denen jener der ältere und dieser der jüngere war (s. De princ. p. $385 ; 386 \mathrm{~K}$ ). ${ }^{1}$ ) Ihrer vergleichenden Würdigung ist

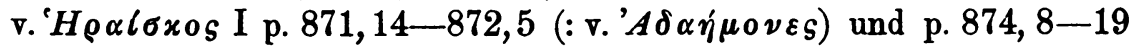

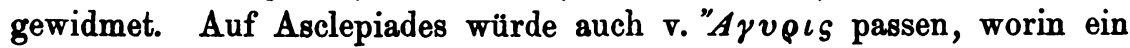
Religionsforscher gekennzeichnet wird. In 93 treffen wir Isidorus unmittelbar nach seiner Überfahrt über das Ägäische Meer in Gesellschaft

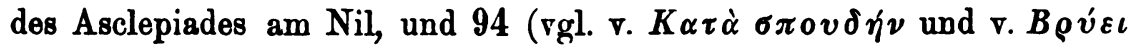
p. 1049, 10) handelt gleichfalls von diesem Mann. Es werden hier einerseits Beobachtungen mitgeteilt, die Asclepiades in Ägypten und Syrien machte, und andrerseits vorgreifend auch solche, die Damascius später an der Seite Isidors in diesen beiden Länderu anstellte (vgl. 9 bzw. 203). Wenn 95, 96 und 252 das zurückgezogene, der Frömmig-

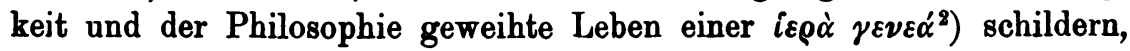
so ist bei dieser Bezeichnung wohl an die alexandrinische Hellenisten-

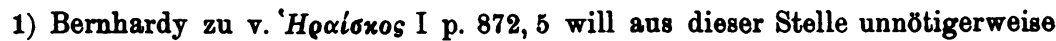
zwei verschiedene 'Träger dieses Namens herauøinterpretieren. Ebenso leitet Zeller S. 900, 2 daraus einen "jüngeren Heraiskos" her.

2) Zumpt S. 80, 2 bezieht diesen Ausdruck auf die platonische Akademie und deren Stammhalter; diese nennt Damascius aber nach 151 und v. $\Sigma \varepsilon \iota \rho \alpha ́$ p. 723, 6

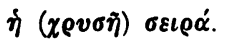


gemeinde zu denken, die den Kó́vıos $\beta$ los verkörperte, als dessen Vertreter (hinter 22) Sarapion, der greise Gönner unseres Philosophen,

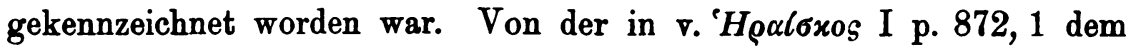
Asclepiades nachgerühmten Kenntnis der ägyptischen Weisheit scheinen die in 97-102 ${ }^{1}$ ) mitgeteilten Zoologika Zeugnis abzulegen, die wohl als Probe seiner Forschertätigkeit angeführt wurden. Auf den hellenistischen Kreis, dem er angehörte, bezieht sich wohl 103 „bis ibre Führer sich zum Verderben des Staates entzweiten". Denn diese Worte sind wohl

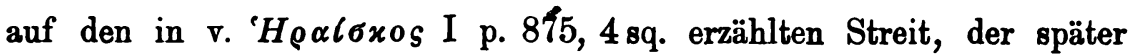
zwischen Ammonius und Erythrius ausbrach, zu deuten, ein Streit, der vielleicht den AnlaB zur ersten Behelligung der alexandrinischen Landsleute dieser beiden Ägypter gab. Was Heraiscus mit dieser Sache zu tun hatte, ist nicht mehr ersichtlich; doch scheint er der Mann zu sein, der nach 104 auf Grund seines mystischen Hellsehens etwas vorher-

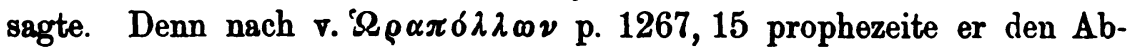
fall des Horapollon vom Hellenismus.

Nun wurden wohl Belege für die wunderbare Traumgabe des Heraiscus geboten: In 105 (:253) ist nämlich von einem wiederholten Traumgesicht die Rede, das zugleich göttlich war und dem Heraiscus

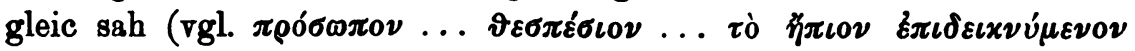

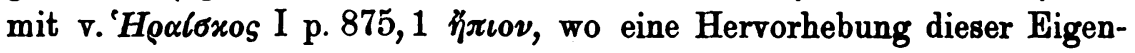
schaft vorausgegangen sein $\mathrm{muB}$ ). Es dürfte sich daher hier um den

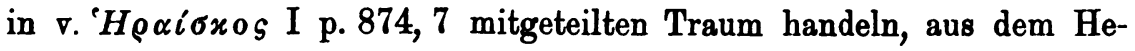
raiscus seine Bacchusnatur erkannte. 254 scheint auf ein politisches Traumgesicht zu gehen, das vielleicht nochmals in 173 berichtet wurde.

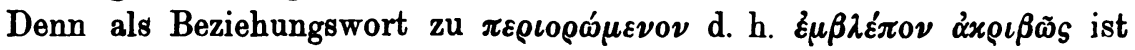
wohl $\pi \rho \sigma_{\sigma} \omega \pi 0 \nu$, und als Objekt (statt des unbestimmten $\tau \dot{\nu} \nu \not \alpha \nu \vartheta \rho \omega \pi 0 \nu$ ) Źं $\omega \omega \nu \alpha$ zu ergänzen, so daB man an Illus und sein Streben nach der Kaiserwürde denken könnte. Diese Auslegung paßt wenigstens auf 173

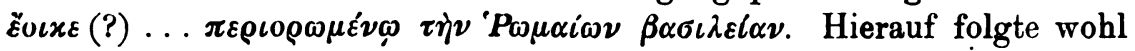

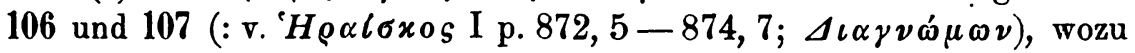

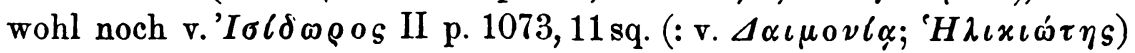
hinzuzufügen ist. Im folgenden handelte es sich wohl um den Stand des Hellenismus zur Zeit des Heraiscus, wobei nach 108 an Anthemius [467-472] und Severus [470] angeknüpft (vgl. v. $\left.A l^{\prime} v v \gamma \mu \alpha\right)$ und nach 109 dem Illus und Leontius bzw. dem sie beeinflussenden Pamprepius hellenistische Repristinationspläne unterschoben wurden. Hier folgte

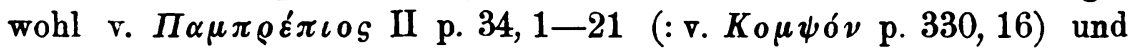
v. $\Gamma \varrho \alpha \mu \mu \alpha \tau \varepsilon l o v(: \nabla . \Pi v \varepsilon v \sigma \alpha \varsigma)$. 110, worin von der Art, wie Da-

1) $\mathrm{Zu} 98$ vgl. neuerdings Ostheide in der Philolog. Wochenschrift 1907 Sp. $1182 \mathrm{ff}$. 
mascius den Charakter und das gewaltsame Ende des letztgenannten Mannes schilderte, die Rede ist, nimmt wohl Elemente vorweg, die noch nicht hier, sondern erst hinter 174 ihre ursprüngliche Stelle hatten (S. 290). Mit 255 griff der Biograph wahrscheinlich wieder zurück auf 103; denn es heiBt hier, sie (d. h. die Hellenisten) seien von den gewöhnlichen menschlichen Behinderungen verschont geblieben, was sich wohl auf jene Epoche vor dem Streit der Führer bezieht. Da auch Horapollon einer von diesen gewesen zu sein scheint, so handelt wohl 256 von seinem späteren Schicksal; denn hier spricht der Autor von der Rache der Götter. Als Bekräftigung der hier vorgetragenen Ansicht könnte vielleicht 257 gedient haben, und schlieBlich steht wohl auch 111 mit Horapollon in Zusammenhang, da hier eine dem Verfasser peinliche Angelegenheit angedeutet wird. Mit 112 will Damascius $\tau \dot{\nu} \nu$ $\Pi v \dot{v} \iota \nu_{\nu}$ verlassen und wieder zu Heraiscus zurückkehren. Danach war wohl eine an jene Prophezeiung des Ägypters anknüpfende Digression über das Orakelwesen (vgl. 69) vorausgegangen. 113 könnte mit der in 112 dem Heraiscus gewidmeten Scherzbezeichnung Ev̉ $\beta$ ozús insofern

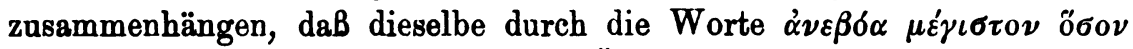
ihre Erklärung fände. ${ }^{1}$ ) Mit diesem Übernamen ist wohl auch $114 \mathrm{zu}$ sammenzubringen; denn die hier dem Philosophen nachgesagte lange Haartracht war für die Euböer charakteristisch..2) Der Rest einer SchluBbetrachtung über Heraiscus liegt wahrscheinlich in $\left.{ }^{~}{ }^{\prime} H \rho \alpha \ell \sigma \varkappa \sigma_{S} \mathrm{II}^{3}\right)$ (: v. $\Sigma v \nu \varepsilon i \nu \alpha \iota)$ vor.

Auf die Würdigung der beiden Lehrer unseres Philosophen läBt sein Biograph noch eine sehr ausführliche und darum auch nicht sehr durchsichtige Charakteristik seines ehemaligen Pädagogen (s.116) folgen. Asclepiodotus begleitete seinen Schüler Isidorus wohl nicht wieder zurück nach Alexandrien, sondern blieb seiner Heimat wohl dauernd fern. Seine

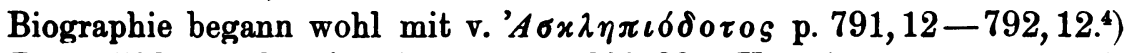
Zu p. 792, 4 vgl. v. ' $E \mu \varepsilon^{\prime} \lambda \lambda \eta \sigma \varepsilon \nu$ p. 203,22. Von Athen, wo er nach

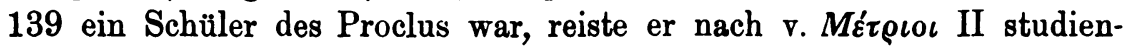
halber nach Syrien. Vielleicht kann man 115, wo von phönizischen und syrischen Gottheiten die Rede ist, auf diese Reise beziehen. 116 führt uns bereits in die Nähe seiner zweiten Heimat, an den Mäander (vgl.

1) So Zeller S. 900, 2.

2) Vgl. Dio Chrysost. Euboicus p. 109, 26 D.

3) Für die von Hemsterhuis und Bernhardy gegen Küster angezweifelte

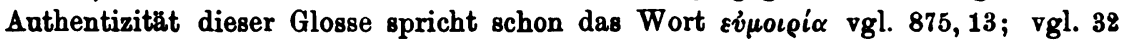
(: v. Evuocpio).

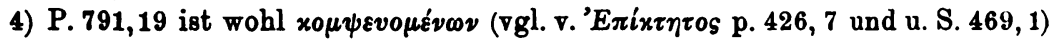

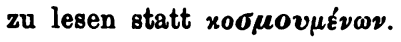


v. 'A $\pi \circ \rho \tilde{v} \nu \tau \iota)$, wohin er, wahrscheinlich in späterer Zeit (s. 214), gemeinsam mit Isidorus einen Ausflug unternahm. 117 zeigt ihn uns

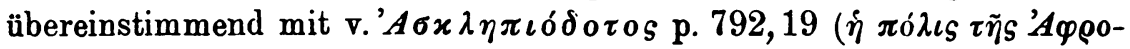

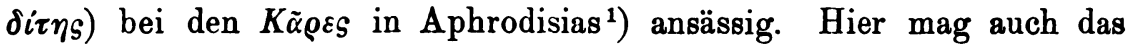
in 118 erwähnte alte Götterbild, dessen Untergang der Verfasser bedauert, gestanden haben. $\mathrm{Da}$ die von 119 gebotenen Worte: $\eta^{\nu} \nu \ldots$

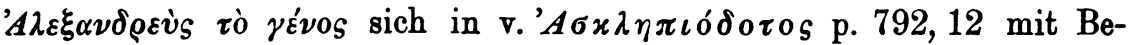
ziehung auf Asclepiodotus wiederfinden, so gehen sie wahrscheinlich auch auf ihn. Zudem paBt auch die in 119 seinen Eltern gewidmete

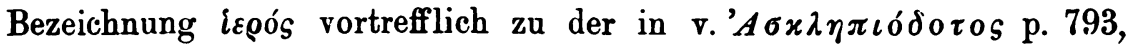
12-17 (: v. $\Delta \iota \dot{\alpha} \pi \varepsilon i \varrho \alpha \varsigma)$ enthaltenen vergleichenden Würdigung des Philosophen und seines ebenso frommen Vaters. Vielleicht schloB sich

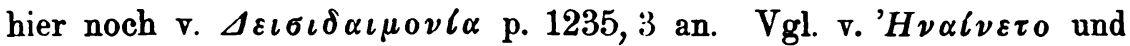

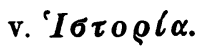

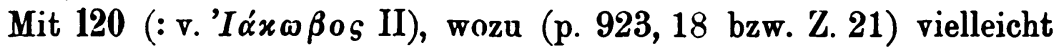

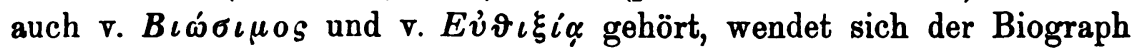
zu Jacobus, dem griechisch-alexandrinischen Lehrer Asclepiodots in der Medizin (s. 128). ${ }^{2}$ ) 121 handelt von dem Gegensatz des Jacobus und seines Vaters, die beide Hellenisten waren (vgl. v.'Ióxœßos II p. 924,8sq.),

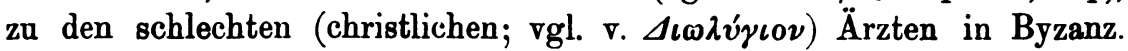

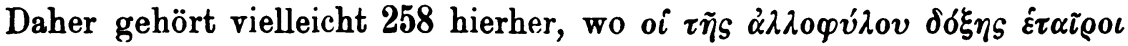
$x \alpha i$ $\sigma v \sigma \tau \alpha \sigma \iota \tilde{\omega} \tau \alpha \iota$ auf diese Rivalen der beiden gehen könnte. Nachdem

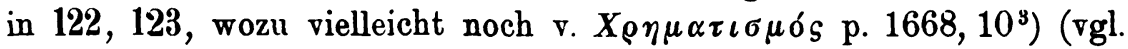

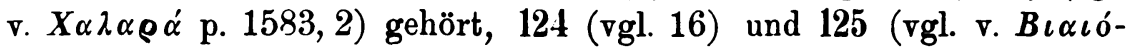
$\tau \varepsilon \rho \circ \nu$ p. 987, 10) Jacobus vorläufig abgetan ist, kehrt 126 (vgl. 275) wieder zu Asclepiodotus zurück. 127 (: v. $\Delta i \varepsilon \sigma \iota \nu)$ schildert seine musi-

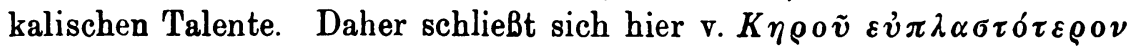

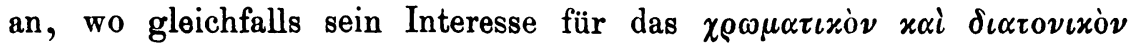

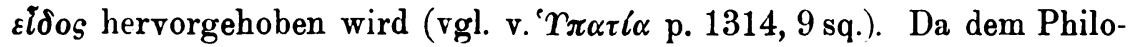
sophen hier p. 245, 1 nachgesagt wird, er habe alle Tierstimmen nach-

1) Bernhardy deutet die Stelle verkehrt auf ${ }_{n}$ alteram utram Aegypti civitatem Aphroditopolim“, Bloch in Puschmanns Handbuch der Geschichte der Medizin I S. 526 auf die "nahe bei Alexandria gelegene Stadt dieses Namens".

2) S. Flach S. $233 \mathrm{ff}$. und Bloch S. j24 ff., dessen Behauptung, Jacobus sei „als Zeuxis und Phidias der Heilkunst" gepriesen worden, nicht aus Suidas herauszulesen ist. Es heibt hier p. 924,14 bloB, er habe ebenso wie Zeuxis und Phidias

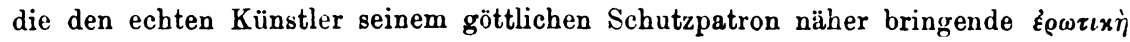

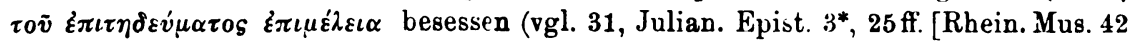

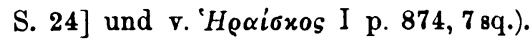

3) Vgl. v. 'Iáxwßos II p. 923,15 und Alexander von Tralles Therap. V 4 ed.

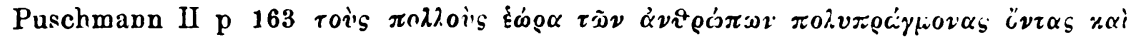

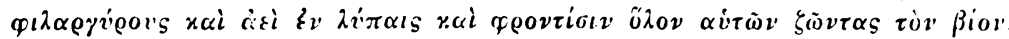


ahmen können, so folgte wohl hier v. $X \alpha \lambda \delta \alpha \iota x o i_{S}$ 'ं $\left.\pi \iota \tau \eta \delta \varepsilon v \mu \alpha \sigma \iota \nu^{1}\right)$,

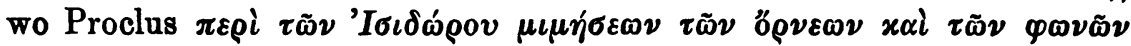
$\tau \tilde{\omega} \nu \grave{\alpha} \pi \eta \chi \eta \mu \alpha ́ \tau \omega \nu$ Auskunft erbittet und diese von ihm selbst, wahrscheinlich auf Grund von Asclepiodots Unterweisung, erhält. 128 und 129 (: v. $\Sigma \omega \varrho$ « vós II p. 859, 12) legen das Verhältnis Asclepiodots zu Jacobus und anderen medizinischen Autoritäten klar. Weiterhin schilderte Damascius wohl seine philosophische Wirksamkeit, von der in

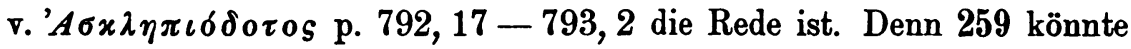
sich sehr wohl auf die ihm zu verdankende philosophische Förderung der Karer beziehen. Weiterhin folgte seine Familiengeschichte. Vielleicht stammte seine Gattin aus dem phrygischen Hierapolis. Denn

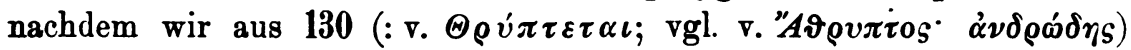
ihren Namen „Damiaue“ ${ }^{2}$ ) kennen gelernt haben, versetzt uns 131 (: 260 ; vgl. 25 ; v. ' $A \pi \alpha \vartheta \tilde{\eta}$ p. 521,2 ) in ein hier gelegenes Heiligtum, das Asclepiodotus selbst und später auch (s. 215) Damascius von Aphrodisias aus besuchte. $261^{3}$ ) und $262^{4}$ ) leiten wohl zur Verheiratung von Asclepiodots Tochter mit einem jüngeren Asclepiodotus (s. 160) ${ }^{5}$ ) über. Denn der Vater der Braut hing dieser (wie einer zweiten Hypatia; s. v. ${ }^{~} T_{\pi \alpha \tau l \alpha}$ p. 1313,17 sq.) bei der Hochzeit den Philosophenmantel

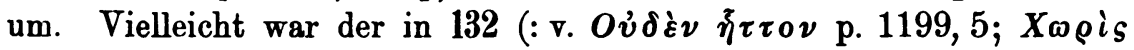
$\tau \grave{\alpha} M v \sigma \tilde{\omega} \boldsymbol{v})$ genannte Patricius, ein sonst nicht näher bekannter Priesterphilosoph, der wohl auch für die in $\mathbf{2 6 3}$ genannte $\vartheta \rho \eta \sigma x \varepsilon i \alpha$ in Betracht kommt, der Vater des Bräutigams.

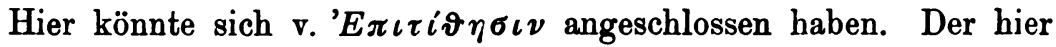
erwähnte Brief an „die beiden Philosophen in Karien“ hatte möglicherweise Proclus zum Verfasser und bezweckte die Übersiedlung der beiden Asclepiodoti von Aphrodisias nach Athen, wo sie vielleicht (s. 160) als Kandidaten für das Diadochenamt in Aussicht genommen waren. Denn von dieser Frage ist nach Erledigung einiger persönlichen Erlebnisse des alteren Asclepiodotus im weiteren die Rede. Deutet man dio ge-

1) S. Zeller S. 823 Anm.; 840 Anm.

2) Fabricius p. 762 u. „Damiane“ und 763 n. „Jacobus" gibt sie für die Frau des Arztes Jacobus aus.

3) Wernsdorf p. 41 schreibt verkehrt $x \alpha i\langle\tau \iota\rangle \xi \xi \xi \delta \omega x \varepsilon v$ im Sinne von ,et aliquid dedit tempori nuptiis apto".

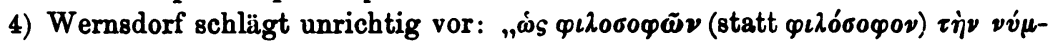

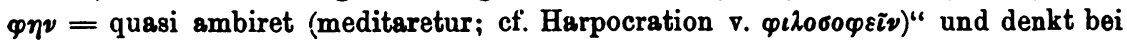
dieser $\nu \dot{v} \mu \varphi \eta$ an "Asclepigenia Plutarchi filia (cf. Marinus in Proclo c. 28)" oder an ,Theodora (cf. Phot. Cod. 181)".

5) Fabricius p. 762 scheint sämtliche Stellen, wo Asclepiodotus genannt wird, auf den "gener magni Asclepiodoti" zu beziehen, da er diesen letzteren von jenem gar nicht besonders unterscheidet. 
nannte Glosse in unserem Sinne, so ließe sich 133 „sie aber sagte: wich bin von bäurischer und ländlicher Art«" als ein von Damiane gegen die angesonnene Ortsveränderung vorgebrachtes Argument auffassen. Nun folgt die Charakteristik des Philosophen Domninus, wahrscheinlich deshalb, weil er infolge von Asclepiodots Absage an dessen Stelle treten

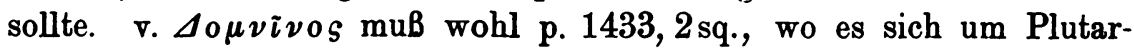
chus handelt, ergänzt werden durch v. $\Sigma \alpha \rho x o \varphi \alpha \gamma i \alpha$ (: v. 'Avvirovs;

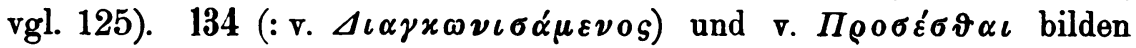
Teile dieser biographischen Glosse (p. 1433, 4sq. bzw. 1434, 4), in welcher am Schlusse übereinstimmend mit 135 noch die Umgänglichkeit des Asclepiodotus auf Kosten des schroffen Domninus gelobt wird

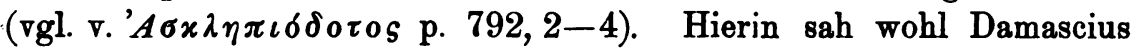
einen Beweis von mangelnder MäBigung und führte nun Gegenbeispiele an, die dem Asclepiodotus in Syrien begegnet waren. Dafür spricht

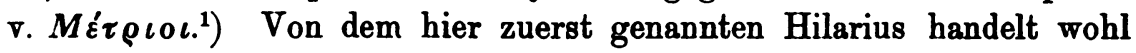

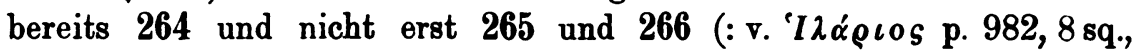

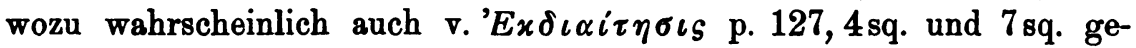
hört). Denn dort ist von einem Manne die Rede, welcher trotz ergangener Einladung nicht nach Aphrodisias übersiedelte. Hilarius aber hielt sich laut v. 'I $\alpha^{\prime} \rho \cos$ p. 983, 7 nach seinem Weggang von Antiochia, ehe er nach Athen kam, tatsächlich einmal auch in Karien auf. Den SchluB dieses Exkurses bildete wahrscheinlich v. Má $\rho \alpha s$, worin das vollkommenste Beispiel der erwähnten Tugend besprochen wird (vgl. 74). 136 kehrt wieder zu Asclepiodotus zurück, der krank war und nach 267 und 268 (vgl. v. ' $E \pi \alpha \iota \nu \varepsilon ́ \sigma \alpha \varsigma$ p. 361, 17) die Fristung seines Lebens nur der Geschicklichkeit seiner Gattin verdankte. Mit 269 geht Damascius wohl auf die Geschichte ihrer Ehe ein. Denn hiernach kam die hier besprochene Frau nach ihrer ersten unglücklich verlaufenen

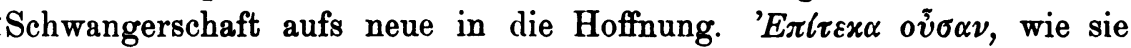
hier bezeichnet wird, hatte sie ihr Gatte nach 137 mit sich genommen. Das Ziel der Reise war wohl Aphrodisias gewesen. 138 (vgl. 87. 105); 139 (:270); 140 (: 271); 272 und 273 beziehen sich auf merkwürdige Wahrnehmungen, die Asclepiodotus gemacht und wahrscheinlich später dem Damascius mitgeteilt hatte.

Das Thema von der Diadochie nimmt 141 wieder auf, wo von Marinus (vgl. 42), dem ersten unter den nach 306 von Proclus erkorenen Diadochen, die Rede ist. Da hier dessen Abfall von der samaritanischen

1) Wahrscheinlich fehlt binter 'I $\alpha \rho i \omega$ (so Hemsterhuis richtig statt ' $I \lambda \alpha \pi i \omega$ )

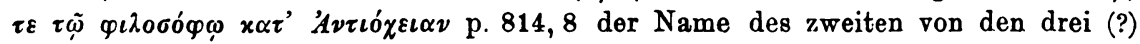

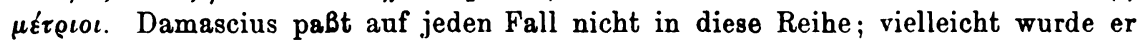
p. 814,11 mit $\Delta o \mu v i \nu \omega \delta \dot{\varepsilon} x \tau \lambda$. (st. $\Delta . \tau \varepsilon x \tau \lambda$.) angeknüpft. 
Religion besprochen wird, paBt v. $Z \dot{\eta} v \omega \nu$ VI p. 726, 1-11 hierher. Denn hier wird ein vom Judentum abgefallener Hellenist geschildert,

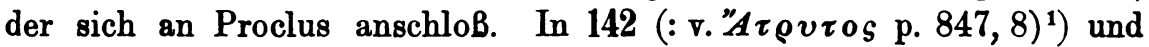
der auf Damascius vorgreifenden Stelle Cod. 181 p. 126 b 42sq. wird die Charakteristik des Marinus fortgesetzt. Da in 143 (: v. "O $O \chi$ ov p.1241,6) ein Kranker erwähnt wird, den Isidorus („aber") mit Rücksicht auf sein Befinden nicht zu befragen gestattet, haben wir es hier wohl mit einem Referat über ein Antwortschreiben unseres Philosophen zu tun, das sich auf eine an ihn ergangene Einladung zur Übernahme der Diadochie bezieht, worüber er aber gerne noch die Ansicht des Patienten gehört hätte. DaB überhaupt eine Mehrzahl von Kandidaten in Frage kam, läBt sich aus der in 144; 145 (: Cod. 181 p. 127 a 9.10); 146 (: v. $A \dot{\eta} \vartheta \eta)$

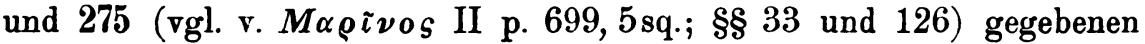
Charakteristik des Marinus begreifen, da diese in 147 darauf hinausläuft, dab Proclus wegen der Kräfteabnahme des jungen Mannes, worauf

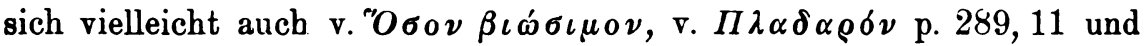

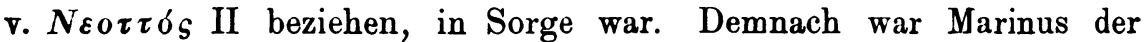
Kranke von 143. In $148^{2}$ ) handelt es sich wohl um einen Traum des Proclus, in welchem diesem ein verstorbener Amtsvorgänger (Syrianus?) erschien und die Kandidatur des Isidorus empfahl. Denn auf 149, worin die Glaubwürdigkeit dieser Geschichte betont wird, folgen in

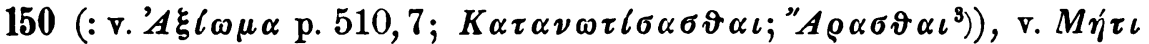

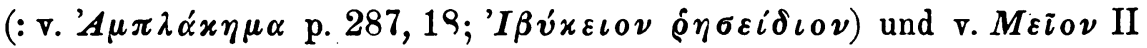
p. 820, 10 (wohl briefliche) Argumente des Proclus, um Isidorus zur Annahme zu bestimmen, samt dessen Gegengründen. In 151 und 152 werden noch einmal die Befürchtungen betont, die Proclus für den Fortbestand der Schule einerseits und wegen der Körperschwäche des Marinus andrerseits hegte, worin wir vielleicht wieder den Inhalt eines

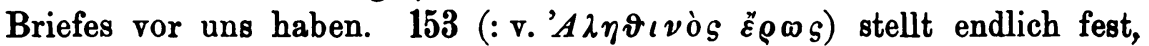
daB Isidorus nachgab und nach Athen zu Proclus eilte. $\left.{ }^{4}\right)$ Vgl. v. $X \rho \tilde{\eta} \nu \alpha \iota$ p. 1670,5 . DaB er dies unter Preisgabe seiner eigenen Interessen, bloB aus Liebe zu seinen Freunden tat, kann man möglicherweise aus v. $\Pi \varrho \circ \varepsilon \dot{\mu} \mu \varepsilon \nu_{\mathcal{L}}$ (: v. $\Phi \iota \lambda i \alpha$ II) herauslesen. Damit war er aber, wie aus dem folgenden Abschnitt hervorgeht, noch nicht endgültig gewonnen.

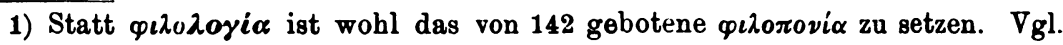

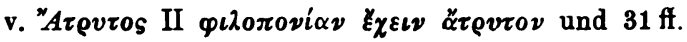

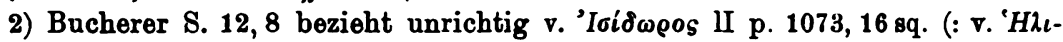
xเ⿳́㇒一 $\eta$ ) hierauf.

3) P. 685, 3 vermutet Bernhardy ohne allen Grund $\mu v \vartheta 0$ - statt $\delta \mu 0 \lambda_{0} \gamma \tilde{\omega} \nu$, das nicht auf $\tau \iota$, sondern auf Isidorus zu beziehen ist.

4) Bucherer S. 12, 9 führt diese Ekloge in dem Abschnitt „De primo itinere Athenas facto" auf. Anders Zeller S. 915, 2; vgl. Zumpt S. 87. 


\section{Zweiter Anfenthalt des Isidorus in Athen.}

Isidorus begründete seine zögernde Haltung wahrscheinlich mit der näherliegenden Kandidatur des Marinus. An dessen Charakteristik könnte

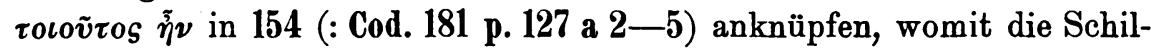
derung von Proclus' Lieblingsschüler Zenodotus beginnt. Dieser wird

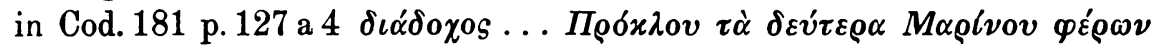
genannt und kam deshalb an zweiter Stelle für das Diadochenamt in Betracht. Auf einen Zusammenhang mit Marinus weist auch 276 und 155-157 (: v. $\Theta \varepsilon \alpha \gamma \varepsilon \dot{\varepsilon} \nu \eta S \quad$ p. $1116,11 \mathrm{sq} . ; \Theta \tilde{\omega} \pi \varepsilon S \quad$ p. 1198,10 ; vgl. v. $\Sigma o \beta \alpha \rho o ́ s$ p. 823,16), wo sein mißliches Verhältnis zu Theagenes zur Sprache kommt. Dem in v. $\Theta \varepsilon \alpha \gamma \varepsilon \dot{\varepsilon} \nu$ s p. 1116, 8-10 erwähnten Mäcenatentum dieses Staatsmannes würde 158 (: v. $\Pi \lambda \alpha^{\alpha} \tau \omega \nu$ III) entsprechen, wo die vielleicht auch durch ihn geförderten materiellen Verhältnisse der Akademie geschildert werden. MuB man schon nach dem Bisherigen die Anwartschaft des Marinus für eine nicht ganz unbedenkliche halten, so sprachen möglicherweise auch seine Antecedenzien nicht sehr für ihn. Denn er scheint der in v. $\Sigma v \sigma \tau o \iota \chi \ell \alpha$ erwähnte Parteigänger der von Damascius als die Minorität bezeichneten Sekte gewesen zu sein. Hierzu würde die Notiz in 277 passen, wonach er sogar

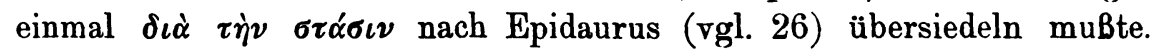
Allein diese ganze Ausführung (von 154 an?) ist nach 159 lediglich eine Digression.

Das Thema wird in 160 wieder anfgenommen mit der Mitteilung, daB sowohl Asklepiodotus d. j., der demnach gleichfalls in Vorschlag

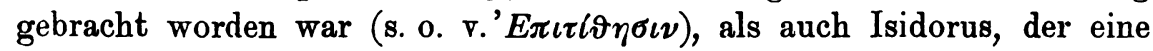
als Ehemann, der andere als Freier ${ }^{1}$ ) - nach $153 \pi \alpha \dot{\nu} \nu \alpha \alpha \eta \eta \gamma \varepsilon \nu \tilde{\eta} \delta \varepsilon \sigma \mu o ̀ \nu$ $\alpha \pi \circ \rho \emptyset \eta \xi_{\alpha}$ hatte er wohl bereits zu Hause geheiratet - ihre Familienpflichten als Vorwand gegen das ihnen angesonnene Amt gebrauchten. 278 erhärtet die Mühe, die sich Marinus und Proclus gaben, um unseren Philosophen endgültig umzustimmen, und dasselbe wiederholt 161 (: 279) bezüglich des Proclus im besonderen. 280 stellt endlich fest, daB Isidorus aus Scheu vor dem Tadel der beiden Männer nachgab. Dies geschah wohl nicht ohne die Mitwirkung des Theagenes. Daher stand wahrscheinlich hier จ. $\Theta \varepsilon \alpha \gamma \varepsilon^{\prime} \nu \eta \varsigma$ p. 1116,1-4. Denn wenn in 281 ein gewaltiges Erdbeben erwähnt wird, so weist dies auf

1) Nach Bucherer S. 11 wäre hier „de Asclepiodoti filiabus" die Rede.

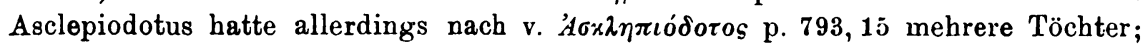
da $B$ aber eine derselben mit der in 301 genannten Domna, der Gattin Isidors, identisch gewesen sei, ist nirgends überliefert. Bei der- engen Beziehung, die zwircher Asclepiodotus und Damascius bestand, wäze auch die in 301 zutage tretende Mißachtung der Domna von seiten des Biographen sehr verwunderlich. 
v. $\Theta \varepsilon \alpha \gamma^{\prime} \nu \eta s$ p. 1116,4 hin, wo seine werktätige Hilfe bei solchen: Anlässen hervorgehoben wird; zudem hat man aber wohl auch die in 282 genannte, im Zureden ( $\pi \varepsilon \iota \vartheta \hat{\omega}$; vgl. 150) geschickte Attikerin in seinem Kreis zu suchen: sie ist aller Wahrscheinlichkeit nach identisch mit seiner Gattin, der jüngeren Asclopigenia, der Tochter des älteren Archiadas. Dieser wird in $\nabla$. $^{\prime} A \rho \chi\left\llcorner\alpha^{\prime} \delta \alpha s^{1}\right)$ wegen der hochsinnigen Geringschätzung der irdischen Güter gepriesen, worin er seinem Schwiegersohn mit gutem Beispiel voranging. Daher paBt diese Glosse vortreff-

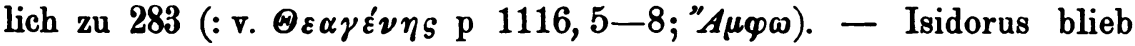
jedoch, wie das Folgende zeigt, trotz seiner Zusage nicht in Athen: er hatte sie wahrscheinlich bloB bedingt für den Fall von Proclus' Hinscheiden gegeben.

\section{Dritter Aufenthalt des Isidorus in Alexandrien.}

Schon 284 und $162^{2}$ ), worin Isidors äußere Erscheinung geschildert wird (vgl. 16), scheint auf eine neue Epoche hinzuweisen. DaB der Schauplatz dieser nicht mehr Athen, sondern Alexandria ist, geht aus 163 (: v. ' $\Upsilon \pi \alpha \tau i \alpha$ p. 1316,1-6) $)^{3}$ hervor. Damascius verglich das Auftreten unseres Philosophen und den Beginn seiner dortigen Wirksamkeit wohl mit der Rolle, die vor ihm einst Hypatia gespielt hatte. Sonst hätte er nicht die noch lebendige Erinnerung an die hellenistische Märtyrerin als einen für seinen Helden hinderlichen Umstand bezeichnen und in 164 den zwischen ihm und seiner Vorgängerin bestehenden Unterschied ausdrücklich hervorheben können. Der SchluB von v. ' $T \pi \alpha \tau(\alpha$, p. 1316, 7 sq., handelt von Isidors kritischer Begabung (vgl. 41) und stellt ibn in dieser Beziehung den Zeitgenossen seines Biographen, dem Agapius, Severianus und Nomus, an die Seite. Daher gehört wohl zunächst v. 'A $\alpha_{\alpha}^{\prime} \pi \cos \mathrm{II}^{4}$ ) hierher. Auf diese Glosse folgte wahrschein-

1) Auffallenderweise schreibt Freudenthal (Pauly-Wissowas Realencyklopadie u. Arch.) diesen Namen mit der Endung -es.

2) Fabricius p. 762 bezieht diese Stelle auf Asclepiodotus.

3) Bereits von Wernsdorf p. 42 hierher gewiesen. Hoche S. 454 übersetzt die

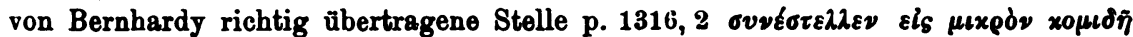
verkehrterweise: „verringerte nur wenig" nnd wundert sich S. 455 „wie Damascius darauf kommt, den Isidorus mit der Hypatis zu vergleichen", da „dies aus Photius nicht zu ersehen" sei.

4) Bernhardy identifiziert den Helden dieser Glosse wohl richtig mit demjenigen von v. 'A $y \alpha \dot{\pi} \pi \iota 0 s$ II. Wellmann (Pauly-Wissowas Realencyklopädie u. "Agapios" 1) will ihn unwahrscheinlicherweise zu einem i. J. 415 aus Alexandria vertriebenen alexandrinischen Juden und Arzt stempeln, was mit dem späten Jahr 489, wo er verfolgt wurde, nicht wohl vereinbar ist, wahrend dies Datum sehr gut auf einen nach Proclus' Tod (485) blühenden Mann (v. 'Ayórios I) pabt. 
lich 165 nnd 285 (: v. $\Sigma \varepsilon \beta \eta \rho \iota \alpha \nu o ́ s ~ p . ~ 695,13-697,11^{1}$ ); 20-698,13;

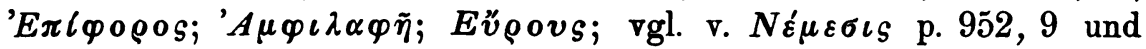
จ. $\Sigma x \alpha \iota o_{s}^{\prime}$ p. 783,8). Zu diesem Passus ist wohl auch v. $X \rho \tilde{\eta} \mu \alpha$ II p. 1664, 5, eine auf den Kontrast zwischen der Naturanlage und der späteren Lebensbetätigung dieses Mannes passende Sentenz, $286^{9}$ ), eine mit seiner p. 697, 11 gerügten Schroffheit vereinbare Geschichte von einem Bittsteller, und v. $K \alpha \tau \alpha \pi \varepsilon \iota \vartheta \varepsilon_{S}$, eine Notiz über einen zur Exegese ungeeigneten Stoff hinzuzunehmen, womit der p. 698, 10 abgelehnte Callimachus gemeint sein könnte. Endlich schlob sich hier allem Anschein nach v. Nóros p. 1003,17-1004, 1 (vgl. 92) als dritte Biographie an.

Dem Helden unseres Werkes wendet sich wohl 166 wieder zu, um seine philosophische Weiterentwicklung zu schildern. Deren ungehinderter Fortgang wird wahrscheinlich durch v. $K \alpha \tau \dot{\alpha} \pi \tilde{\eta} \chi v \nu$ (: v. 'Exi-

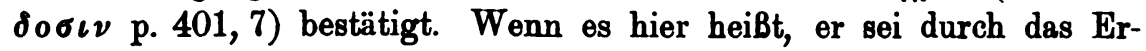
scheinen des $\Pi \alpha \nu\left(x o \nu^{3}\right) \delta v \sigma \tau v \dot{x} \eta \mu \alpha$ in Alexandria aufgehalten worden, so hat man diese auf den ersten Blick sehr dunkle Bemerkung wohl aus 167 (: v. $\Sigma \alpha \rho \alpha \pi i \omega \nu$ p. $677,8-13 ; 678,5$ sq.), wozu vielleicht v. X९ฑ๊ $\mu \alpha$ II p. 1664, 17 gehört, zu erklären. Denn in der Sarapionglosse wird dem alten Freunde unseres Philosophen (s. o. hinter 22) Pamprepius als sein Widerspiel gegenübergestellt. Hier haben wir nun (vgl. 109. 110) die chronologisch richtige Stelle für seine Ein-

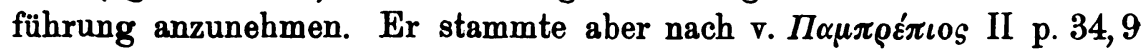

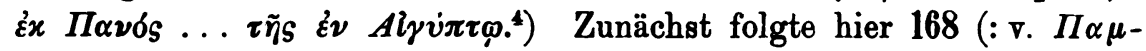

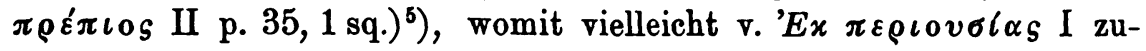

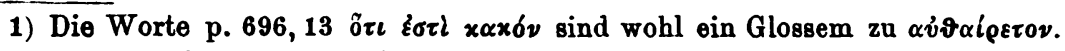

2) Bucherer S. 10,12 schreibt ov (statt $\delta$ ) $\delta \varepsilon \delta \mu \varepsilon v o s$ im Sinne von „ohne ...

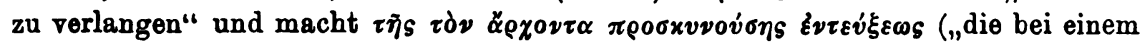
orientalischen Könige übliche $\pi \rho \circ \sigma x v ́ \nu \eta \sigma \iota \varsigma^{(1)}$ von diesem Partizipium statt von dem folgenden Intinitiv $\alpha \xi \iota \omega \vartheta \tilde{\eta} \nu \alpha \iota$ abhängig; $\delta \delta \varepsilon o ́ \mu \varepsilon \nu o s$ ist aber hier geradeso wie in

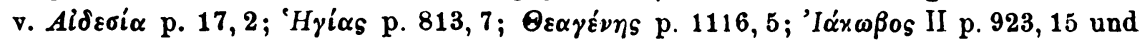

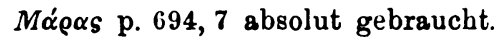

3) Toup, Hemsterhuis und Boissonade schreiben mit verfehlter Bezugnahme

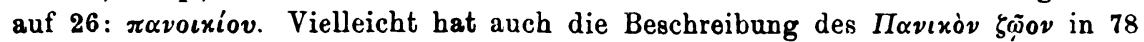
etwas mit Pamprepius zu tun.

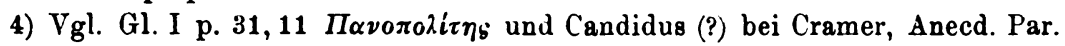

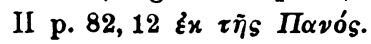

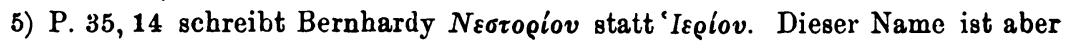

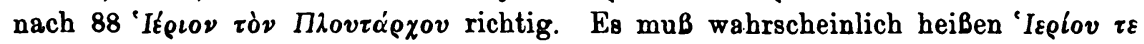

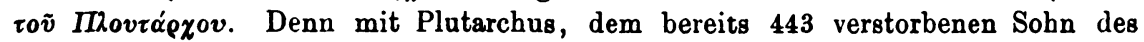
Nestorius, kann Pamprepius nicht mehr konkurriert haben, wohl aber mit seinem Sohne. P. 35, 15 ist wohl hinter $x \alpha i$ einiges ausgefallen, vielleicht der Name des Ammonus, der ein Sohn des Hermeias war und sich zeitweilig in Athen aufhielt. Allerdings war auch er kein Rhetor. 
sammenhängt, da dort von Pamprepius' Berufung nach Athen und hier von einer überflüssigen Berufung desselben die Rede ist. 169 versetzt uns schon in die Zeit des zwischen Illus und Zenon ausbrechenden Zwistes ([484]; vgl. 103), bei welchem wahrscheinlich der in 170 abfällig beurteilte Bischof Petrus ${ }^{1}$ ) im Interesse des Kaisers gegen die Hellenisten tätig war. Hier dürfte sich 287 angeschlossen haben, wonach eine Majorität (in Alexandria?) sich wieder aufrichtete und im

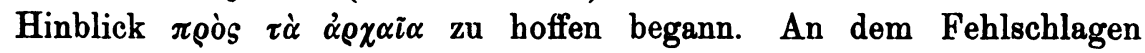
dieser Erwartungen war wohl niemand anders schuld als Pamprepius, der in 288 als ein Werkzeug der der guten Sache (des Hellenismus) feindlichen Notwendigkeit (vgl. 118) bezeichnet wird. Seine in 171 (:289) getadelten Prophezeiungen schoben nämlich wahrscheinlich auch noch

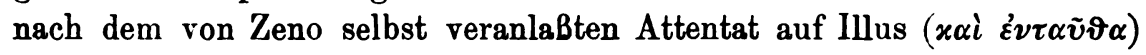
den Krieg hinaus. Nun folgte wohl die Schilderung von Pamprepius' Verrat. Denn nach 172 hielt Isidorus diesen schon, als er in Ägypten erschien - auf die ihm hier von seiten der hellenistischen Bekannten unseres Philosophen zuteil gewordene schlechte Aufnahme würde v. ' $A \mu$ -

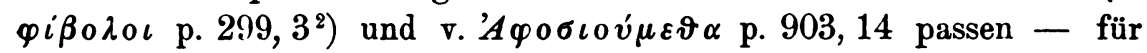

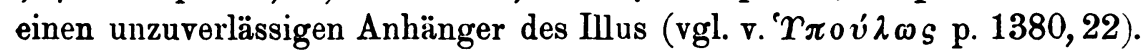
Dessen wankende Stellung wurde wohl im folgenden besprochen und dabei u. a. behauptet, daß er nicht mehr für kaisertreu galt. So würde sich wenigstens der Satz in 173 erklären: "sondern er sieht bereits so aus wie ein Mann, der Verrat üben will und ein Auge auf die Römerherrschaft geworfen hat (vgl. 254)“. Vielleicht liegt hier eine Äußerung des Heraiscus vor, welche die Deutung des ihm nach 254 gewordenen Traumgesichtes enthielt. 174 beschreibt einen Felsen, auf dessen Dimensionen wohl $308 \mathrm{zu}$ beziehen ist. Auf ihm stand wahr-

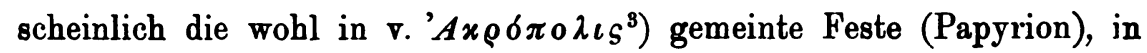
welcher Illus sein Ende fand. 290 (vgl. 87; 105; 138) enthält eine Aufzählung der hellenistischen Repristinationsversuche von Julian bis Illus [Julianus 361-363; Lucius 412; Theoderich, der Sohn des Triarius ${ }^{4}$ ) 481; Severianus 488; Marsus und Illus: +488$]$. Da hier

1) Fabricius p. 763 spricht ungenau von einem „Praefectus". Vgl. Valesius

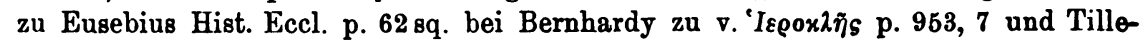
mont VI p. 208 b.

2) Von Bernhardy im Index dem Malchus, im Text diesem oder dem Damascius zugeteilt.

3) Von Bernhardy angezweifelt.

4) S. Cramer, Anecdota Paris. II p. 83, 16; Gibbon IV p. 8; 13; Fabricius p. 764 deutet den "magnus dux orientis" irrtümlich auf Zeno. Mit 290 (p. 143, 29)

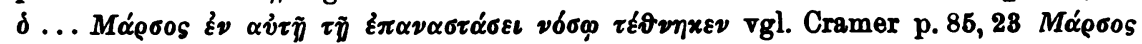
$\mu \varepsilon \tau \dot{\alpha} \lambda^{\prime} \dot{\eta} \mu \varepsilon \rho \alpha \varsigma \alpha \dot{\alpha} 0 \vartheta \alpha \nu \dot{v} \nu$, wo der Herausgeber (im Index historicus p. $417 \mathrm{u}$. "Marsus") verkehrterweise "Marcianus" schreiben will. 
u. a. anch Severianus erwähnt wird, so könnte an dieser Stelle v. $\Sigma \varepsilon$ $\beta \eta \rho \iota \alpha \nu$ ós p. $697,11-20$ und p. 698, 13sq. gestanden haben. Das Haupt des Pamprepius ist es wohl, das nach 291 von den Zinnen der Burg ins feindliche Lager geschleudert wurde (vgl. 110). Dieser religions-historische Abschnitt hatte an die Begegnung des Pamprepius mit Isidorus in Alexandrien angeknüpft. Er ist nach 175 als eine Digression zu betrachten, von welcher der Biograph nunmehr wieder zu seinem Helden zurückkehren will.

Er tat dies wohl, indem er die nach 167 unterbrochene Charakteristik จ. $\Sigma \alpha \rho \alpha \pi l \omega \nu$ durch p. $677,14-678,4$, womit (p. 677,17 sq.) wahrscheinlich auch 309 zusammenzubringen ist, ergänzte.

Zunächst wurde wohl gezeigt, wie Isidorus durch Pamprepius in die Verschwörung des lllus hineingezogen wurde und dadurch sich selbst in groBe Gefahr brachte. 176 schildert unseren Philosophen, wohl als Abbild des Sarapion im Gegensatz zu seinem typhonischen Gegenbild, als nicht $\tau \varepsilon \tau v \varphi \omega \mu \varepsilon ́ v o s$, sondern als einen umgänglichen

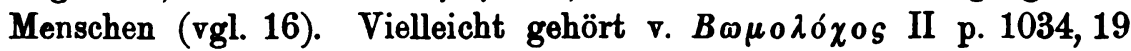

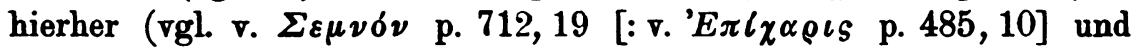

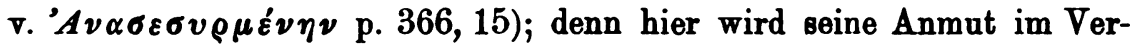
kehr gepriesen. Nach 177 war er $\tau \delta$ $\tau \varepsilon$ (d. h. während oder nach der genannten Empörung) heiter, obschon „die“ Besorgnisse für sein Leben noch fortbestanden. In Gefahr schwebte Isidorus offenbar wegen seiner nahen Beziehungen zu Ammonius (s. $74 \mathrm{ff}$.). Dieser hatte sich wahrscheinlich bei der Verschwörung des Illus kompronittiert. Vielleicht

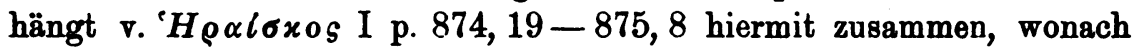
sich Ammonius und Erythrius ${ }^{1}$ ) in Byzanz durch ihren Zwist in die äuBerste Gefahr brachten. Hierauf bezieht sich v. 'A hiernach wurde dieser Bekannte des Ammonius als Mitwisser desselben vergebens gesucht. Nach v. ' $\Omega \propto \alpha \pi \delta \delta^{\prime} \lambda_{\omega \nu}$ p. 1267, 5-12 hörte dies Isidorus und lieB ihn warnen. Der Bote wurde aber abgefangen und verriet seinen Auftraggeber, worauf man den Horapollon und den $\mathrm{He}$ raiscus folterte und (wahrscheinlich vergebens; vgl. v. $K \alpha \tau \alpha \tau \varepsilon i \nu \alpha S$ p. 135, 2) nach Isidorus und Harpokras ausfragte. Der in 178 vorkommende schlechte Mensch dürfte mit dem bereits in 170 erwähnten und wohl auch in 179 (: 292) gemeinten Bischof Petrus ${ }^{8}$ ) identisch sein,

1) Le Beau VII p. 213 schreibt falsch „Erythraeus". Vielleicht ist dieser

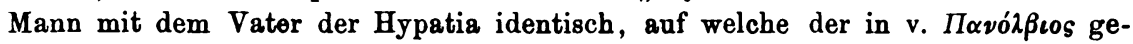

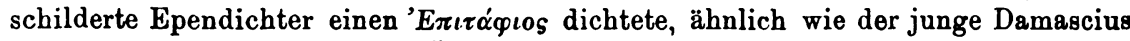

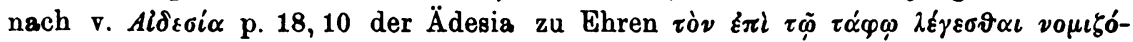

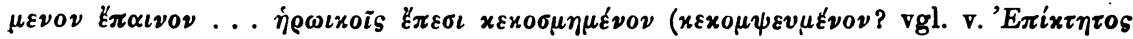
p. 426,7 u. o. S. 460,4$)$ bielt.

2) In 179 ist fälschlich (wohl nach Maßgabe von 180, 185 und 290) AthaByzant. Zeitschrift XVIII 3 u. 4. 
mit welchem Ammonius nach 292 aus schnöder Habgier (vgl. 46 und

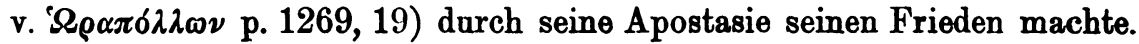
Diese Treulosigkeit führte wohl auch zur nochmaligen Hereinziehung Isidors and der alexandrinischen Philosophen in diese Untersuchung. Denn v. $\Sigma v \sigma x \varepsilon v \alpha \dot{\xi} \varepsilon \iota$ berichtet von einer ihm(?) durch einen Traum vermittelten Mahnung, sich reisefertig zu machen (vgl. v. 'Ex $\iota \varepsilon \iota x \tilde{\omega} s$ p. 402, 21), und 293 und 180-184 schildern die von Damascius' Bruder Julianus unterstützten Anstalten Isidors zur Flucht aus Alexandria (vgl.

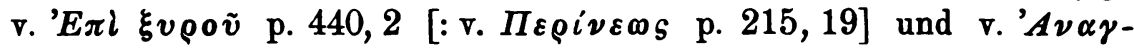

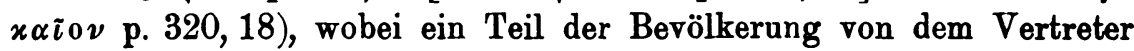
der Staatsgewalt (?) zurückgedrängt werden mußte und die Philosophen abermals verhaftet wurden. Dabei zeigte Julianus nach 185 große

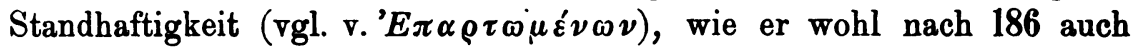
bei den weiteren Maßnahmen große Umsicht an den Tag legte. 310 enthält eine (wahrscheinlich briefliche) Bitte Isidors an Damascius, dieser möge ihm bei sich Unterschlupf gewähren.

\section{Dritter Anfenthalt des Isidoras in Athen. ${ }^{1}$ )}

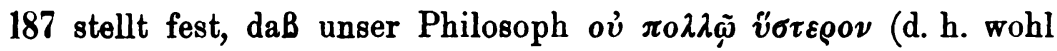
nach seinem aus $310 \mathrm{zu}$ erschlieBenden Schreiben) ankam und im Hause des Damascius Wohnung nahm. AnschlieBend hieran kommt dieser, wahrscheinlich nachdem er von seiner eigenen Tätigkeit in Athen ge-

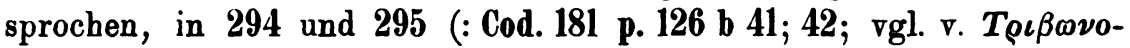

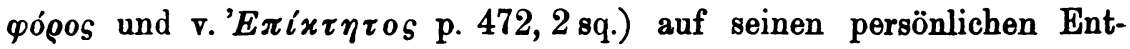
wicklungsgang zu reden. 294 scheint auf eine von Isidorus an ihn gerichtete Bemerkung über den richtigen Zeitpunkt zum Heiraten za gehen, auf welche sich der in 219 mitgeteilte Traun zurückbeziehen könnte. Als Gegenstand zu dieser Probe von praktischer Philosophie

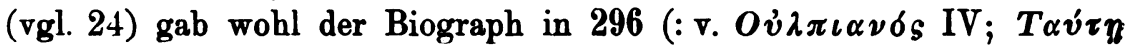

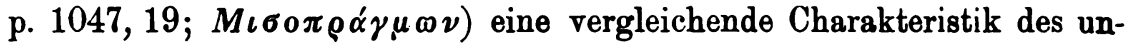
praktischen, ungeselligen, ledig gebliebenen und unpolitischen Bruders seines Helden. Hierauf wandte er sich wahrscheinlich zur Schilderung der letzten Tage des Proclus. Denn 297 und 188²) erzählen, wie ein

nasius eingedrungen, und Fabricius p. 762 denkt auch tatsächlich an den Gegner Julians, da er diesen selbst in diesem Zusammenhang mit dem Bruder des Damascius verwechselt.

1) Wernsdorf p. 35 sq. spricht bloB von einem zweimaligen Aufenthalt Isidors in Athen. Allein v. Mapivos Il p. 698, 12 sq., worauf er sich stützt, scheint eher zu verraten, daB er nach Proclus' Tod noch zweimal mit Marinus in Athen zusammentraf.

2) Brucker p. 34:3 bezieht diese Ekloge auf Isidorus. 
Urgenannter noch zu dessen Lebzeiten zu ihm nach Athen reiste, aber erst bei seinem Begräbnis [485] dort ankam. Dieser Mann ist wohl der Alexandriner Agapius (s. hinter 164), von dem 298 (: v. 'A jáx cos $_{\text {II; }}$

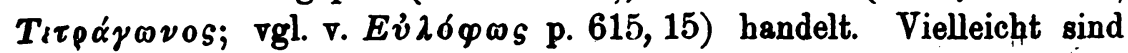

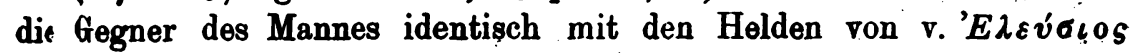

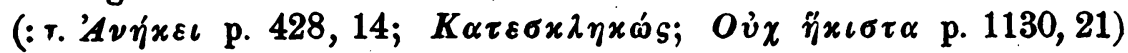

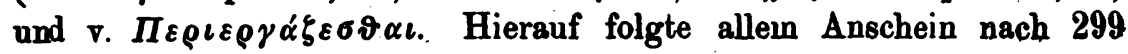
(: T. $\Gamma \dot{\varepsilon} \sigma\left(\varsigma_{S}^{1}\right)$ ), wonach Agapius mitsamt den andern Philosophen verhaftet (vgl. 184), Heraiscus aber von Gesius verborgen gehalten wurde.

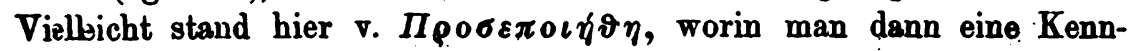
zeichnung des von Isidorus in dieser kritischen Lage im Gegensatz zu seine Umgebung bewiesenen Gleichmuts erblicken könnte. Daran schloB

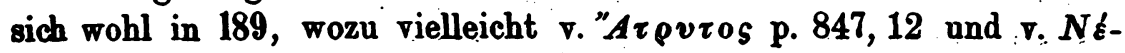
$\mu \varepsilon \sigma$ us p. 952, 8 gehört, in 190 und 191 eine Schlußbetrachtung über die truhere oder spätere Rache der Gottheit (vgl. 256; v. 'Procica p. 1315, 22) und das standhafte Ausharren der bedrohten Philosophen.

\section{Vierter Auforithalt des Isidorus in Alexandiria.}

Jie Beschäftigung mit dialektischen Übungen, von der 300 und der atobiographische Passus in Cod. 181 p. 127 a 10-14 handelt, dürfte sich wohl auf die Zeit beziehen, wo Isidorus, wahrscheinlich zusammen mit Iamascius, sich wieder in Alexiandrien aufhielt. Seine Heimatstadt ist whl auch der Schauplatz von 310 ( gl. 160), einer Notiz über seine

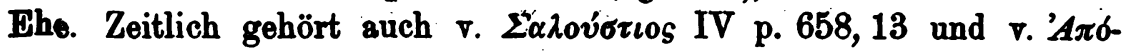
זsup $\alpha$ hierher, woraus anf einen Verkehr des Damascius mit dem Zyniker zu soließen ist. Ebenso fällt in diese Epoche das in 93 erwähnte $\mathrm{Zu}$ sammensein des Biographen mit Asclepiades und seinem ehemaligen Schülbr Isidorus. 192 betrifft die Künste einer dem Philosophen bekannt gewordenen Wahrsagerin und 193 wohl eine von Anatolius unter

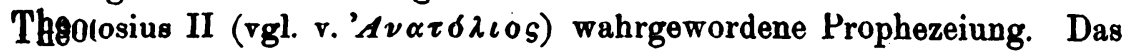
Folgelde zeigt, daB Isidorus (vgl. 239 und v. Mźr Asclejiodotus) damals Studienreisen unternahm, wobei Damascius ihn wohl begleitete. Denn 194 handelt von einer Gesandtschaftsreise, geJegentich welcher Damascius einen gewissen Emision traf, dem er seine nach 338 für die typhonische $\pi 0 \lambda \iota \tau \varepsilon i \alpha$ charakteristische $i \eta \nu \varepsilon l \alpha$ vorwirft (s. S. 429). Vielleicht ist dieser Mann identisch mit dem Helden

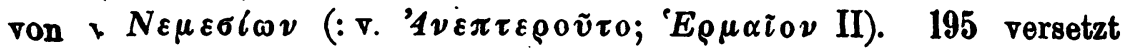
unseren Philosophen nach Arabien, wo wir ihn in 196-198 in Bostra

1 P. 1097, 11 will Bernhardy, Addenda p. 1809 verkehrterweise den Namen

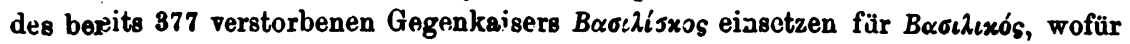

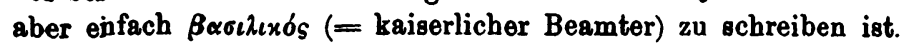


und in 199 in der Gegend von Dia treffen. 200 (: Cod. 181 p. 125 b 30) zeigt ihn uns in Damascus. An den gemeinsamen Aufenthalt daselbst (202) knüpft Damascius in 201 (: Cod. 181 p. 126 b 41. 42; vgl. \$§ 35; 61) und 202 autobiographische Notizen an. 2035) erzählt an der chronologisch richtigen Stelle, was bereits in 94 (vgl. 9) vorweggenommen war. In das syrische Heliopolis, von welchem hier die Rede ist, paBt

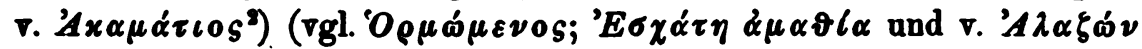

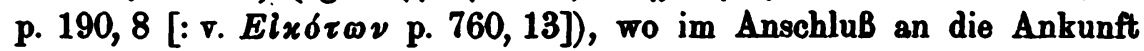
des Isidorus und seines Biographen ein aus dieser Stadt stammender Philosophaster und Hieroskop charakterisiert wird.

204 schildert einen nicht weiter bekannten Hellenisten namens Maximinus und 205 kennzeichnet das Benehmen eines gleichfalls unbekannten unphilosophischen Menschen, ohne daB wir von ihrem Aufenthaltsort etwas erfahren. Vielleicht handelt es sich hier und in 206 bereits um Hegias und die auch in 228 als unheilbar bezeichneten athenischen Verhältnisse, die unsern Philosophen dorthin riefen. 207-209 halten sich über einen gewissen Cyllenius auf, weil er durch Verschleppung einer Angelegenheit den Isidorus an deren erfolgreicher Erledigung hinderte und ihn nicht so schnell, als er es wünschte und in Gebeten exflehte, nach Karien und Athen gelangen lieB. Er muB demnach zu dieser Zeit eine größere Reise zu seinem alten Pädagogen und zu seinen athenischen Freunden geplant haben. 210 beginnt mit

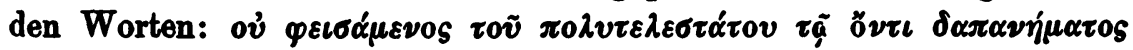

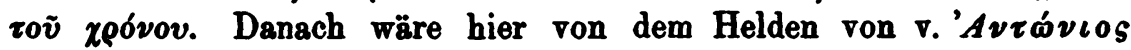
'A $\lambda \varepsilon \xi \alpha \nu \delta \rho \varepsilon v ́ s$, einem Gönner des Damascius, die Rede; denn hier heiBt

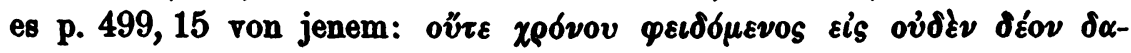

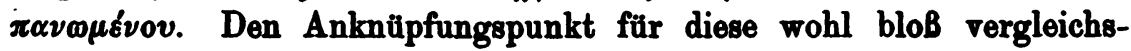
weise eingeflochtene Biographie bildete wahrscheinlich die vorher bei Isidorus beklagte Zeitverschwendung. 211 gehört vielleicht zu 212 (: 302$)$ und wäde dann obenso wio auch 213 mit einem Besuch zusammenhängen, den Damascius nach 302 dem Asclepiusheiligtum im phönizischen Berytus abstattete, um seinem Lehrer nachher von der Kultlegende des Esmunus(-Attis) Bericht zu erstatten. 214 führt uns in Übereinstimmung mit dem in 207 angedeuteten karischen Reiseziel an

1) Bucherer 8. 19,44 dentet Éó hier fälschlich anf Eusebius statt auf Damascius. Dis anch in den Index bei Westermann $n$. "Eusebius" ubergegangene

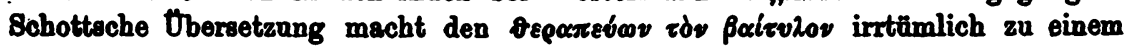
"medicns", woran n. s. auch Brsigk, De Baetyliis (Diss. Berol. 1854) p. 27 keinen AnstoB nimmt; in Bokkers Namensverzeichnis steht richtig "minister".

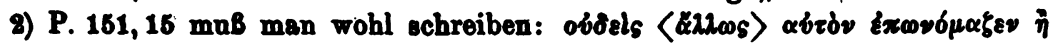

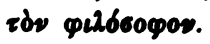


den Mäander; denn die hier erwähnte Todesgefahr bezieht sich wohl auf die bereits in 116 vorweggenommene Durchschwimmung dieses Flusses von seiten des Asclepiodotus and seines ehemaligen Zöglings Isidorus. Damit wären wir in Aphrodisias in Karien angelangt. Von hier aus machte Damascius nach 131 in Gemeinschaft mit einem gowissen Dorus einen Ausflug nach dem phrygischen Hierapolis. Vielleicht ist daher der in 215 kritisierte Philosoph mit diesem Dorus identisch. Dann könnte v. $\Delta \tilde{\omega} \rho \circ \mathrm{s}$ hier gestanden haben, wonach dieser ron Isidorus ans einem Aristoteliker zu einem Platoniker gemacht wurde (vgl. 35) Der Aufenthalt unseres Philosophen bei Asclepiodotus gab wohl dem Damascius Veranlassung zu einer abschlieBenden Würdigung dieses Mannes, wie sie in 216 (: v. 'A $\sigma x \lambda \eta \pi \iota \delta \delta$ oros p. 793,4 sq.;

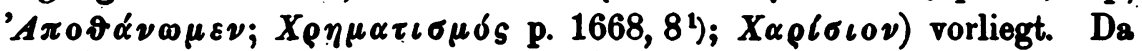

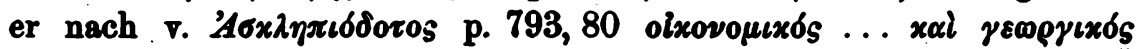

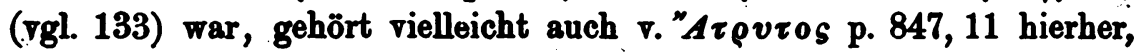

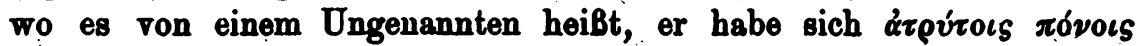
(s. 142) tagaliber der Landwirtschaft gewidmet ( 217 versetzt uns nach Samos. 218 konstatiert die Erkrankung und 219

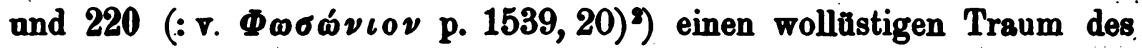
Damascins, welcher ihn in Erinnerung an die in 294 verzeichnete. Mahnung seines Lehrers zum Heiraten bestimmt haben dürfte. Das Schiff, auf welchem er dieses Traumgesicht hatte, führte die beiden Philosophen, nach 207 zu schlieBen, wohl nach Athen.

\section{Vierter Aufenthalt des Isidorns in Athen.}

221 handelt von dem Tiefstand der Philosophie in Athen unter Hegias. Daher schloB sich hier wohl dessen von $\nabla$. 'H $H$ ías gebotene Charakteristik an, die an seinen Vater (s. p. 813,4) anknüpft, worauf

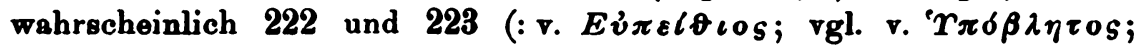

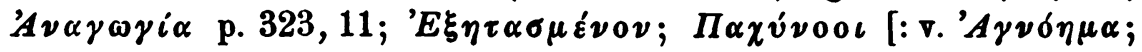

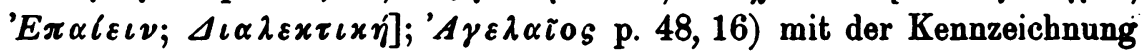
seiner Söhne und seiner ganzen Schule folgte. Da es in der Suidas-

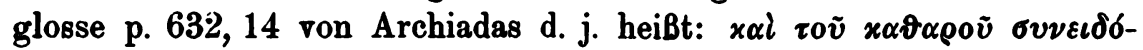

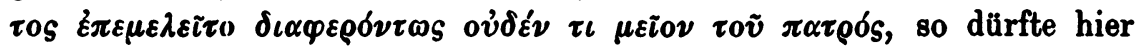

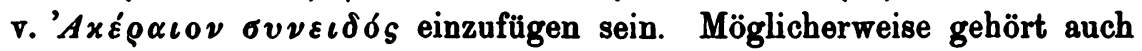

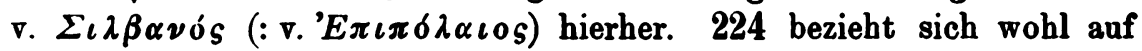

1) Hemsterhuis' Verweisung auf p. 547, 36 bezieht sich anf $\pi 0 \lambda v \alpha \dot{\rho} \alpha \tau o s$ und

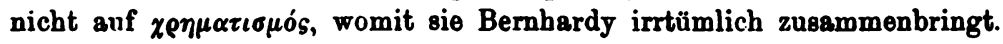

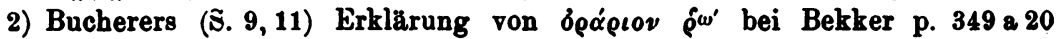

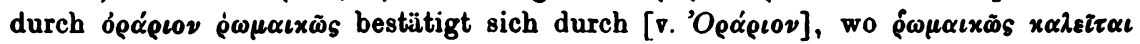
beigeschrieben ist. S. Reinesius p. 432. 
den totkranken Marinus, der dem Isidorus das Diadochenamt anempfahl, 303 (vgl. v. $\Delta \iota \omega \lambda v ́ y \iota 0 v$ ) auf dessen Gegenargumente, wobei der Hinweis auf die nnerreichbare GröBe des Proclas wohl eine groBe Rolle spielte, und 304 (: . $\Pi \rho \circ \sigma \eta \gamma \alpha^{\prime} \sigma \vartheta \eta \sigma \alpha \nu$ ) auf die Anerkennung, welche die Entgegnung des jungen Mannes (Isidorus) bei der Umgebung des Marinus fand. Denn bei dieser wachs infolge derselben die Begeisterung für Proclus. DemgemäB ist in 225 der über die seinen Erwartungen nicht entsprechende $\alpha \pi 0 \lambda 0 \gamma l \alpha$ ungehaltene Mann $(\delta \delta \varepsilon)$ wohl wieder Marinus. Denn in 226 gelingt es diesem tatsächlich durch vieles $7 \mathrm{u}$ -

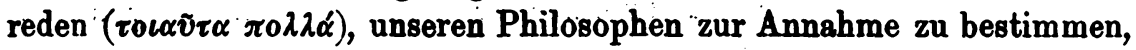
worauf auch seine Ernennung zum Diadochen erfolgt. Nach 227 scheint aber Isidorus gelegentlich mit Hegias in Meinungsverschiedenheiten geraten zu sein. Denn diese Ekloge stammt aus einer Diskussion der beiden (und des Damascius?) tuber den relativen Wert der Theologie

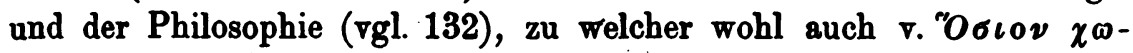

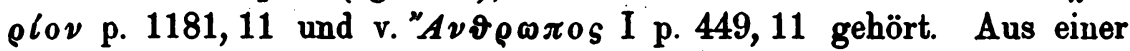

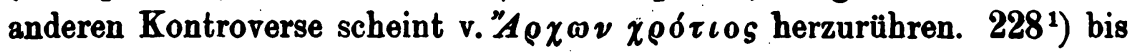
230 konstatieren schlieBlich Isidors Unfähigkeit, die heillosen Zustände (vgl. 206) zu bessern, seinen nach Marinus' Tod [c. 490] gefaBten Ent-

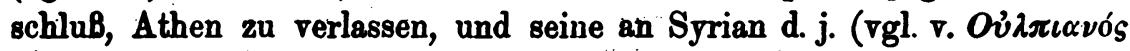
p. 1218, 10) und Hegias gerichtete Aufforderung, die ins Wanken geratene Philosophie wieder aufzurichten.

\section{Funfter Aufonthalt des Isidorns in Alexandria.}

Über den letzten, aller Wahrscheinlichkeit nach in Alexandria zugebrachten Lebensabschnitt unseres Philosophen ist anscheinend nichts mebr erhalten.

\section{Schlu.B.}

Den Übergang zum SchluB bildete.wohl eine Bemerkung über die allmähliche Ausarbeitung dor Biographio und den Umfang, den sie während derselben erlangte. Denn 305 . lantet: „noch hatte sich die Schwierigkeit des Stoffes nicht heruusgestellt" und 306 bzw. v. $\Sigma \varepsilon i \rho \alpha ́$ II p. 723, $\left.5^{2}\right)$ : „mich aber riB die Gewalt des Wortes dazu hin, mir

1). Zeller S. 915, 2 beziøht diese Stelle auf das übermächtige Eindringen des Christentums.

2) Die Wiederkehr des Ausdrucks $\dot{\eta}$ rov 20 jov $\dot{\rho}^{\prime} \mu \eta$ in diesem Fragment und

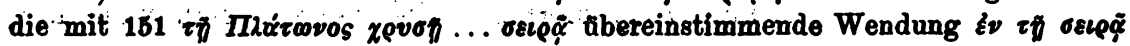
gewährleisten seine bereits von Bernhardy vermutete Zugehørigkeit zu unserem

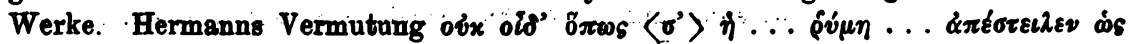

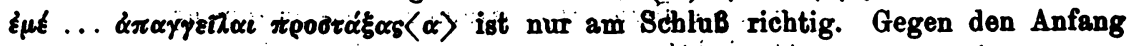

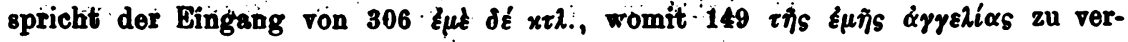
gleichen ist. 
»die (d. h. die anscheinend unnötige)《 Abschweifung zu den späteren (d. h. den unmittelbar auf Proclus' Zeit folgenden) Ereignissen zu gestatten, wobei ich mich an den Lebenslauf der von Proclus erkorenen Diadochen anschloB" bzw. "die Gewalt des Wortes suchte Schritt für Schritt die Reihenfolge in der Kette aufzuspüren und sandte, da seine (d. h. Isidors) Seele nicht in dem reinen Chor ihren Platz angewiesen erhielt, sondern, wie gezeigt worden ist, nach diesem, auf irgendeinem mir unbegreiflichen unsichtbaren Wege eine Botschaft an mich mit dem Auftrag, den genauesten Bericht zu erstatten". Demnach entschuldigte sich der Verfasser wohl, daB er nicht von Proclus unmittelbar auf Isidorus übergegriffen habe, mit der Notwendigkeit der historischen Kontinuität. Vielleicht stand in diesem Zusammenhang auch v. $\Delta \iota \alpha$ -

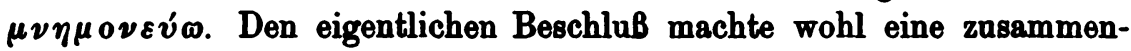
fassende Charakteristik des Helden. Zu dieser gehört wahrscheinlich

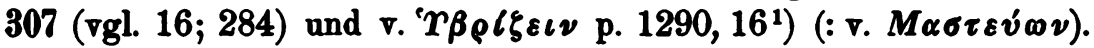

Nach unserem Rekonstruktionsversuch läBt sich unser Werk folgendermaßen disponieren:

Einleitung: A. Proömium mit der Widmung.

B. Überleitung zum Thema.

Durchführung: A. Herkunft des Isidorus.

B. Charakteristik des Isidorus.

C. Leben und Lebenssphäre des Isidorus.

I. In Alexandria (Anfänge).

II. In Athen (1. Aufenthalt).

III. In Alexandria (2. Aufenthalt).

IV. In Athen (2. Aufenthalt).

V. In Alexandria (3. Aufenthalt).

VI. In Athen (3. Aufenthalt).

VII. In Alexandria (4. Aufenthalt).

VIII. In Athen (4. Aufenthalt).

[IX. In Alexandria (5. Aufenthalt).]

SchluB: A. Rückblick auf die Komposition.

B. Zusammenfassende Charakteristik des Isidorus.

Da der erste unter den von Proclus erkorenen Diadochen, Marinus, ebenfalls ein biographisches Werk verfaBt hat und sowohl er selbst als sein Held Proclus in unserer Biographie eine sehr bedeutende Rolle spielen, so liegt es nahe, dieselbe mit der Lebensbeschreibung des

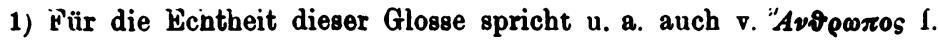


Proclus zu vergleichen. Hierbei muB man sich selbstverständlich davor hüten, Berührungspunkte, die sich in allen neuplatonischen Viten gleichmäBig nachweisen lassen, da sie aus dem philosophischen Charakter der Darsteller und der Dargestellten gemeinsam hervorgehen, besonders hervorzuheben. Es ergeben sich aber zwischen unseren beiden Biographien trotz der geringschätzigen Beurteilung, die Damascius seinem Lehrer Marinus angedeihen läbt, eine Reihe von Ähnlichkeiten, die beweisen, dab er sich von diesem bei der Abfassung seines Werkes da and dort beeinflussen lieB. Vielleicht darf man schon bei der Notiz

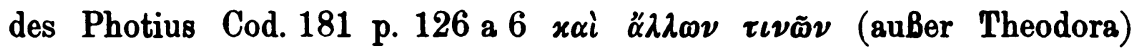

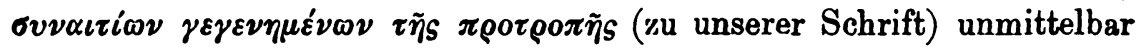
an den SchluB der Proclusbiographie denken, wo es c. 28 p. 169, 54 sq.

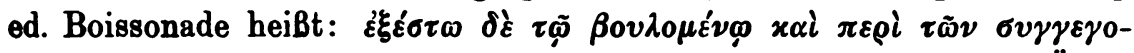

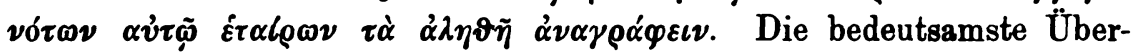
einstimmung zeigt aber die Komposition der Isidorusvita ${ }^{1}$ ) mit ihrer Vorgängerin. Wie nämlich Marinus c. 2 p. 151, 36 sagt: $\tau \dot{\eta} \nu$ $\varepsilon \dot{v} \delta \alpha \iota-$

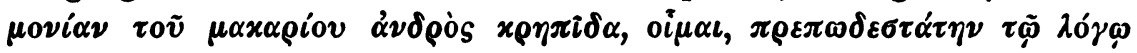
$\vartheta \eta^{\prime} \sigma o \mu \alpha \iota$ und am Schlusse seines Werkes c. 34 p. 168, 25 noch einmal auf die $\varepsilon \dot{v} \delta \alpha \iota \mu \nu \nu l \alpha$ seines Helden zurückkommt, so schickt auch Damascius der eigentlichen Biographie eine Apotheose voraus, deren Berechtigung er erst durch jene erweisen will, und schlieBt gleichfalls mit einer zusammenfassenden Charakteristik. Beide Autoren schildern ferner die Natur ihrer Helden nach der körperlichen wie nach der seelischen Seite und gewinnen durch diese Darstellung eine passende Einleitung für die Jugendgeschichte, beide bedienen sich bei der Zeichnung der ethischen und philosophischen. Persönlichkeit ihrer Meister eines philosophischen Kanons, und bei beiden bildet nicht das biographische Datenmaterial oder die gelehrt-systematische Wiedergabe von Philosophemen, sondern die fromm-erbauliche Schilderung eines fast ganz im Geistigen aufgehenden Philosophentypus den Schwerpunkt der Ausführung. Die Abhängigkeit von Marinus verrät sich aber auch deutlich durch viele formale und inhaltliche Entsprechungen im einzelnen.

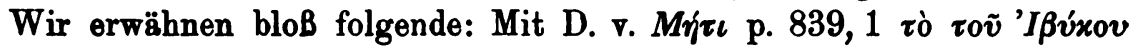
छ̇ं

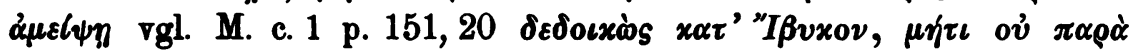

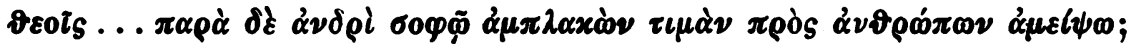

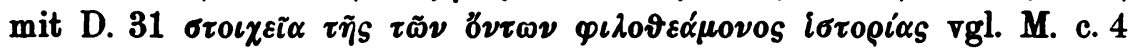

1) Hiernach ist Leos Behauptung S. 266, man müsse „die vom Leben des Isidorus handelnden Stücke aus der wirren Masse zusammensuchen, ohne daB darans ein anderes Bild als das der vollig gesprengten biographischen Form entstünde" einzuschränken. 


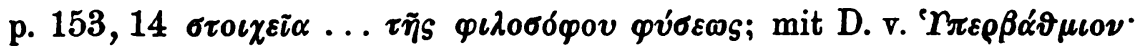

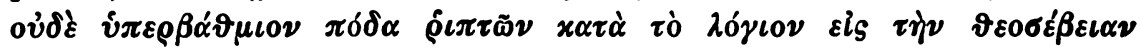

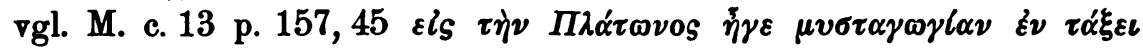

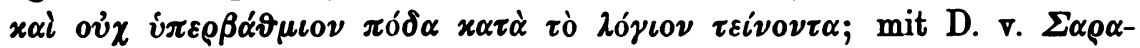

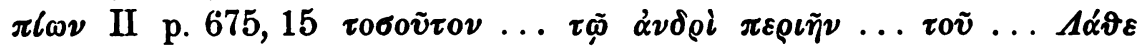

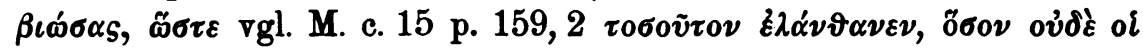

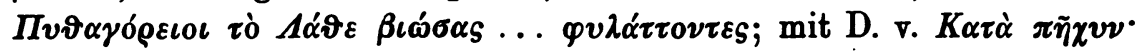

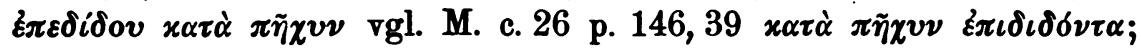

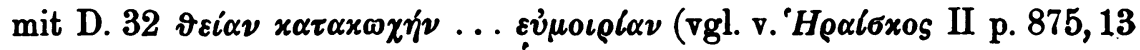

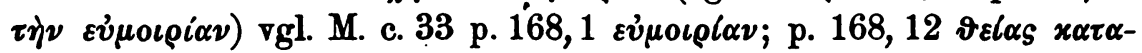

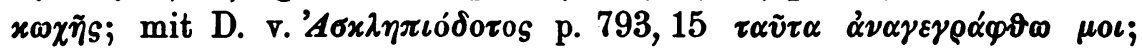

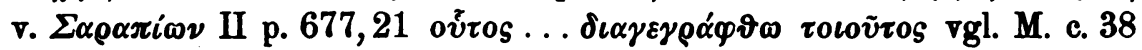

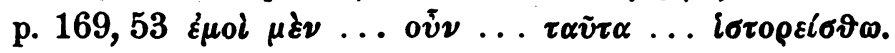

Zum Schlusse lassen wir, um die jeweilige Stelle, die wir den einzelnen Fragmenten in unserem Rekonstruktionsversuch angewiesen haben, leicht ausfindig zu machen, zwei Tabellen folgen:

\section{A. Die Damascinseklogen bei Photius.}

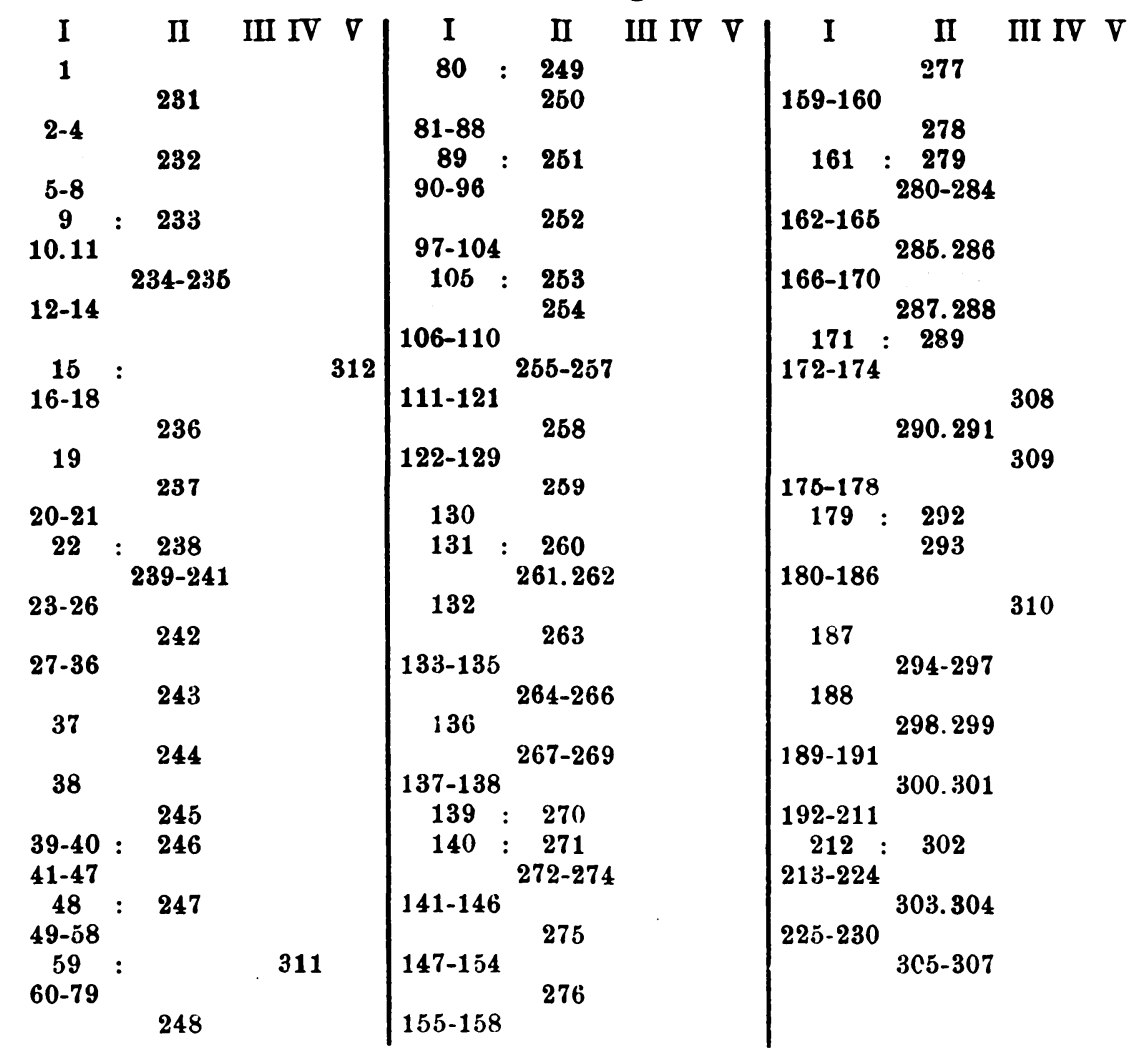




\section{B. Damasciusglossen bei Suidas.}

(Stern vorn $=$ unmittelbare, Stern hinten $=$ mittelbare Beglaubigung durch Lemma bzw. Zugehörigkeit zu einer mit Lemma versehenen Glosse; Kreuz hinten $=$ mittelbare Beglaubigung durch Zugehörigkeit zu einer durch Photius beglaubigten Glosse; gesperrter Druck = erstmalige Beiziehung zu unserem Werke; : = enge Berührung mit Photius; n. = Einordnung nach der betreffenden Photiusekloge, wobei gelegentliches Zurückgreifen über diese nicht ausgeschlossen ist.)

\begin{tabular}{|c|c|c|c|c|c|}
\hline 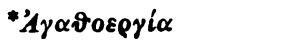 & n. 237 & $A \nu \eta x \in \iota$ p. 428,14 & n. 298 & $B \iota \omega \sigma \iota \mu \circ S$ & n. 120 \\
\hline $\mathcal{A} \gamma \alpha \vartheta 0 \vartheta \varepsilon \lambda_{\varepsilon L \alpha}$ & n. 20 & * $A \nu \vartheta \rho \omega \pi 0 s \mathrm{I}$ & n. 227 & * $B \lambda \alpha x \varepsilon v \varepsilon \varepsilon \alpha \iota$ & : 237 \\
\hline 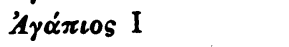 & n. 164 & Áví p. 438,5 & : 33 & 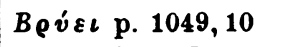 & n. 94 \\
\hline 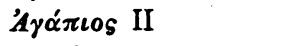 & $: 298$ & \multirow{2}{*}{\multicolumn{2}{|c|}{$\begin{array}{r}\left\{\nu \tau \varepsilon \lambda \alpha \mu \beta \alpha^{\prime} \nu 0 \nu \tau 0 \mathrm{p} .462,6\right. \\
\mathrm{n} .75\end{array}$}} & ${ }^{*} \mathrm{Ba}$ & n. 176 \\
\hline 'A $y \in i_{\varrho} \in \iota$ & rchf. A & & & & \\
\hline$A \gamma \varepsilon \lambda \alpha i$ os p. 48,16 & n. 223 & 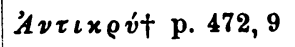 & $: 84$ & ${ }^{*} \Gamma \varepsilon$ & n. 21 \\
\hline $1 \gamma \nu$ ó $\eta \mu \alpha$ & n. 223 & 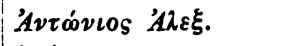 & $: 210$ & $\Gamma \varepsilon ́ v \varepsilon$ & n. 32 \\
\hline 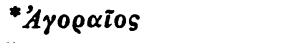 & n. 24 & 'Á̧ia & $: 150$ & ios p. 1082,8 & 3 n. 24 \\
\hline 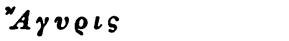 & n. 92 & $\tilde{\eta}$ p. 521, 2 & $: 260$ & $\Gamma \hat{\varepsilon} \sigma$ & : 299 \\
\hline 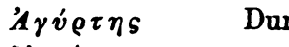 & rchf. A & $* \prime A \pi$ & n. 88 & 1106,13 & 3 n. 75 \\
\hline 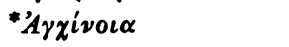 & $: 31$ & $\dot{A} \pi$ & n. 12 & $\Gamma \rho$ & 136,12 \\
\hline 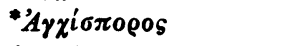 & $: \mathbf{4 0}$ & $A \pi$ & $: 80$ & & n. 109 \\
\hline $\mathcal{A} \dot{\delta} \alpha \dot{\eta} \mu о \nu \varepsilon s \dagger$ & n. 92 & $\omega \mu \varepsilon \nu \dagger$ & n. 216 & ${ }^{*} \Gamma \rho$ & $: 75$ \\
\hline$A \varepsilon i \delta \varepsilon \lambda \circ \nu$ p. 123,14 & n. 30 & $A \pi$ & n. 216 & & \\
\hline 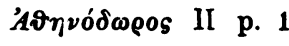 & 141,17 & $* A \pi$ & n. 88 & $\Delta \alpha$ & n. 51 \\
\hline & n. 88 & 'Amc & n. 116 & $\Delta \alpha \iota$ & n. 107 \\
\hline teos & $: 50$ & 'A $\pi$ & $: 80$ & $\Delta \varepsilon i 0$ & n. 119 \\
\hline $\boldsymbol{A} \boldsymbol{v}$ & n. 133 & Ap & $: 150$ & yós p. 124 & 48,17 \\
\hline$A i \delta \varepsilon$ & n. 75 & $A \rho$ & n. 177 & & n. 30 \\
\hline$A i \delta$ & n. 248 & Ap & n. 282 & $\Delta \iota \alpha$ & $: 134$ \\
\hline$\mu \alpha$ & n. 108 & Aex & n. 227 & $\Delta \omega$ & $: 107$ \\
\hline$A x \alpha$ & n. 203 & 'A $\sigma \times \lambda$ & & & $: 29$ \\
\hline 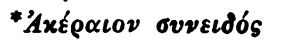 & n. 223 & $-792,12$ & n. 114 & $\Delta \iota \alpha$ & $: 24$ \\
\hline Axe & $: 28$ & -17 & : 119 & $\Delta \iota$ & \\
\hline oles & n. 308 & -7 & n. 129 & & n. 223 \\
\hline v p. 190,8 & n. 203 & -4 & : 135 & $\Delta \iota$ & n. 306 \\
\hline òs हैews & $: 153$ & sq. & $: 216$ & & n. 119 \\
\hline$A \lambda$ & n. 92 & 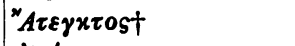 & $: 58$ & $\Delta i \varepsilon$ & $: 127$ \\
\hline$A \mu \alpha$ & n. 236 & 'A $A \varepsilon$ & $: 48$ & & $: 26$ \\
\hline${ }^{*} \dot{\prime} \mu \eta^{\prime}$ & $: 40$ & $A \tau$ & n. 75 & $\Delta \iota$ & n. 77 \\
\hline$\dot{A} \mu \mu$ & $: 60$ & "Ate & $: 142$ & $\Delta o$ & n. 240 \\
\hline$\hat{A} \mu \pi \lambda$ & n. 150 & p. 847,11 & n. 216 & $* \Delta o$ & $: 134$ \\
\hline$\dot{A} \mu \varphi l \beta O \lambda_{0 \iota}$ & n. 172 & 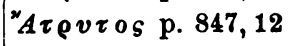 & n. 189 & $\Delta \rho \alpha$ & 9,6 \\
\hline 'A $\mu \varphi i \lambda \alpha$ & $\mathbf{2} 285$ & 847,14 & $: 31$ & & n. 28 \\
\hline$A \mu \varphi \omega$ & : 283 & 2,18 & n. 15 & $* \Delta$ & $: 61$ \\
\hline$A \nu \alpha \beta \alpha \lambda \lambda \alpha^{\prime}$ & n. 25 &, 20 & $: 61$ & $\Delta v 0$ & $: 66$ \\
\hline$x \operatorname{tov}$ & n. 184 & $A \dot{v} \gamma c$ & n. 54 & $\Delta \cos$ & $: \mathbf{5 0}$ \\
\hline$A v \alpha \gamma \omega \gamma i \alpha p .3$ & n. 223 & 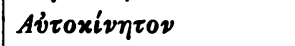 & $: 74$ & * $\Delta \dot{\omega} \rho O s$ & .216 \\
\hline$A \nu \alpha \lambda x \iota \mathrm{S}$ & $: 29$ & *'A & $: 23$ & & \\
\hline & n. 176 & 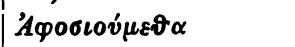 & n. 172 & ${ }^{n} E_{\gamma}$ & n. 84 \\
\hline Avo & n. 193 & $B \iota \alpha \iota \tau^{\prime} \tau \varepsilon \rho \nu$ p. & & 'E $E 0 \times i$ & n. 28 \\
\hline 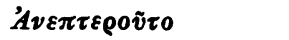 & n. 194 & & n. 125 & 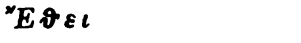 & a. 84 \\
\hline
\end{tabular}


Eldos $:\left.80\right|^{\prime} E \sigma \chi \alpha \dot{\tau} \eta \dot{\alpha} \mu \alpha \boldsymbol{\imath} i^{\prime} \alpha$

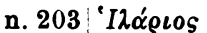

$: 266$

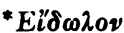

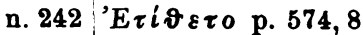

n. 26 "I $\mu \varepsilon \rho \circ S$

: 250

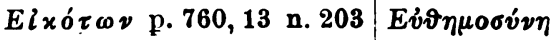

n. 51 'I

Eí $\omega \omega$ p. 777, 17

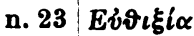

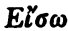

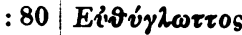

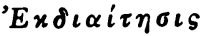

n. 135 EÜxolos

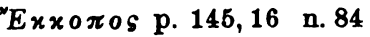

'Ex $\pi \varepsilon \rho t o v \sigma i \alpha s$ I

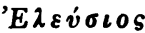

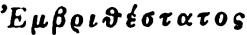

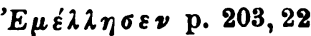

n. 168

n. 298

$: 61$

'Epén joev p. 208, 2

*'Ev $\alpha \gamma \varepsilon \tilde{s}$

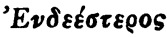

*'Evdópvxos

114

n. 236

n. 28

${ }^{\prime} E \nu \sigma \tau \alpha \sigma \iota s$ p. 275, 16 n. 29

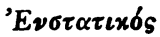

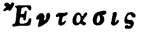

n. 29

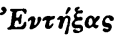

n. 88

n. 54

' $E \xi \dot{\alpha} \gamma \iota \sigma \tau 0$ s p. 288,11 n. 23

'E $\xi \eta \gamma \eta \tau \alpha i$ p. 315,12 n. 51

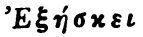

n. 28

' $E \xi \eta \tau \alpha \sigma \mu \varepsilon \nu 0 \nu$

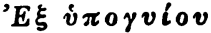

n. 223

'E $\pi \alpha$ l $\varepsilon \iota \nu$ p. 348,14 n. 223

'Ex $\alpha \iota v \varepsilon \sigma \alpha s$ p. 361,15 n. 22

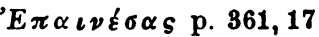

n. 268

' $E \pi \alpha \rho \tau \omega \mu \varepsilon v \omega \nu$

n. 185

'Ex $\varepsilon \times \alpha \dot{\alpha} \lambda \varepsilon \iota$ p. 365,14 n. 237

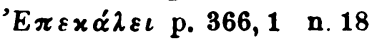

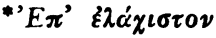

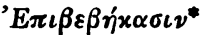

:61

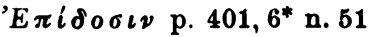

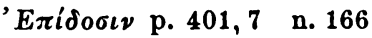

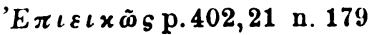

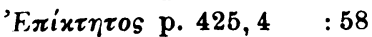

'Exi $\xi v \rho o \tilde{v}$ p. 449,2 n. 184

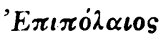

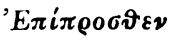

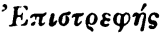

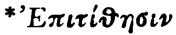

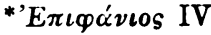

'Eлі́рофоs

n. 223

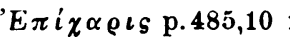

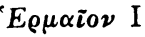

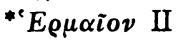

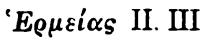

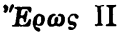

n. 80

$: 21$

n. 263

n. 51

: 285

$H \gamma i \alpha, s$

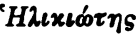

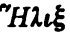

' $H \nu \alpha l \nu \varepsilon \tau 0$

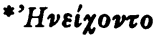

'Hexíoxos I

'Heaíoxos II

$\Theta \varepsilon \alpha \gamma \varepsilon \dot{\varepsilon} \eta \bar{s}$

p. 1116,4

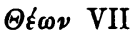

* @oívn

$\Theta \varrho v \pi \tau \varepsilon \tau \alpha \iota$

$\Theta \tilde{\omega} \pi \varepsilon$

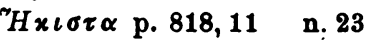

p. $871,14-872,5 \dagger$

n. 120

p. $1073,9.10$

n. 92

:23 p. 1073, 11 sq.

n. 21 'I $\sigma \tau 0 \rho i \alpha$

n. 107

n. 298 *'I

n. 119

: 89

: 89

:32 ${ }^{*} K \alpha \dot{\alpha} \rho \omega \nu$

n. 8

: 29

: 32

$: 40$

$: 285$

$: 80$

n. 28

28

$\alpha \tau \tau \nu \nu \omega \tau i \sigma \alpha \sigma \vartheta \alpha \iota$

$: 150$

n. 285

$K \alpha \tau \dot{\alpha} \pi \tilde{\eta} \chi v \nu \quad$ n. 166

$K \alpha \tau \dot{\alpha} \sigma \pi \sigma v \delta \eta^{\prime} \quad$ n. 94

$K \alpha \tau \alpha \tau \varepsilon i v \alpha S$ p. 135, 2

n. 141

p. $872,5-874,7$ : 107

p. $874,7-874,8 \dagger$

$: 105$

p. $874,8-19$

n. 92

p. $874,19-875,8+$ n. 177

n. 114

$M \alpha \dot{\alpha} \alpha$

p. 1116, 1-4†

n. 280 ?

$K \alpha \tau \varepsilon \alpha \gamma \delta \tau \omega \nu$

n. 177

$K \alpha \tau \varepsilon \beta$ ó $\alpha$

: 77

$K \alpha \tau \varepsilon \sigma x \lambda \eta x \dot{\infty} s$

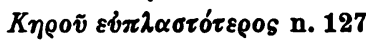

$K о \mu \psi \delta \nu$ p. 330, 16 n. 109

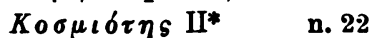

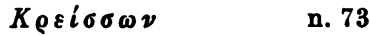

Kอv४ivovs* $\quad$ n. 28

$\Lambda \alpha^{\prime} \boldsymbol{\varepsilon} \beta \iota \dot{\iota} \sigma \alpha \boldsymbol{s}^{\dagger} \quad$ n. 22

$\Lambda \alpha \chi \alpha \dot{\eta} \eta$ p. 512,8 $: 84$

Aท่⿰ท $\quad: 146$

$\Lambda \tilde{\eta} \rho O S$ p. 568,10 n. 77

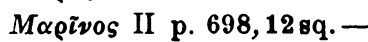
699,5

$: 42$

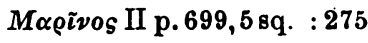

: $281 M \alpha \sigma \tau \varepsilon \dot{v} \omega \nu$

$: 91$

p. $1116,5-8$

n. 307

p. 1116, 8-10†

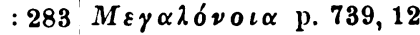

p. $1116,11 \mathrm{sq}$.

n. 157

n. 240

: 157 Meiov II p. $820,8^{*}$ n. 28

:62 Meĩov II p. 820,10 n. 150

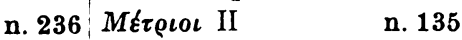

$: 130$ Mrं $\iota \iota \quad$ n. 150

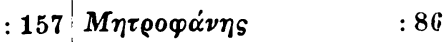

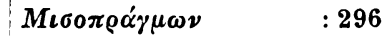

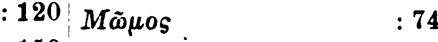

n. 150

n. $28 N \alpha i \mu \grave{\alpha} \tau o ́ v$ p. 945,11

: 232 n. 236

$: 54$ NÉ $u \varepsilon \sigma \iota s$ p. 952,8 n. 189 


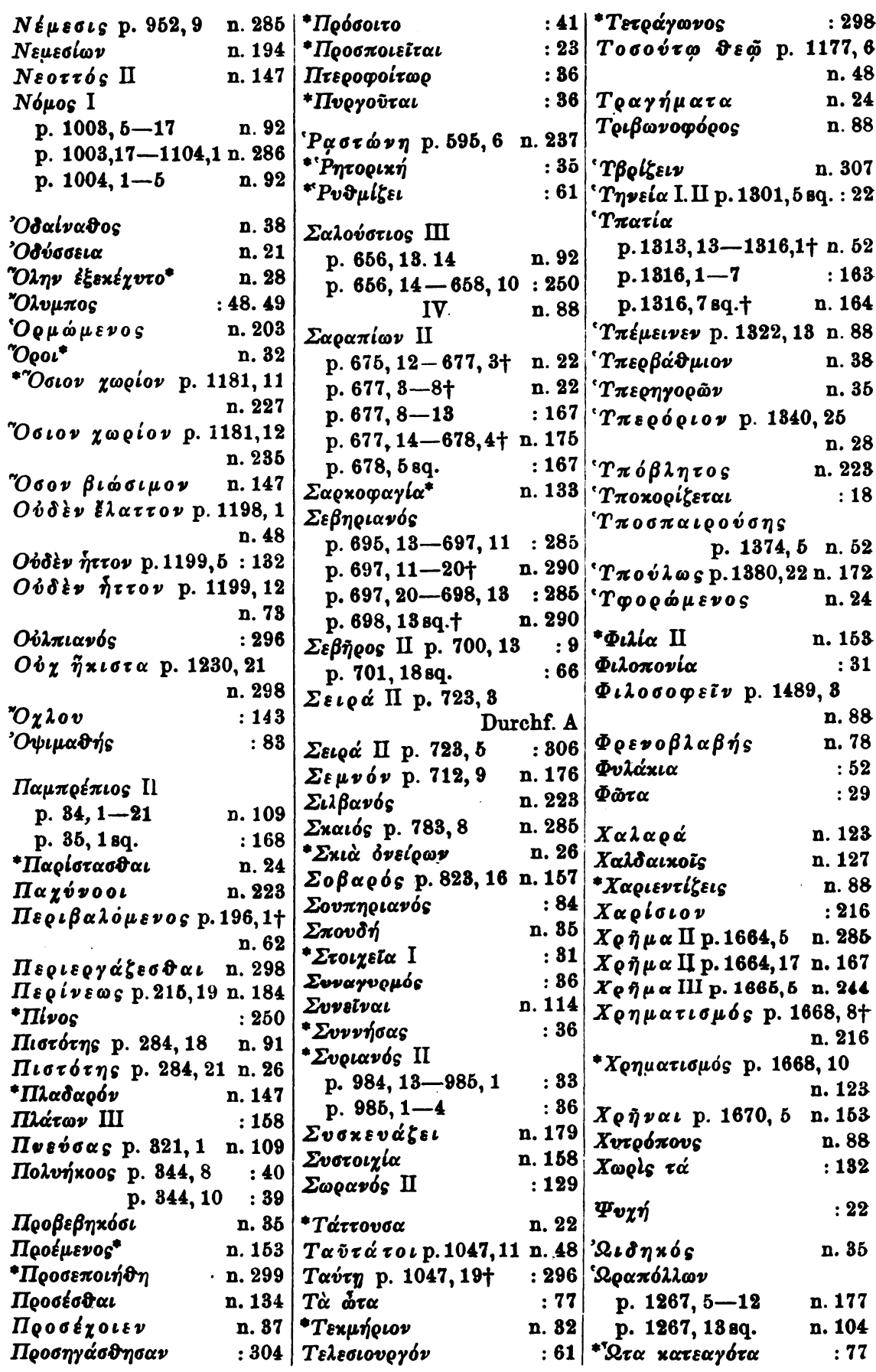

Freiburg i. B.

J. R. Asmus. 